\title{
Synthesis of Macrolides with Nitrogen-Containing Fragments
}

\author{
Gumer Yu. Ishmuratov, ${ }^{\circledR}$ Marina P. Yakovleva, Galina R. Mingaleeva, \\ and Alexander G. Tolstikov
}

Institute of Organic Chemistry, Ufa Scientific Centre of RAS, 450054 Ufa, Russia

${ }^{\circledR}$ Corresponding author E-mail: insect@anrb.ru

\begin{abstract}
This overview summarizes the materials on the synthesis of macrolides with nitrogen-containing fragments using macrolactonization, macroamidization and metathesis reactions at the key cyclization stage. The undying interest in macrolide synthesis is due to the fact that substances with powerful antibiotic (antimicrobial, antiviral, antiparasitic) and antitumor functions have been found among this class of organic compounds. Furthermore, there is evidence for positive effects of pharmacophoric nitrogen-containing (hydrazide, amine, amide, pyrrolidone, pyrrolizidine, oxazole, etc.) fragments in the macrolide molecules on identification or intensification of anti-inflammatory, analgetic, antiviral and antimicrobial, fungicidal, anticancer and anti-tumor as well as immunomodulating activities.
\end{abstract}

Keywords: Macrolides with nitrogen containing fragments, synthesis, biological activity, application.

\section{Синтез макролидов с азотсодержащими фрагментами}

\author{
Г. Ю. Ишмуратов, ${ }^{\circledR}$ М. П. Яковлева, Г. Р. Мингалеева, А. Г. Толстиков
}

Институт органической химии Уфимского научного иентра Российской академии наук, 450054 Уфа, Российская Федераичия

@E-mail: insect@anrb.ru

\begin{abstract}
В обзоре обобщены материаль по методам синтеза макролидов с азотсодержамими фрагментами с использованием на ключевой стадии ичиклиации реакций макролактонизации, макроамидации и метатезиса. Неугасаюший интерес к синтезу макролидов объясняется тем, что среди этого класса органических соединений выявлены вещества, обладающие мощным антибиотическим (антимикробным, противовирусным, противопаразитным) и противоопухолевым действием. Кроме того, имеются данные о положстельном влиянии фармакофорных азотсодержащих (гидразидный, аминный, амидный, пирролидоновый, пирролизидиновый, оксазольный и др.) фрагментов в молекулах макролидов на проявление или усиление противовоспалительной, анальгетической, противовирусной и антимикробной, фунгицидной, противораковой и противоопухолевой, а также иммуномодулирующей активности.
\end{abstract}

Ключевые слова: Макролиды с азотсодержащими фрагментами, синтез, биологическая активность, применение.

\section{Введение}

Полифункциональные макрогетероциклы, обладая интересными комплексообразующими свойствами и широким спектром биологической активности, находят все более широкое применение в органическом и нефтехимическом синтезе, выявлении и разделении металлов экстракцией, сорбционных и хроматографических методах анализа, ионометрии и фармакологии, что обусловлено, в первую очередь, вхождением в их состав сложноэфирной функции. Неослабевающий интерес к синтезу макролидов объясняется тем, что среди этого класса органических соединений выявлены вещества, обладающие мощным антибиотическим (антимикробным, противовирусным, противопаразитным) и противоопухолевым действием. Кроме того, имеются данные о положительном влиянии фармакофорных азотсодержащих (гидразидный, аминный, амидный, пирролидоновый, пирролизидиновый, оксазольный и др.) фрагментов в молекулах макролидов на проявление или усиление противовоспалительной, анальгетической, противовирусной и антимикробной, фунгицидной, противораковой и противоопухолевой, а также иммуномодулирующей активности. ${ }^{[1-6]}$ Поэтому разработка методов получения 
макролидов с азотсодержащими фрагментами остается актуальной на протяжении уже ряда десятилетий для развития современной химической науки, фармакологии и передовой техники.

Методы построения молекул макролидов с азотсодержащими фрагментами делятся по типу образования функциональной группы на ключевой стадии циклизации:

1) макролактонизация - формирование сложноэфирной (макролидной) группы в ациклическом предшественнике, уже включающем азотсодержащую функцию;

2) макроамидация - создание амидной группы в ациклическом предшественнике, уже содержащем сложноэфирную группу;

3) метатезис - макроциклизация непредельных соединений, имеющих в своей структуре как азотсодержащие, так и сложноэфирные функции.

Данные методы являются наиболее разработанными и чаще всего используемыми. Если синтез пяти- и шестичленных циклов обычно не вызывает затруднений, то для получения макроциклов требуются, как правило, специальные приемы. Так, трудности в синтезе макролидов обусловлены малой вероятностью реализации подходящего для этого процесса конформера и побочной реакцией межмолекулярной конденсации, приводящей к линейным и циклическим олигомерам. Для уменьшения образования побочных продуктов синтез макроциклов проводят в сильно разбавленных растворах, а также применяют активирующие агенты, способствующие внутримолекулярной циклизации. ${ }^{[7]}$

\section{1. Макролактонизация}

Синтез циклических сложных эфиров (лактонов) возможен двумя способами: реакциями внутри- или межмолекулярной циклизации.

\section{1. Внутримолекулярная цฺиклизащчия}

Этот вид циклизации заключается в катализируемой этерификации гидроксикарбоновых кислот, ${ }^{[8,9]}$ причем возможна активация как кислотной, так и спиртовой части молекулы (Схема 1).

\subsection{1. Макролактонизация через «кислотную активацию»}

Для успешного получения макролактонов наряду с катализом требуется использование специальных дегидратирующих веществ (дициклогексилкарбодиимид, $N, N$ '-карбонилдиимидазол, пиридиниевые соли и другие), ${ }^{[10]}$ превращающих кислоту в соединение с более хорошей уходящей группой. Одним из таких широко используемых соединений является йодид 1-метил-2хлорпиридиния (1) (соль Мукаяма).

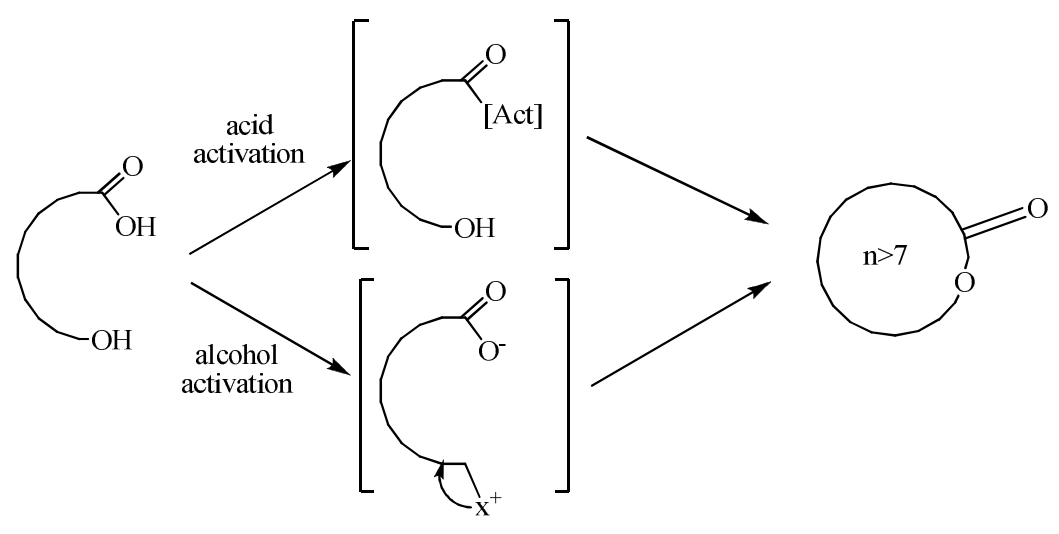

\section{Схема 1.}

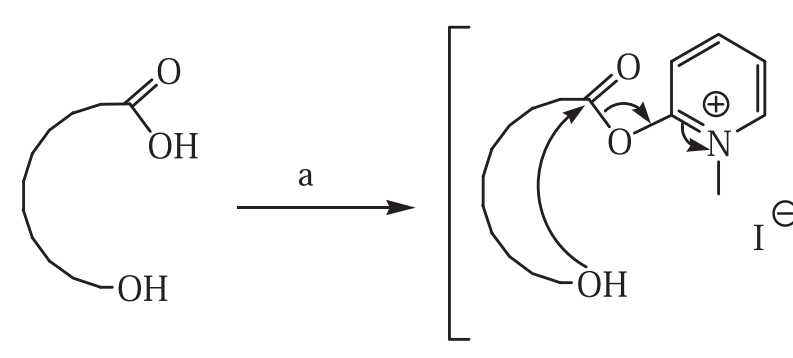

2

3

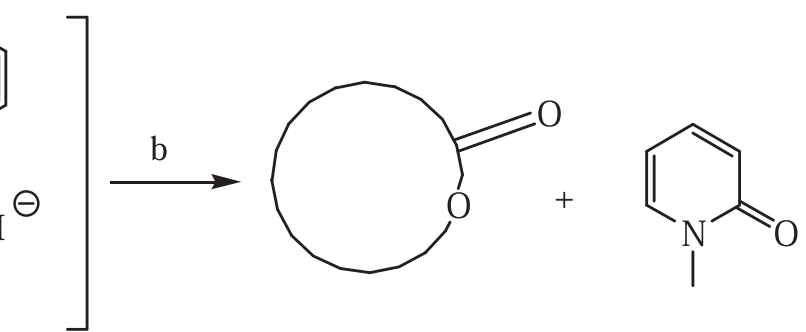

4

a)<smiles></smiles>

(1), $\left.\mathrm{Et}_{3} \mathrm{~N}, \mathrm{MeCN}, \mathrm{b}\right) \mathrm{Et}_{3} \mathrm{~N}$.

Схема 2. 
Механизм реакции циклизации включает в себя нуклеофильное замещение атома хлора в пиридиновом кольце соединения (1) карбоксилат-ионом гидроксикислоты (2) с получением высокоактивированного алкоксипиридина (3), который затем подвергается макролактонизации в соединение (4) ${ }^{[7]}$ (Схема 2).

Использование этого подхода позволило осуществить синтез энантиомерно чистого макролактонного алкалоида $S$-эпилахнина (8), обнаруженного в выделениях куколок двух видов жуков рода Epilachna. Он базировался на превращениях $L$-норвалина (5) в ациклический предшественник (7) через промежуточный $N$-тозилазиридин (6). При этом необходимое наращивание углеродной цепи проведено последовательными реакциями нуклеофиль- ного замещения магнийкупратным агентом по азиридиновому кольцу и олефинирования по Виттигу-Хорнеру. Катализируемая йодидом 2-хлор-1-метилпиридиния (1) циклизация соединения (7) и последующее снятие защиты приводят к целевому соединению (8) ${ }^{[11]}$ (Схема 3).

В макроциклизации также широко используется реагент Паломо, представляющий собой оксим дипиридинзамещенного кетона (9). Полученный из него и гидроксикислоты (2) оксимоэфир (10) хотя пространственно и сближает гидрокси- и карбокси-функции, но является стабильным и без дополнительной активации не лактонизуется. Лишь обработка промежуточного медьсодержащего комплекса (11) фторидом пиридиния приводит к макроциклу (4) (Схема 4).<smiles>CCCC(N)C(=O)OCCCCC(N)COCC</smiles>

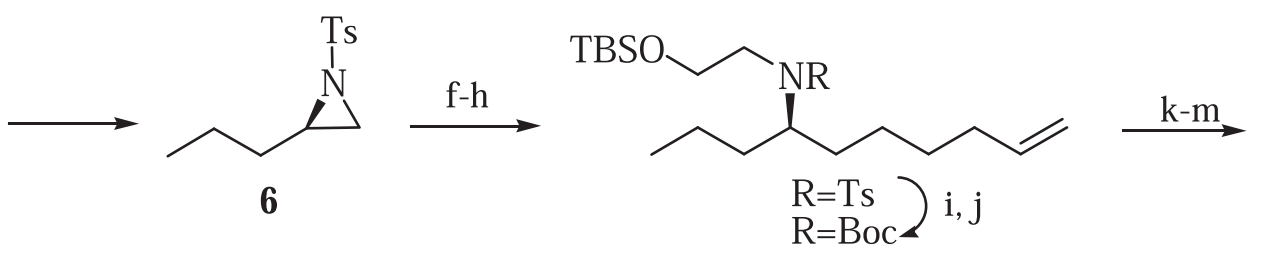

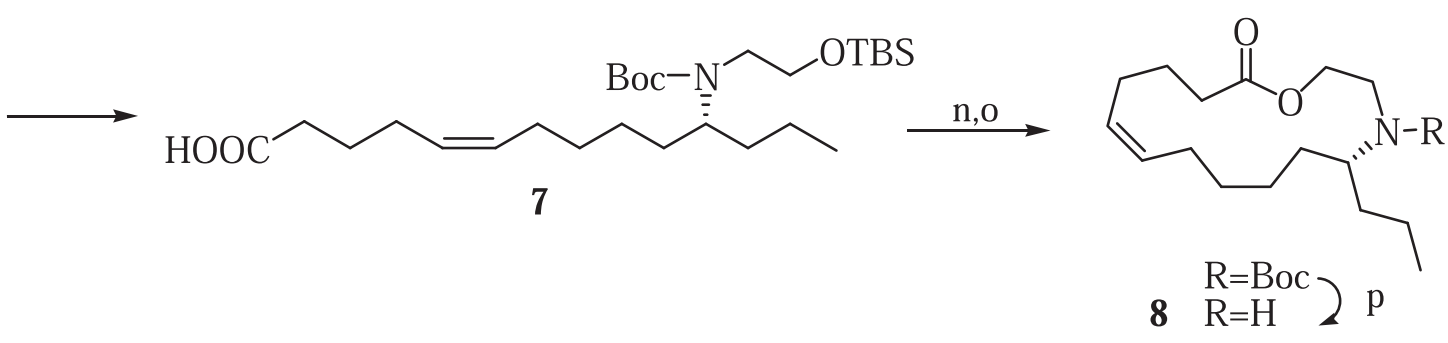

a) $\mathrm{LiBH}_{4}, \mathrm{MeOH}$; b) TMSCl, $\mathrm{Et}+\mathrm{N}$; c) TsCl, $\mathrm{Py}$; d) $\mathrm{H}_{2} \mathrm{SO}_{4}$; e) $\mathrm{K}_{2} \mathrm{CO}_{3}$, acetone; f) $\left(\mathrm{CH}_{2}=\mathrm{CHCH}_{2} \mathrm{CH}_{2} \mathrm{CH}_{2}\right)_{2} \mathrm{Mg}$, $\mathrm{CuI}$, THF; g) NaH; h) TBSOCH${ }_{2} \mathrm{CH}_{2} \mathrm{Br}$; i) Na, naphtalene, $\left(\mathrm{MeOCH}_{2}\right)_{2}$; j) Boc 2 O, THF; k) $\mathrm{O}_{3}, \mathrm{MeOH}$; l) $\mathrm{Me}_{2} \mathrm{~S}$; m) $\left.\left.\left.\mathrm{PPh}_{3}=\mathrm{CH}\left(\mathrm{CH}_{2}\right)_{3} \mathrm{COOK}, \mathrm{THF} ; \mathrm{n}\right) \mathrm{TBAF}, \mathrm{THF} ; \mathrm{o}\right) \mathbf{1}, \mathrm{MeCN} ; \mathrm{p}\right) \mathrm{CF}_{3} \mathrm{COOH}$.

Схема 3.

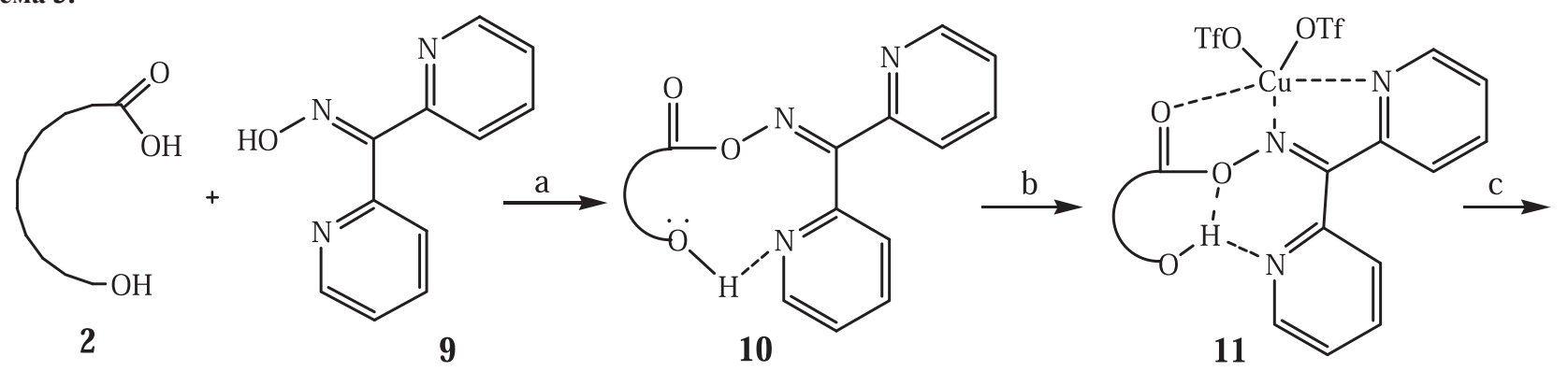

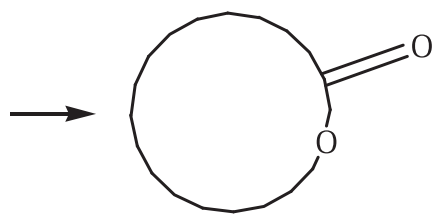

a) EDC, DMAP, $\mathrm{CH}_{2} \mathrm{Cl}_{2}$; b) $\mathrm{Cu}(\mathrm{TfO})_{2}, \mathrm{MeCN}$; c) HF-Py, THF.

Схема 4. 
С использованием такого подхода синтезирован депсипептид гаполазин (21), обладающий противоопухолевым действием. ${ }^{[12]}$ Реакция альдольной конденсации полученного из $R$-камфоры (12) кетона (13) (в виде литиевого енолята) с аминоальдегидом (14) протекает с образованием единственного диастереомерного продукта (15). Взаимодействием полученного из него амина (16) с хлорангидридом (17) образован азотсодержащий фрагмент макролида (21). Сложноэфирные составляющие введены взаимодействием кислоты (18) (в виде хлорангидрида) с $\beta$-гидроксибензиловым эфиром (19), а затем при циклизации полученной гидроксикислоты (20) с ис- пользованием метода «двойной активации» (Схема 5).

Хорошо известным реагентом этерификации является также дициклогексилкарбодиимид (DCC) (22). Макроциклизация под действием этого агента протекает по следующему механизму (Схема 6).

Макролиды, содержащие в своем составе тетрагидро-2,4-пирролидоновый фрагмент, проявляют противогрибковую, противомикробную и противоопухолевую активность. Синтез такого рода соединений выполнен реакцией имина (23) с енолпроизводными пировиноградной кислоты (24 A-F) с образованием продуктов (25 A-F), самопроизвольно циклизующихся в<smiles>CC(=O)C1(O[Si](C)(C)C)CC2CCC1(C)C2(C)C(C)C</smiles>

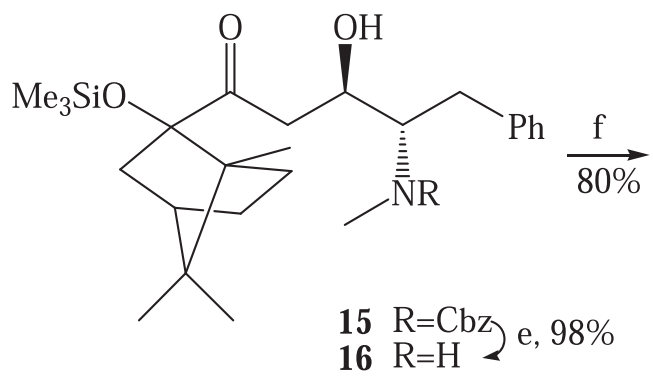

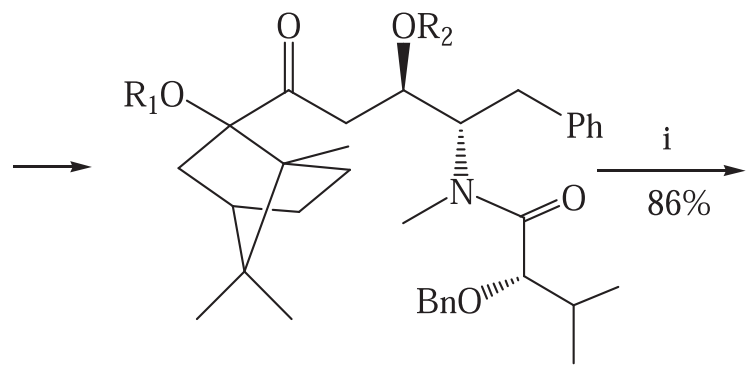

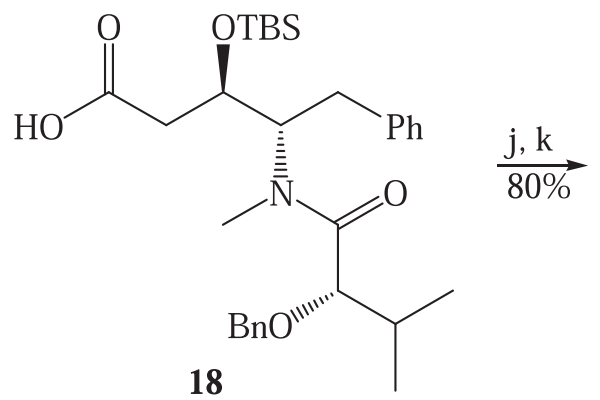

$$
\begin{aligned}
& \mathrm{R}_{1}=\mathrm{Me}_{3} \mathrm{Si}, \mathrm{R}_{2}=\mathrm{H} \\
& \mathrm{R}_{1}=\mathrm{H}, \mathrm{R}_{2}=\mathrm{H} \\
& \mathrm{R}_{1}=\mathrm{H}, \mathrm{R}_{2}=\mathrm{TBS}
\end{aligned}\left\{\begin{array}{l}
\mathrm{g}, 95 \% \\
\text { h, } 92 \%
\end{array}\right.
$$

18

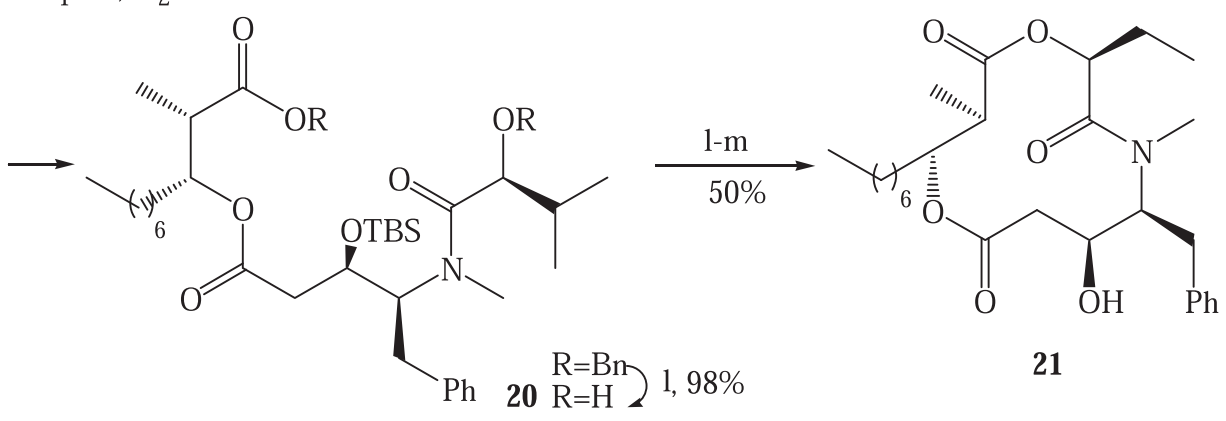

a) $\mathrm{HC} \equiv \mathrm{CLi}$, THF, $-78^{\circ} \mathrm{C}$; b) $\mathrm{HgO}, \mathrm{H}_{2} \mathrm{SO}_{4}, \mathrm{Me}_{2} \mathrm{CO}$; c) $\mathrm{KH}$, TMSCl, THF; d)<smiles>CN(C(=O)O)[C@@H](C=O)Cc1ccccc1</smiles>

(14), n-BuLi, THF;

e) $\mathrm{H}_{2}$, Pd-C, EtOAc; f)<smiles>CC(C)[C@H](Br)C(=O)Cl</smiles>

(17), DMAP, $\mathrm{CH}_{2} \mathrm{Cl}_{2}$; g) TBAF, THF; h) TBSOTf, $\mathrm{Py}, \mathrm{CH}_{2} \mathrm{Cl}_{2}$;

i) $\left(\mathrm{NH}_{4}\right)_{2} \mathrm{Ce}\left(\mathrm{NO}_{3}\right)_{6}, \mathrm{MeCN}, 0^{\circ} \mathrm{C}$; j) $\left.(\mathrm{COCl})_{2}, \mathrm{CH}_{2} \mathrm{Cl}_{2} ; \mathrm{k}\right)$<smiles>CO[C@H](O)CC(=O)OCc1ccccc1</smiles>

1) 9, EDC, DMAP, $\mathrm{CH}_{2} \mathrm{Cl}_{2}$; m) $\mathrm{Cu}(\mathrm{TfO})_{2}, \mathrm{MeCN}, \Delta$; n) HF-Py, THF.

\section{Схема 5.}




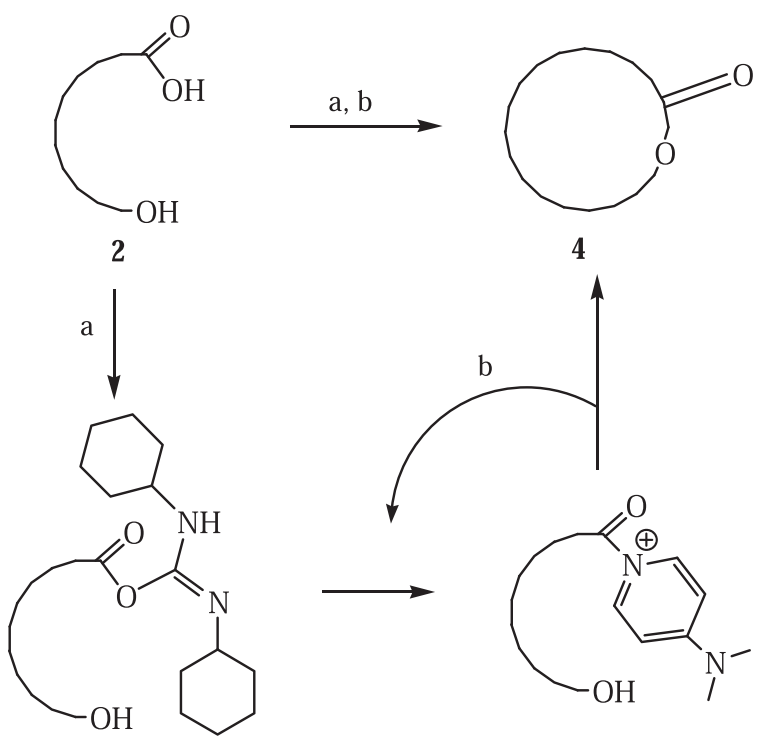

a) DCC (22); b) DMAP.

Схема 6.

тетрагидро-2,3-пирролидоны (26 A-F). Макролактонизация последних с использованием связанного с полимером DCC (22) в присутствии DMAР приводит к образованию как мономерных (27 A-F) (22-26\%), так и димерных (28 A-F) (в количествах не более 5\%) продуктов ${ }^{[13]}$ (Схема 7).

В синтезе макроциклического соединения рапамицина (35), выделенного из Streptomyces hydroscopicus как потенциального иммуносупрессанта. ${ }^{[14]}$ Введение в молекулу полифункционального соединения (29) остатка аминокислоты (30) дает возможность сформировать как сложноэфирный фрагмент соединения (35), так и азотсодержащий при взаимодействии замещенного пиперидинового кольца молекулы (32) с ангидридом бромуксусной кислоты. Добавление к каталитической системе DCC (22)-DMAР катехола позволяет успешно провести циклизацию полученной бромкислоты (33) в макролид (34) - предшественник рапамицина (35) (Схема 8).

Формирование сложноэфирной функции макролактонов при катализируемом четвертичной аммонийной солью $\mathrm{Bu}_{4} \mathrm{NCN}$ раскрытии $\beta$-лактамной группировки с последующей циклизацией применено в синтезах иммуно-<smiles>CCc1cccc(OCC(=O)O)c1C=O</smiles><smiles>[R]C(=O)C(C(=O)OCC)C(NCCCCO)c1cc(C[18OH])ccc1OCC(=O)O</smiles>

25 A-F

26 A-F<smiles>[R]C(=O)C1=C(O)C(=O)N(CCCCC)C1c1ccccc1OCC(=O)OCCC</smiles>

27 A-F<smiles></smiles>

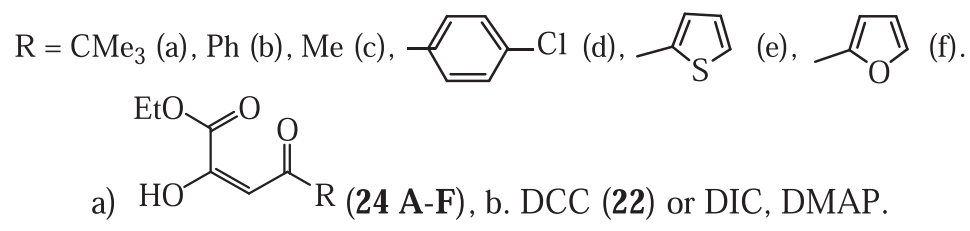

Схема 7. 


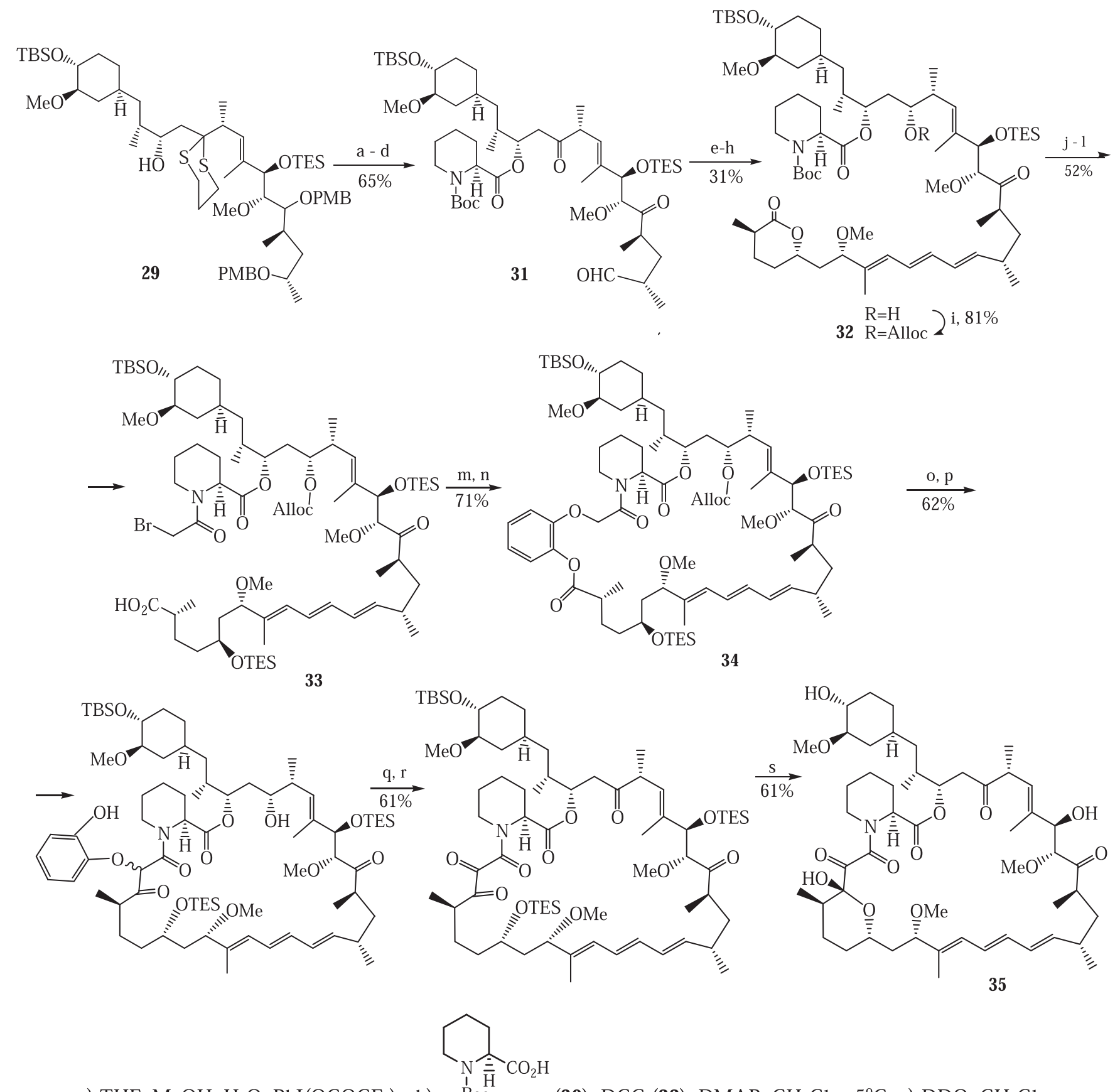

a) THF, $\mathrm{MeOH}, \mathrm{H}_{2} \mathrm{O}, \mathrm{PhI}\left(\mathrm{OCOCF}_{3}\right)_{2}$; b) Boc (30), DCC (22), DMAP, $\mathrm{CH}_{2} \mathrm{Cl}_{2},-5^{\circ} \mathrm{C}$; c) DDQ, $\mathrm{CH}_{2} \mathrm{Cl}_{2}$;

d) $(\mathrm{COCl})_{2}, \mathrm{DMSO}, \mathrm{Et}_{3} \mathrm{~N}, \mathrm{CH}_{2} \mathrm{Cl}_{2} ;$ e) $\mathrm{CrCl}_{2}, \mathrm{CHI}_{3}, \mathrm{THF}, 0^{\circ} \mathrm{C}$; f) $\left[\mathrm{Pd}\left(\mathrm{PFur}_{3}\right)_{2} \mathrm{Cl}_{2}\right],\left(\mathrm{Me}_{3} \mathrm{Sn}\right)_{2}, \mathrm{NMP}$;

g) $\left[\mathrm{Pd}\left(\mathrm{PFur}_{3}\right)_{2} \mathrm{Cl}_{2}\right]$,

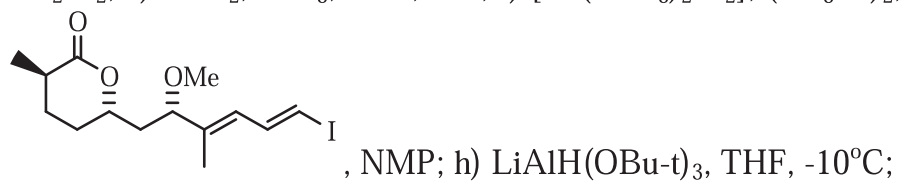

i) Alloc-Cl, ${ }^{2}, \mathrm{CH}_{2} \mathrm{Cl}_{2}$; j) LiOH, $\mathrm{H}_{2} \mathrm{O}$, THF, $0^{\circ} \mathrm{C}$; k) TESOTf, 2,6-lutidine, $\mathrm{CH}_{2} \mathrm{Cl}_{2},-20^{\circ} \mathrm{C}$;

1) $\mathrm{BrCH}_{2} \mathrm{CO}_{2} \mathrm{Br}$, 2,6-lutidine, $\mathrm{CH}_{2} \mathrm{Cl}_{2},-20^{\circ} \mathrm{C}$; m) catechol, DCC (22), DMAP, $\mathrm{CH}_{2} \mathrm{Cl}_{2}, 0^{\circ} \mathrm{C}$; n) $\mathrm{K}_{2} \mathrm{CO}_{3}$, DMF;

o) LiHMDS, THF, $-78^{\circ} \mathrm{C}$; p) $\left[\mathrm{Pd}\left(\mathrm{PPh}_{3}\right)_{4}\right]$, dimedone, THF; q) $\mathrm{PhI}(\mathrm{OAc})_{2}, \mathrm{MeCN}, \mathrm{H}_{2} \mathrm{O}, 0^{\circ} \mathrm{C}$; r) DMAP, $\mathrm{Py}, \mathrm{CH}_{2} \mathrm{Cl}_{2}$; s) HF-Py, THF, $50^{\circ} \mathrm{C}$.

\section{Схема 8.}

депрессанта патеамина А с низкой цитотоксичностью[15] и противовоспалительного агента галипептина D. ${ }^{[16-19]}$

Этот же метод использован в синтезе криптофицина24 (41), выделенного из сине-зеленых водорослей Nostoc и проявляющего свойства эффективного про- тиворакового агента. Этерификация проведена взаимодействием сложного эфира гидроксикислоты (36) с хлорангидридом (37) в присутствии катализатора 4-диметиламинопиридина. Формирование амидного фрагмента происходит в реакции кислоты (38) с амином 
(39) при катализе гексафторфосфатом $O$-бензотриазол-1ил- $N, N, N$, $N$ '-тетраметилурония (40) (HBTU) в присутствии $N$-этилдиизопропиламина (DIPEA) (Схема 9). ${ }^{[20,21]}$

Наряду с азотсодержащими лактонизующими агентами в литературе описано также применение фосфорсодержащих реагентов для синтеза макролидов, в частности бис-(2-оксо-3-оксазолидинил)фосфинхлорида (BOP-Cl):<smiles>O=C1OCCN1P(=O)(Cl)N1CCOC1=O</smiles>

В синтезе макроциклического лактона (45) - структурного аналога выделенного из морских губок ${ }^{[22]}$ циклодепсипептида геодиамолида А- введение трех амидных фрагментов происходит при реакции сочетания доступной из $S$-цитронеллаля (42) кислоты (43) с трипептидом (44). Заключительное замыкание макролидного цикла протекает под действием реагента $\mathrm{BOP}-\mathrm{Cl}$ в присутствии диизопропилэтиламина (Схема 10).

Широкое распространение получила макролактонизация в условиях реакции Ямагучи, проходящая через образование смешанных ангидридных интермедиатов. В качестве активирующих агентов при лактонизации использовались 2,6-дихлорбензоилхлорид и 2,4,6трихлорбензоилхлорид (46) (Схема 11). ${ }^{[23]}$

Данный подход успешно использован в синтезе (-)-дисоразола C1, проявляющего широкий спектр противоопухолевых, антимикробных, фунгицидных и иммуномодулирующих свойств, ${ }^{[24,25]}$ а также выделенных из культуральной жидкости Penicillium sp. NK 374186 стевастелинов А3 (47), В3 (48) и С3 (49). Последние представляют новый класс природных циклических депсипептидов с иммуноподавляющими свойствами. Построение молекулы их ациклического предшественника (50) осуществлено последовательными реакциями пептидного синтеза, а циклизация - по методу Ямагучи: лакто-<smiles>CC(C)COC(=O)/C=C/C[C@@H](OC(=O)[C@H](CC(C)C)OC(=O)/C=C/C[C@H](O)[C@@H](C)/C=C/c1ccccc1)[C@@H](C)/C=C/c1ccc(C(C)C)cc1</smiles><smiles>COc1ccc(C[C@H](NC(=O)/C=C/C[C@H](OC(=O)[C@H](O)CC(C)C)[C@@H](C)/C=C/c2ccccc2)C(=O)N2C[C@](C)(C(C)(C)C)C2=O)cc1</smiles>

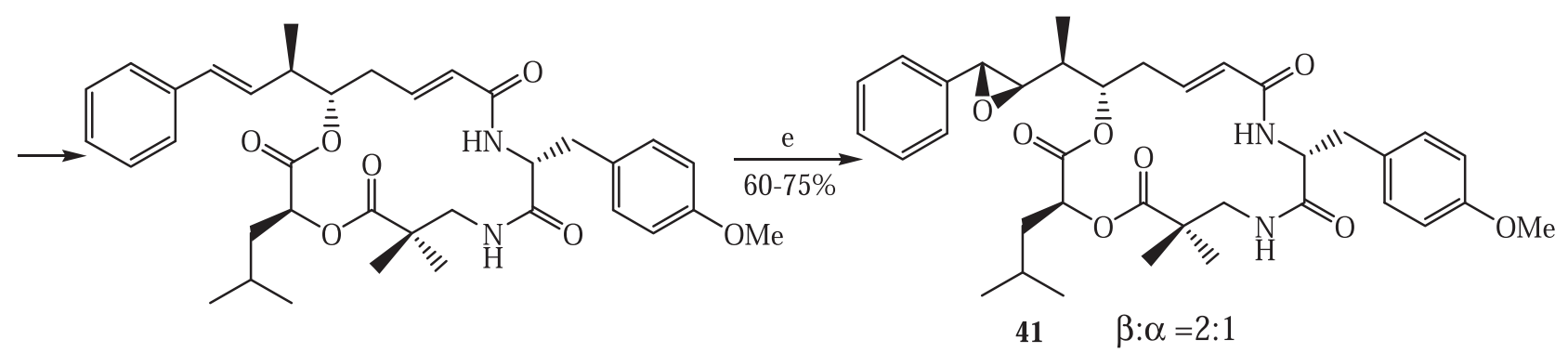

a) TBSO (37), $\mathrm{Et}_{3} \mathrm{~N}, \mathrm{DMAP}, \mathrm{CH}_{2} \mathrm{Cl}_{2}$; b) $\mathrm{CF}_{3} \mathrm{CO}_{2} \mathrm{H}, \mathrm{CH}_{2} \mathrm{Cl}_{2}$;

c)<smiles>[CH2-][NH2+][C@@H](Cc1ccc(OC)cc1)C(=O)N1CC(C)(C)C(=O)N1</smiles>

(39),<smiles>[PH3+]CC1CCCN1[PH](On1nnc2ccccc21)(N1CCCC1)N1CCCC1</smiles>

e) DMD, acetone.

\section{Схема 9.}


<smiles>CC(C)=CCCC(C)C[C@@H](C)O[AsH3]</smiles>

42<smiles>CCOC(=O)/C=C(\C)CCCC(C)C[C@@H](C)C[C@H](C)O[Mg]</smiles>

43<smiles>CC(=O)C(C)NC(=O)[C@H](C)NC(=O)C(C)NC(=O)[C@H](C)CCCCC(C)C</smiles>

a) $\mathrm{MeMgBr}$, THF; b) TBSCl, $\mathrm{Et}_{3} \mathrm{~N}, \mathrm{CH}_{2} \mathrm{Cl}_{2}$; c) $\mathrm{O}_{3}, \mathrm{CH}_{2} \mathrm{Cl}_{2}$ then $\mathrm{Me}_{2} \mathrm{~S}$; d) $\mathrm{Ph}_{3} \mathrm{PCH}(\mathrm{Me}) \mathrm{CO}_{2} \mathrm{Et}$, $\mathrm{PhMe}$; e) $\mathrm{H}_{2}$, Pd-C; f) $\left.\mathrm{KOH}, \mathrm{MeOH}, \mathrm{H}_{2} \mathrm{O} ; \mathrm{g}\right) \mathrm{CF}_{3} \mathrm{CO}_{2} \mathrm{H}, \mathrm{CH}_{2} \mathrm{Cl}_{2}$;

h)<smiles>CC(=O)NC(C)C(=O)N[C@@H](C)C(=O)NC(C)C(C)=O</smiles>

(44), DCC (22), $\mathrm{HOBT}, \mathrm{Et}_{3} \mathrm{~N}, \mathrm{DMF}$; i) $\mathrm{KOH}, \mathrm{EtOH}, \mathrm{H}_{2} \mathrm{O}$; j) $\mathrm{HCl}$, DIPEA, BOP-Cl, $\mathrm{CH}_{2} \mathrm{Cl}_{2}$, DMF.

Схема 10.<smiles>O=C(O)CCCCO</smiles>

2

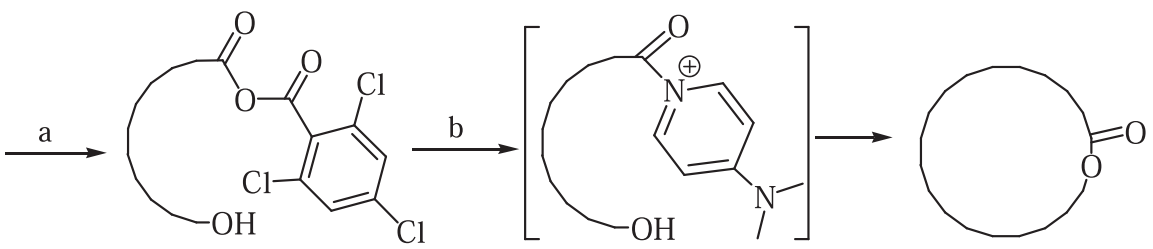

4 a)<smiles>O=C(Cl)c1c(Cl)cc(Cl)cc1Cl</smiles>

(46), $\mathrm{Et}_{3} \mathrm{~N}$; b) DMAP.

\section{Схема 11.}

низация с использованием 2,4,6-трихлорбензоилхлорида (46) в присутствии DMAP (Схема 12)..$^{[26,27]}$

Использование в качестве активирующего агента 2-метил-6-нитробензоильного ангидрида (MNBA) на ключевой стадии циклизации соединения (53) позволяет с хорошим выходом получить перспективный природный макроциклический иммуносупрессант FR252921 (54), выделенный из культуральной жидкости Pseudomonas fluorescens, ${ }^{[28]}$ а также биологически активный синтетический аналог FK228 как мощный противоопухолевый агент (Схема 13). ${ }^{[29]}$

Описано также применение для макроциклизации метилтиометиловых эфиров гидроксикарбоновых кислот. Сложный эфир активируется окислением перекисью водорода на молибденовом катализаторе, и затем спирт депротонируется с получением циклической структуры. Этот подход использован в синтезе бислактонного пирролизидинового алкалоида интегерримина (57), ${ }^{[30]}$ введение азотсодержащего фрагмента и формирование одной из сложноэфирных групп в котором проведено при ацилировании спирта (55) ангидридом (56) (Схема 14).

Еще один метод получения макролактонов (62 A-I), являющихся важными биологическими соединениями, базируется на активировании карбоксильной функции внутренними оксазолами (61). Макролактонизация, предшественники для которой получены трехкомпонентной конденсацией соответствующих альдегидов (58), аминоспиртов (59) и дипептидных изоцианидов (60), ${ }^{[31]}$ успешно протекает в кислых условиях (Схема 15).

В синтезе 14-членных полифункциональных макрогетероциклов (64 A-C), являющихся основными 


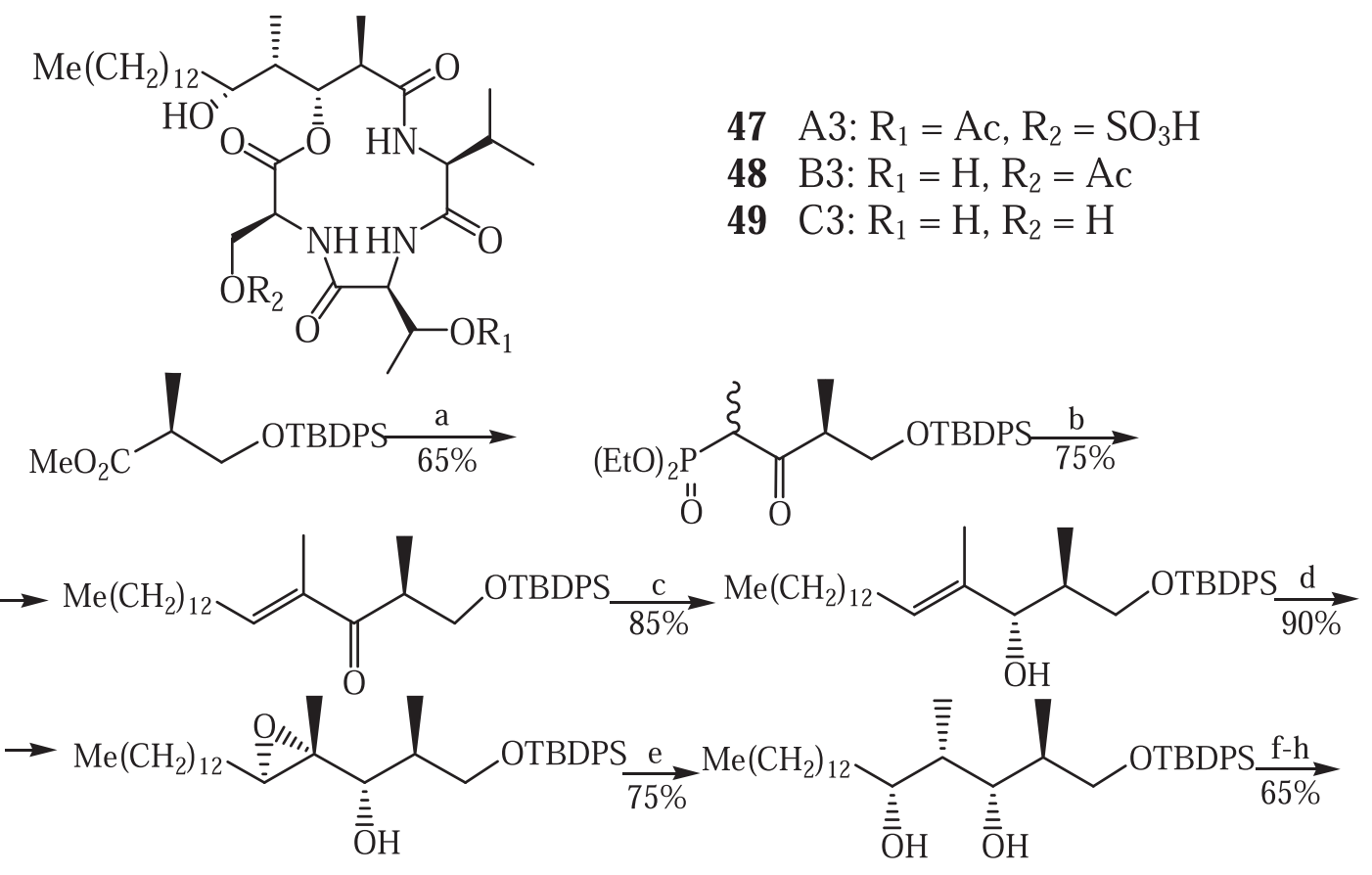

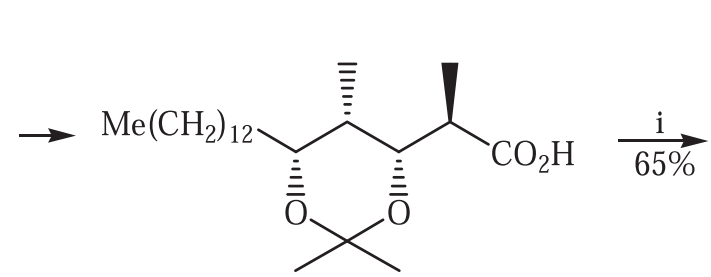

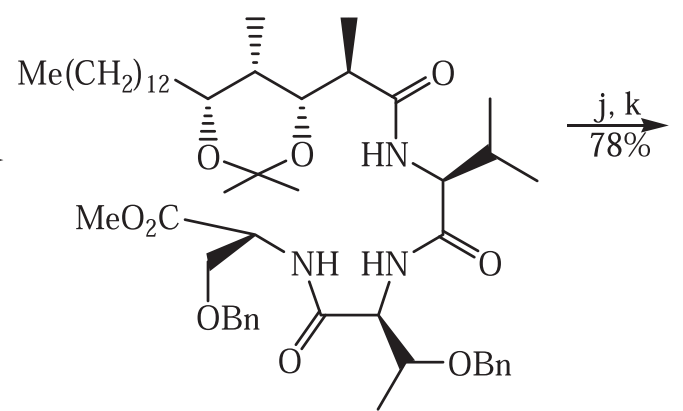

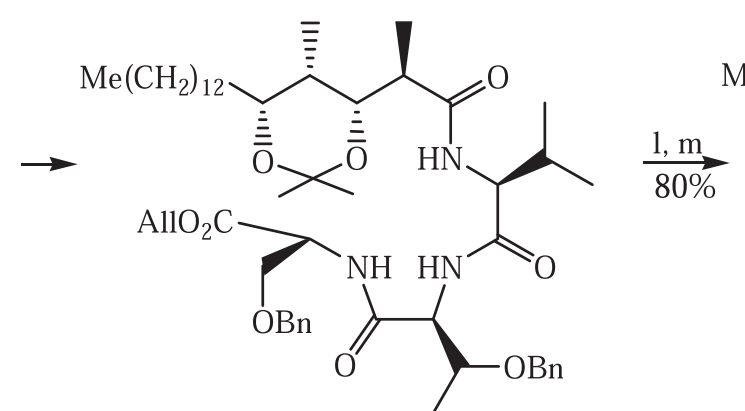

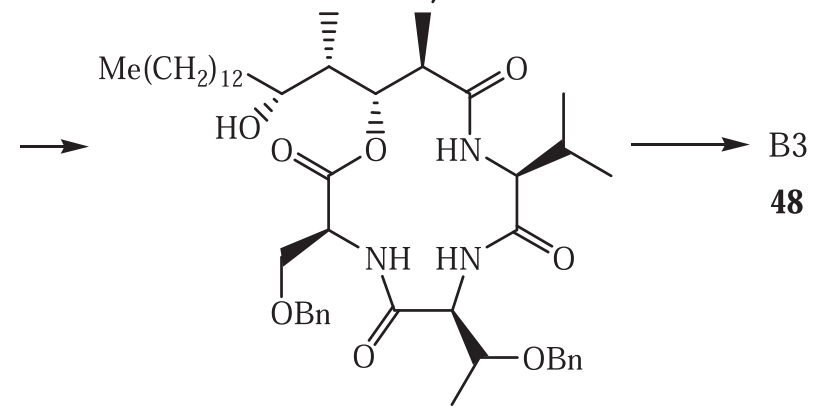

a) $(\mathrm{EtO}){ }_{2} \mathrm{P}(\mathrm{O}) \mathrm{Et}$, n-BuLi, THF, $-78^{\circ} \mathrm{C}$; b) n-BuLi, THF, $-78^{\circ} \mathrm{C}$; then $\mathrm{Me}\left(\mathrm{CH}_{2}\right){ }_{2} \mathrm{CHO},-78^{\circ} \mathrm{C}$; c) DIBAH, toluene, $-78^{\circ} \mathrm{C}$; d) $m$-CPBA, $0^{\circ} \mathrm{C}$; e) $\mathrm{Cp}_{2} \mathrm{TiCl}$, hexa-1,4-diene, THF, $-20^{\circ} \mathrm{C}$; f) $\mathrm{Me}_{2} \mathrm{C}(\mathrm{OMe})_{2}$, CSA, $0^{\circ} \mathrm{C}$; g) TBAF, THF, $0^{\circ} \mathrm{C}$;

h) $\mathrm{RuCl}_{3} \cdot 3 \mathrm{H}_{2} \mathrm{O}, \mathrm{NaIO}_{4}, \mathrm{MeCN} \mathrm{CCl}_{4}, \mathrm{H}_{2} \mathrm{O}, 0^{\circ} \mathrm{C}$;

i) EDC, $\mathrm{HOBT}, \mathrm{CH}_{2} \mathrm{Cl}_{2}, 0^{\circ} \mathrm{C}$, then<smiles>CCCCOCC(NC(=O)[C@@H](NC(=O)C(NCC(C)C)C(C)C)C(C)O)C(=O)OCc1ccccc1</smiles>

k) $\mathrm{CH}_{2}=\mathrm{CHCH}_{2} \mathrm{OH}, \mathrm{DCC}(22)$, DMAP, $\mathrm{CH}_{2} \mathrm{Cl}_{2}, 0^{\circ} \mathrm{C}$; l) $\mathrm{CSA}, \mathrm{CH}_{2} \mathrm{Cl}_{2}, 0^{\circ} \mathrm{C}$; m) $\mathrm{Pd}_{2}\left[\mathrm{PPh}_{3}\right]_{4}$, morpholine, THF;

n) $46, \mathrm{Et}_{3} \mathrm{~N}$, THF, $0^{\circ} \mathrm{C}$; then DMAP, toluene, $0^{\circ} \mathrm{C}$. 

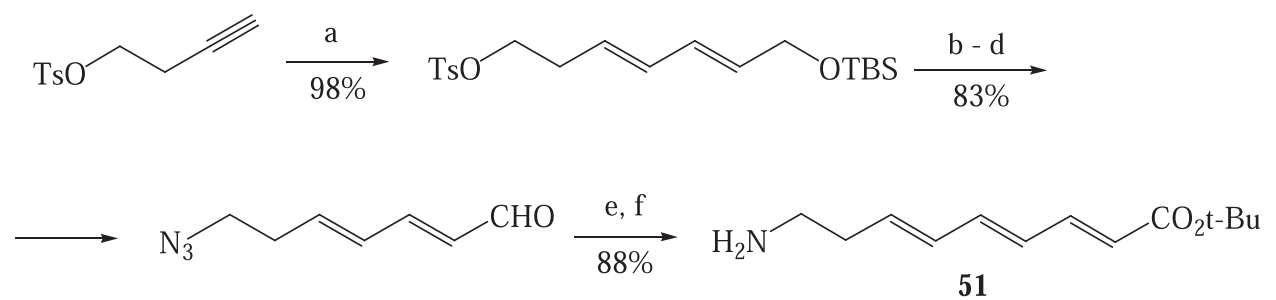

51

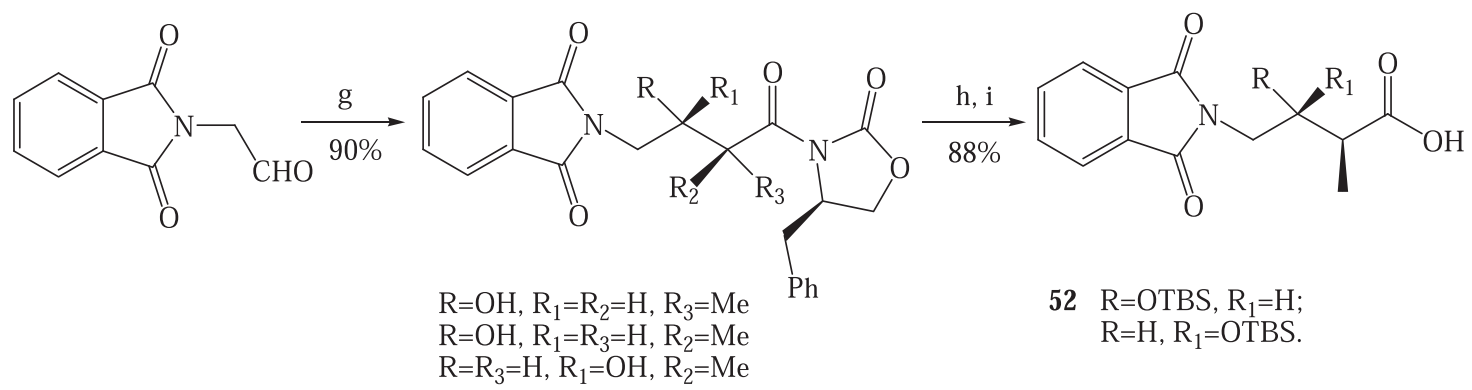<smiles>CCCCNC(=O)[C@@H](C)[C@H](O)CNC(=O)C[C@@H](O)/C(C)=C/C=C/CCNC(=O)[C@@H](C)[C@@H](O)CN</smiles><smiles>CC=CC=CC=CC(=O)O[C@@H](CC(=O)NC[C@H](O)[C@H](C)C(=O)NCCCCCCCC)C(C)=CC=CCC</smiles>

a) $\left[\mathrm{Cp}_{2} \mathrm{ZrClH}\right]$, THF then $\left.\mathrm{OTBS}, \mathrm{Pd}(\mathrm{OAc})_{2}, \mathrm{DPBA}, \mathrm{THF} ; \mathrm{b}\right) \mathrm{NaN}_{3}, \mathrm{DMF}$; c) TBAF, THF, $0^{\circ} \mathrm{C}$

d) $\mathrm{MnO}_{2}, \mathrm{CH}_{2} \mathrm{Cl}_{2}$; e) $(\mathrm{MeO})_{2} \mathrm{P}(\mathrm{O}) \mathrm{CH}_{2} \mathrm{CO}_{2} \mathrm{Bu}$-t, $\mathrm{NaH}$, THF, $0^{\circ} \mathrm{C}$; f) $\mathrm{Ph}_{3} \mathrm{P}, \mathrm{THF}, \mathrm{H}_{2} \mathrm{O}$;<smiles>CCC(=O)N1C(=O)OCC1Cc1ccccc1</smiles>

g) $\mathrm{PhH}_{2} \mathrm{C} \quad$, n-Bu $\mathrm{Bu}_{2}$ BOTf, DIPEA, $\mathrm{CH}_{2} \mathrm{Cl}_{2},-78^{\circ} \mathrm{C}$; h) TBSOTf, 2,6-lutidine, $\mathrm{CH}_{2} \mathrm{Cl}_{2}, 0^{\circ} \mathrm{C}$;

i) $\mathrm{LiOH}, \mathrm{H}_{2} \mathrm{O}_{2}$, THF, $\mathrm{H}_{2} \mathrm{O}, 4^{\circ} \mathrm{C}$; j) EDC, $\mathrm{HOBT}, \mathrm{CH}_{2} \mathrm{Cl}_{2}$; k) TBAF, $\left.\mathrm{AcOH}, \mathrm{THF} ; \mathrm{l}\right) \mathrm{N}_{2} \mathrm{H}_{4} \bullet \mathrm{H}_{2} \mathrm{O}, \mathrm{EtOH}, 45^{\circ} \mathrm{C}$;

m)<smiles>CCCC=CC=C(C)[C@@H](O)CC(=O)O</smiles>

n) TBSOTf, 2,6-lutidine, $\mathrm{CH}_{2} \mathrm{Cl}_{2}, 0^{\circ} \mathrm{C}$ then citric acid, $\mathrm{MeOH}, 4^{\circ} \mathrm{C}$; o) , EDC, $\mathrm{HOBT}, \mathrm{CH}_{2} \mathrm{Cl}_{2}$;<smiles>Cc1cccc([N+](=O)[O-])c1C(=O)O</smiles>

\section{Схема 13}

структурными фрагментами ряда природных биологически активных соединений, при катализе системой TsCl/Py протекает межмолекулярная циклизация с образованием только димерных продуктов (64 A-C). ${ }^{[32]}$ Отсутствие в реакционной смеси продуктов внутримолекулярной циклизации (65 А-C), вероятно, обусловлено наличием в интермедиатах (63 A-C) водородной связи между атомом кислорода карбонильной группы и протоном гетероароматической аминогруппы. При такой геометрии интермедиатов (66 A-C), стабилизированных водородной связью, реакционные центры максимально удалены друг от друга, что, по всей вероятности, и определяет меж- 
Macrolides with Nitrogen-Containing Fragments

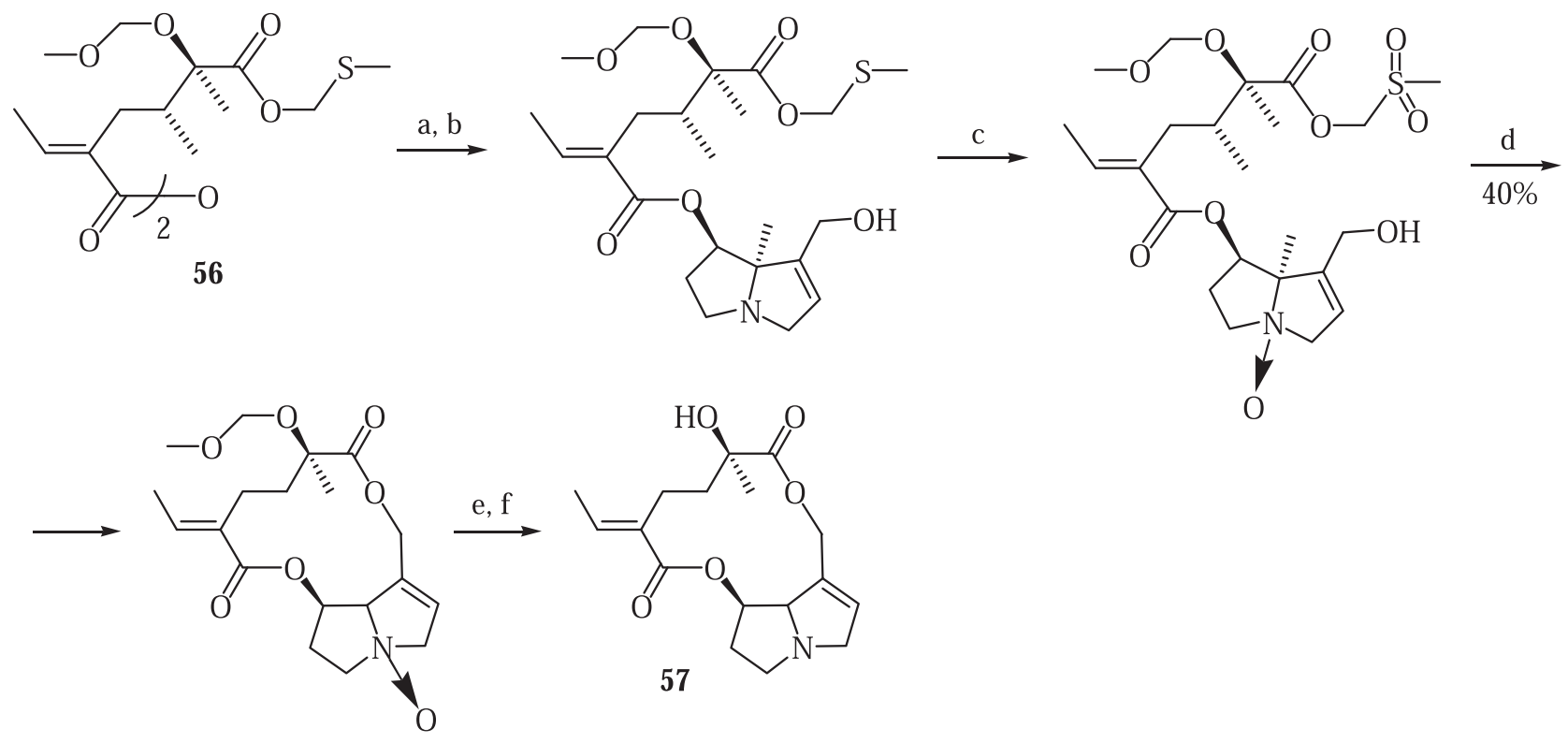

a)

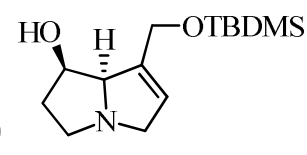

c) $\mathrm{H}_{2} \mathrm{O}_{2}$, $\left(\mathrm{NH}_{4}\right)_{2} \mathrm{MoO}_{3}$, EtOH, $\mathrm{H}_{2} \mathrm{O}$; d) n-BuLi, $\mathrm{Ph} 3 \mathrm{CH}, \mathrm{THF},-78^{\circ} \mathrm{C}$; e) $\mathrm{Zn}, \mathrm{H}_{2} \mathrm{SO}_{4}, \mathrm{H}_{2} \mathrm{O}, \mathrm{MeOCH}_{2} \mathrm{CH}_{2} \mathrm{OMe}$;

f. $\mathrm{H}_{2} \mathrm{SO}_{4}, \mathrm{H}_{2} \mathrm{O}, \mathrm{MeOCH}_{2} \mathrm{CH}_{2} \mathrm{OMe}, 40^{\circ} \mathrm{C}$.

Схема 14.<smiles>[R]OC([R])[R]</smiles>

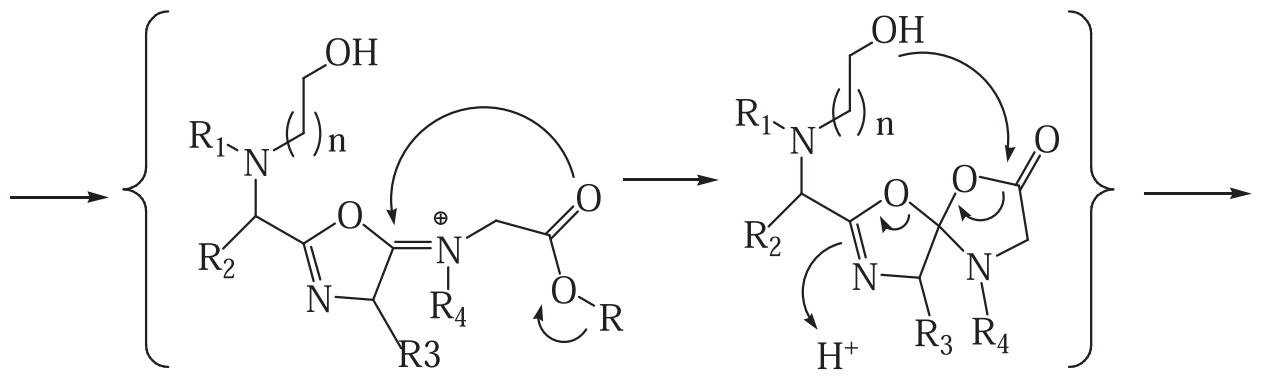<smiles>[R3]C1NC(=O)C([R2])N([R])CCOCCOC(=O)CN1[R]</smiles>

62 A-I

a) $\mathrm{MeOH}$; b) $\mathrm{F}_{3} \mathrm{CCO}_{2} \mathrm{H}$.

$\begin{array}{ccccccc} & \mathbf{R}_{1} & \mathbf{R}_{2} & \mathbf{R}_{3} & \mathbf{R}_{4} & \mathbf{n} & \text { Выход } \\ \mathrm{A} & \mathrm{H} & \mathrm{C}_{6} \mathrm{H}_{13} & \mathrm{Bn} & \mathrm{Me} & 5 & 85 \% \\ \mathrm{~B} & \mathrm{H} & \mathrm{Bn} & \mathrm{Bn} & \mathrm{Me} & 5 & 88 \% \\ \mathrm{C} & \mathrm{H} & \text { cyclooctyl } & \mathrm{Bn} & \mathrm{Me} & 5 & 55 \% \\ \mathrm{D} & \mathrm{H} & \mathrm{C}_{6} \mathrm{H}_{13} & \mathrm{Bn} & \mathrm{Bn} & 5 & 84 \% \\ \mathrm{E} & \mathrm{CH}_{2} \mathrm{CH}_{2} \mathrm{OH} & \mathrm{C}_{6} \mathrm{H}_{13} & \mathrm{Bn} & \mathrm{Me} & 1 & 40 \% \\ \mathrm{~F} & \mathrm{H} & \mathrm{C}_{6} \mathrm{H}_{13} & \mathrm{Bn} & \mathrm{Me} & 2 & 59 \% \\ \mathrm{G} & \mathrm{H} & \mathrm{C}_{6} \mathrm{H}_{13} & \mathrm{Bn} & \mathrm{Me} & 3 & 57 \% \\ \mathrm{H} & \mathrm{H} & \mathrm{C}_{6} \mathrm{H}_{13} & \mathrm{Bn} & \mathrm{Me} & 4 & 61 \% \\ \mathrm{I} & \mathrm{Bn} & \mathrm{C}_{6} \mathrm{H}_{13} & \mathrm{Bn} & \mathrm{Me} & 4 & 75 \%\end{array}$

Схема 15 . 


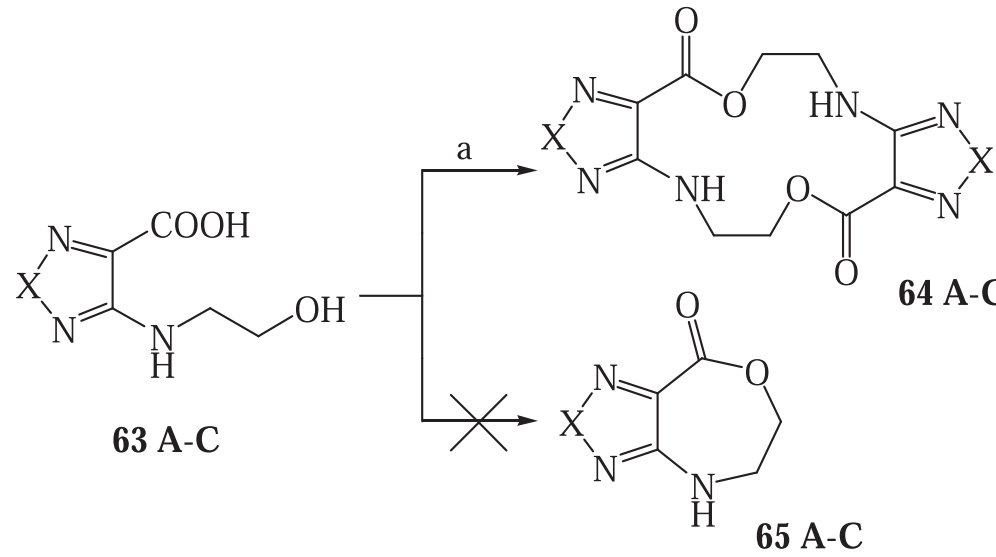<smiles>OCC[n+]1[nH]cc2c([SeH])n[nH]c21</smiles>

$66 \mathrm{~A}-\mathrm{C}$

$\mathrm{X}=\mathrm{O}, \mathrm{S}$, Se. a) TsCl, Py.

Схема 16.

молекулярный характер дальнейшего взаимодействия (Схема 16).

\subsection{2. Макролактонизация через «спиртовую активацию»}

Гораздо меньшее распространение для получения макроциклов получила реакция Мицунобу. Вначале происходит активация гидроксильной группы при действии на гидроксикислоту (2) диизопропилового эфира азодикарбоновой кислоты (DIAD) (67) и трифенилфосфина. ${ }^{[33]}$ Последующая нуклеофильная атака карбоксилат-иона в интермедиате (68) приводит к макролиду (4) (Схема 17).

Этот подход использован в синтезе нового бициклического депсипептида FR-901375 (69), выделенного из культуральной жидкости Pseudomonas chloroaphis № 2522 и проявляющего притивоопухолевую активность. Построение цепи его ациклического предшественника (68) проведено последовательными реакциями пептидного синтеза, а лактонизация - по методу Мицунобу с последующим формированием дисульфидного мостика (Схема 18). ${ }^{[34]}$

\section{2. Реакцุии межмолекулярной ичиклизацฺии}

Многие из макроциклических лактонолактамов проявляют высокую селективность комплексообразования по отношению к ряду щелочных и щелочноземельных металлов, в частности к кальцию. Поскольку он играет важную роль в регуляции многих биологических процессов, то макроциклические лактонолактамы, особенно содержащие замещенные пиразольные или пиридиновые фрагменты, перспективны в качестве мембраноактивных компонентов и ионоселективных электродов. ${ }^{[35]}$

Синтез макроциклов (72 A-F и 75 A-F), содержащих пиридиновые, амидные и сложноэфирные группировки и являющихся селективными рецепторами по отношению к ряду одновалентных $\left(\mathrm{Li}^{+}, \mathrm{Na}^{+}, \mathrm{K}^{+}, \mathrm{Ag}^{+}\right)$и двухвалентных $\left(\mathrm{Pb}^{2+}, \mathrm{Mg}^{2+}, \mathrm{Ca}^{2+}, \mathrm{Sr}^{2+}, \mathrm{Ba}^{2+}\right.$ и $\left.\mathrm{Tl}^{2+}\right)$ ионов, осуществлен взаимодействием дихлорангидридов кислот с $\alpha, \omega$-дигидроксидиамидными производными пиридина (71 A-F) под действием активирующего агента тетрабутиламмония гидросульфата (TBA· $\mathrm{HSO}_{4}$ ) в присутствии в качестве промоутеров солей калия: $\mathrm{K}_{2} \mathrm{CO}_{3}$ - для дихлорангидрида ароматической (2,6-пиридиндикарбоновой) кислоты (73), ${ }^{[36]} \mathrm{KF}$ - дихлорангидрида ациклической (3-тиапентандикарбоновой) кислоты (74) ${ }^{[37]}$ (Схема 19).

Диамидодиэфирные макроциклы (79) также могут быть получены последовательными реакциями амидирования хлорангидрида X-содержащей дикарбоновой кислоты (76) R-замещенным аминоэтанолом (77) и последующей [1+1]-конденсацией полученных диолов (78) с соответствующим дихлорангидридом Ү-содержащей дикарбоновой кислоты $(\mathbf{8 0})$. Наиболее эффективно циклизация протекает в присутствии ДМАР в качестве катализатора (Схема 20). ${ }^{[38-40]}$

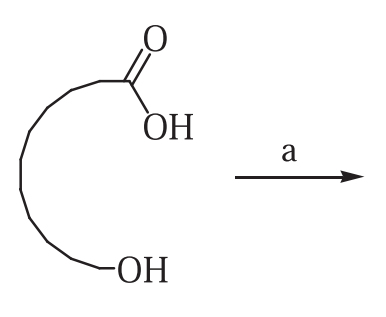

2

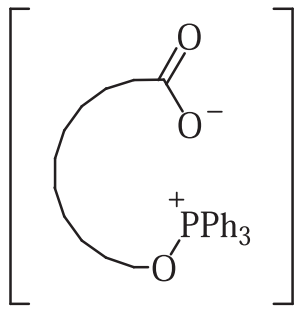

68

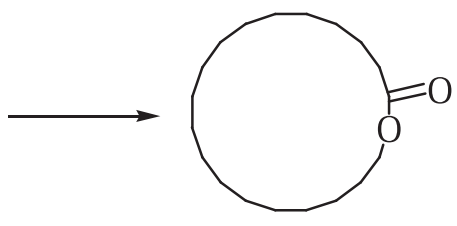

4

a) i-PrOOC-N=N-COOPr-i (67), $\mathrm{Ph}_{3} \mathrm{P}, \mathrm{C}_{6} \mathrm{H}_{6}$.

Схема 17. 

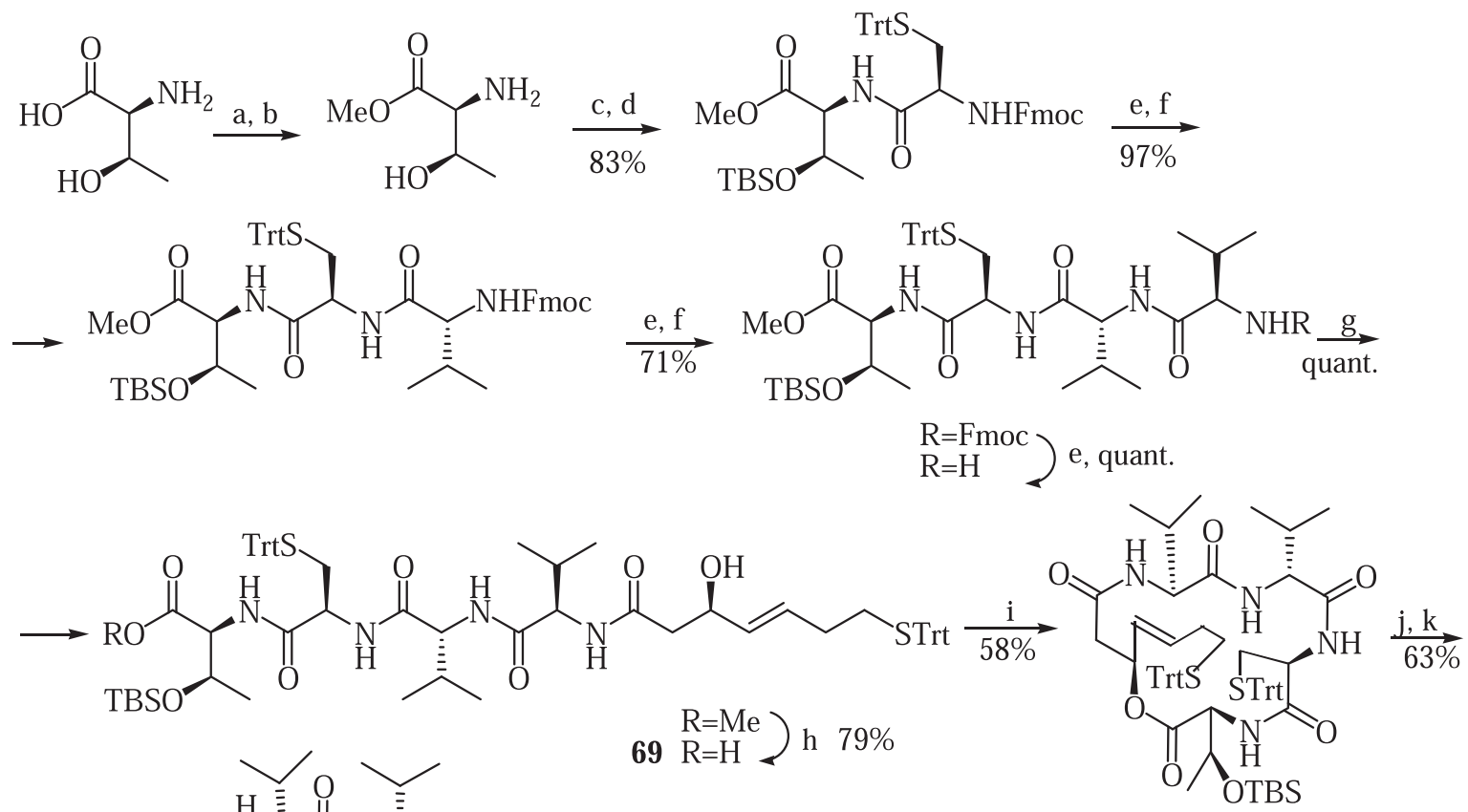<smiles>[R16][R15](=O)[O-]</smiles>

FR-901375

a) $\mathrm{HCl}, \mathrm{MeOH}$; b) $\mathrm{NH}_{3}, \mathrm{Et}_{2} \mathrm{O}$; c) HOOC NHFmoc , EDC, HOBT; d) TBSCl, imidazole;

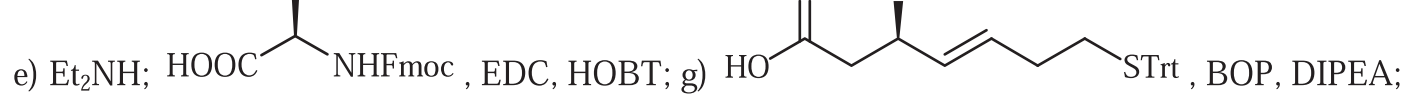

h) $\mathrm{LiOH}$; i) $\mathrm{PPh}_{3}$, DIAD (66), THF, TsOH; j) I, $\mathrm{MeOH}$; k) HF, MeCN.

Схема 18.

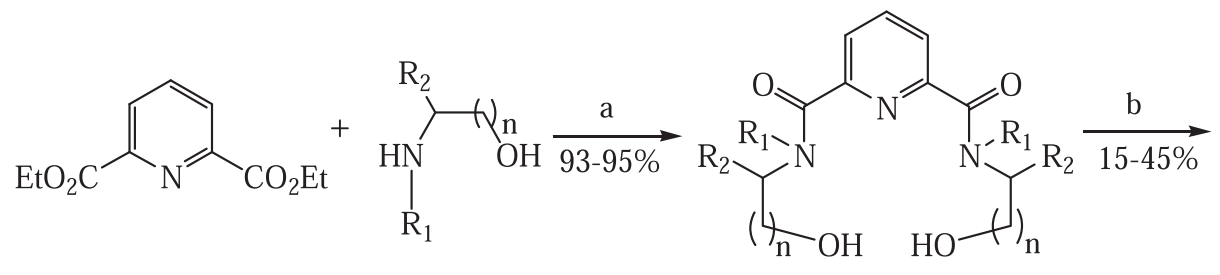

71 A-F

a) $80-90^{\circ} \mathrm{C}$; b) $\mathrm{Cl} \quad \mathrm{Cl}$ (73), $\mathrm{K}_{2} \mathrm{CO}_{3}, \mathrm{TBA} \cdot \mathrm{H}_{2} \mathrm{SO}_{4}, \mathrm{CH}_{2} \mathrm{Cl}_{2}, \mathrm{MeCN}$.<smiles>[R]N1CCOC(=O)CSCC(=O)OCCN([R])C(=O)c2cccc(n2)C1=O</smiles>

$75 \mathrm{~A}, \mathrm{C}$

Схема 19.

a) $\mathrm{KF}, \mathrm{TBA} \cdot \mathrm{HSO}_{4}, \mathrm{MeCN}$ or $\mathrm{CH}_{2} \mathrm{Cl}_{2}$.

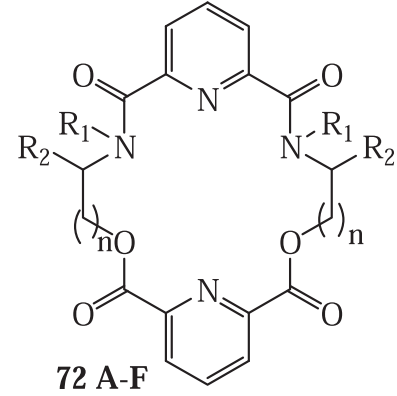


<smiles>[X]CC(=O)Cl</smiles>

76<smiles>[R]C(N)CO</smiles>
77
78<smiles>[X]CC(=O)NC([R])COC(=O)C[Y]CC(=O)OCC([R])NC(=O)C[X]</smiles>

79

$$
\text { a) } \mathrm{CH}_{2} \mathrm{Cl}_{2}, \mathrm{Et}_{3} \mathrm{~N} \text {; b) }
$$

Схема 20.

\section{2. Макроамидация}

Образование амидолактонов возможно реакциями межмолекулярной либо внутримолекулярной циклизации.

\section{1. Реакцฺии внутримолекулярной цฺиклизаџии}

Для уменьшения образования побочных (линейных) продуктов внутримолекулярной циклизации применяют специальные активирующие агенты, способствующие её внутримолекулярному протеканию. ${ }^{[7]}$

Наиболее широко используемым активирующим агентом для макроамидации является гексафторфосфат $O$-(7-азабензотриазолил)- $N, N-N$ ', $N$ '-тетраметилурония (HATU) (81) ${ }^{[41]}$ в присутствии различных оснований $\left(\mathrm{Et}_{3} \mathrm{~N},{ }^{i} \operatorname{Pr}_{2} \mathrm{NEt}\right)$ :

$\mathrm{C}$ использованием этого реагента на стадии циклизации синтезированы депсипептиды тамандарин А, обладающий способностью ингибировать пролиферацию клеток, ${ }^{[42]}$ и паулоамид с его противоопухолевыми свойствами, ${ }^{[43]}$ а также циклодепсипептид апротоксин А, проявляющий цитотоксичность к некоторым линиям опухолевых клеток человека. ${ }^{[44,45]}$

В синтезе нового триоксазольного макролида (-)-улапуалида А (89), выделенного из морских губок, этерификацией спирта (85) кислотой $(84)$ в условиях реакции Ямагучи получен эфир (86), который содержит все 10 асимметричных центров целевого макролида (89). Макроциклизация соединения (87), содержащего аминную и гидроксильную функции, при использовании HBTU (81) в присутствии $\mathrm{Et}_{3} \mathrm{~N}$ преимущественно протекает по азотсодержащей группе и приводит к образованию макролактама (88), формирование третьего оксазольного кольца в котором и завершает синтез (Схема 21). ${ }^{[46]}$

Природный (+)-ларгазол (96), выделенный из цианобактерий Symploca sp., является мощным антираковым агентом. Синтезы его основаны на трансформациях триазола (93), полученного, в свою очередь, конденсацией нитрила (91) с $L$-цистеином (92). В первом из них построение цепи макролида начинается с кислотной части соединения (93). Катализированное солями пиридиния
(РуВОР) взаимодействие призводного триазола - кислоты (93) - с эфиром (94), протекающее с формированием амидной связи, приводит к образованию ациклического предшественника ларгазола (95). Макроамидация последнего проведена на катализаторе HATU (81) в присутствии основания ${ }^{i} \operatorname{Pr}_{2} \mathrm{NEt}$ (Схема 22). ${ }^{[47-49]}$

В другом подходе [исходя из соединения (97)] формирование амидной и сложноэфирной групп ациклического предшественника ларгазола (102) проведено последовательными реакциями аминоэфира (98) со спиртом (99) и полученного соединения (100) с аминокислотой (101). Макроамидация в приведенных выше условиях (HATU/i $\mathrm{Pr}_{2} \mathrm{NEt}$ ) позволяет построить циклический остов ларгазола (103), а реакция метатезиса на катализаторе Граббса 2 поколения - ввести в молекулу тиоэфирный фрагмент (Схема 23). ${ }^{[50,51]}$

Для макроамидации используется и другой азотсодержащий активирующий агент - 2-гидроксипиридин (2-НР). С его помощью удалось осуществить синтез цитотоксического макроциклического депсипептида криптофицина-52 (105), выделенного из сине-зеленых морских водорослей (Схема 24). ${ }^{[52,53]}$

Наряду с азотсодержащими активирующими агентами макроамидации широко используются и фосфорсодержащие, одним из которых является бензотриазол-1илокси-трис(диметиламино)фосфоний гексафторфосфат (BOP) в присутствии основания DMAP. С использованием его на ключевой стадии циклизации удалось с высоким выходом получить обладающий противораковым действием депсипептид (-)-доликулид (108), ${ }^{[54]}$ в молекулу которого сложноэфирная группа введена катализируемой DCC (22) реакцией спирта $(\mathbf{1 0 6})$ и соответствующей эфиру (107) кислоты (Схема 25).

Другим реагентом для макроамидации служит бис(2-оксо-3-оксазолидинил)фосфоний хлорид (ВОР$\mathrm{Cl})$. С применением этого агента осуществлен синтез четырех биологически активных пролиновых аналогов (114-117) циклического депсипептида гапалозина (109), проявляющего широкий спектр антираковой активности. Для этого транс-4-гидрокси- $L$-пролин (110) был переведен в замещенную кислоту (111), трансформация которой в ациклический предшественник (112) включала 
<smiles></smiles>

82<smiles>CCC(=O)N1C(=O)OCC1Br</smiles>

83

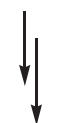

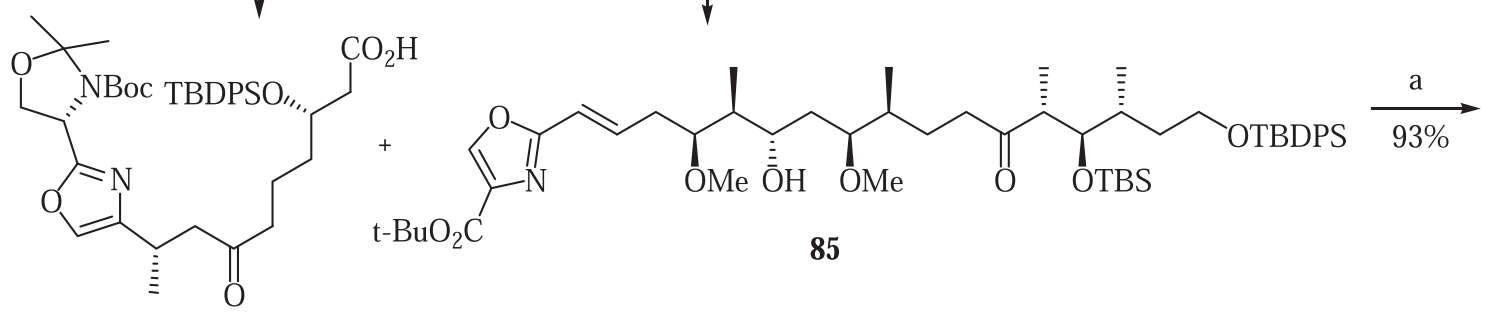

84

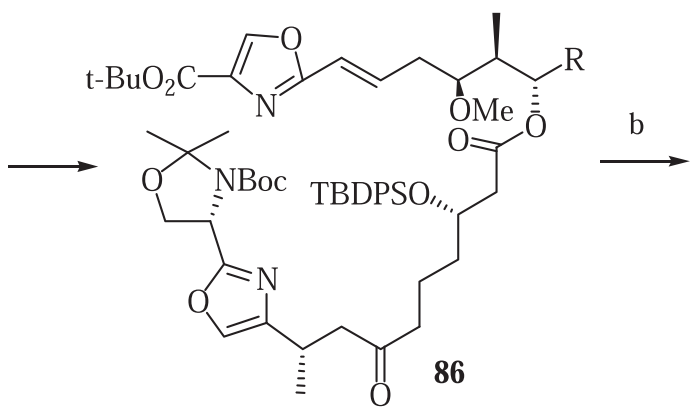

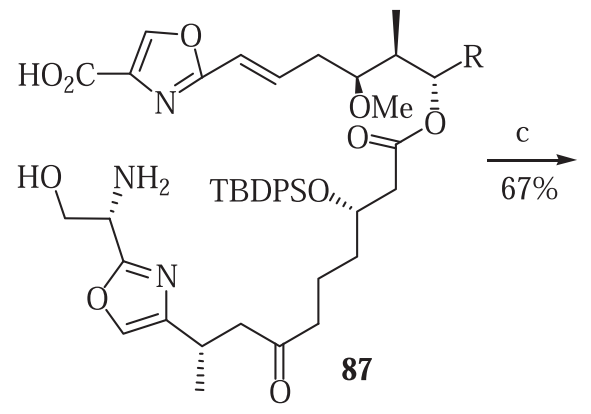

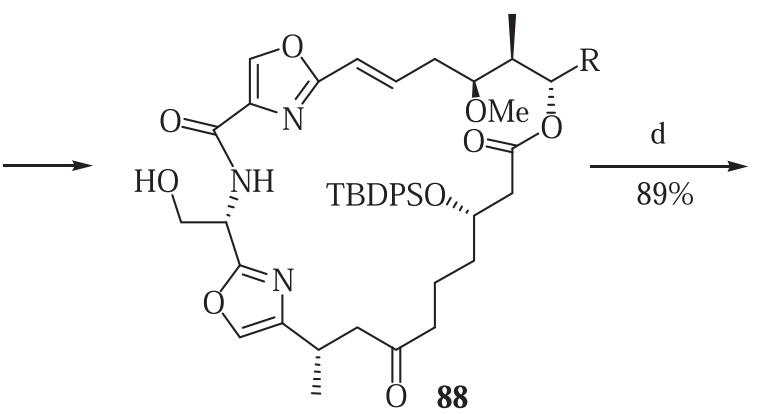

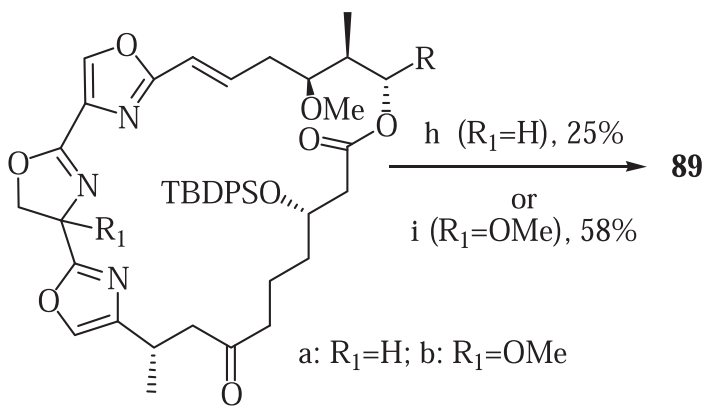

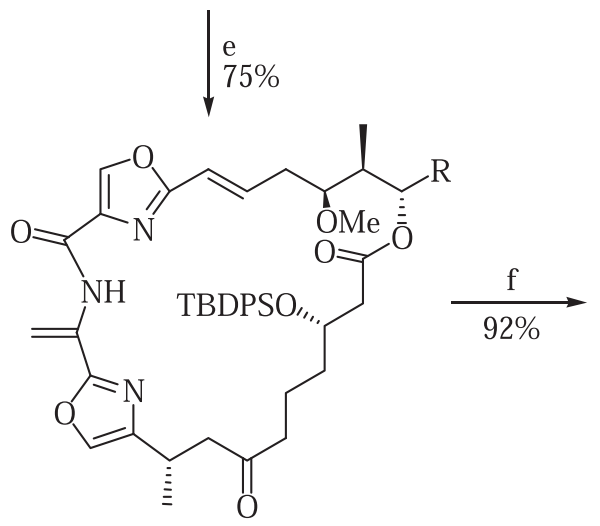

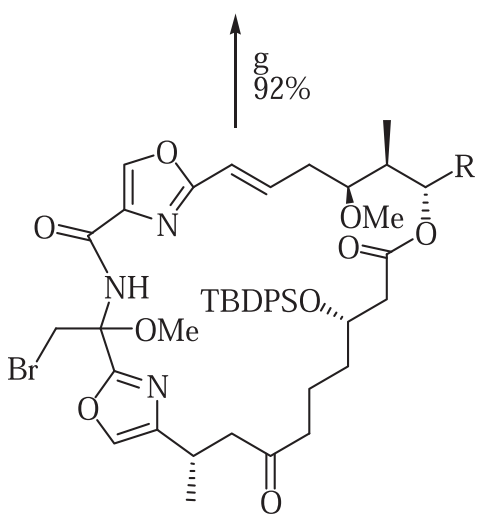

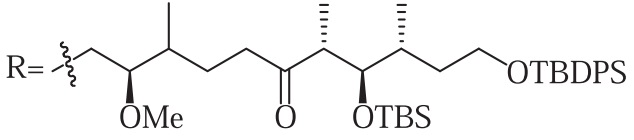



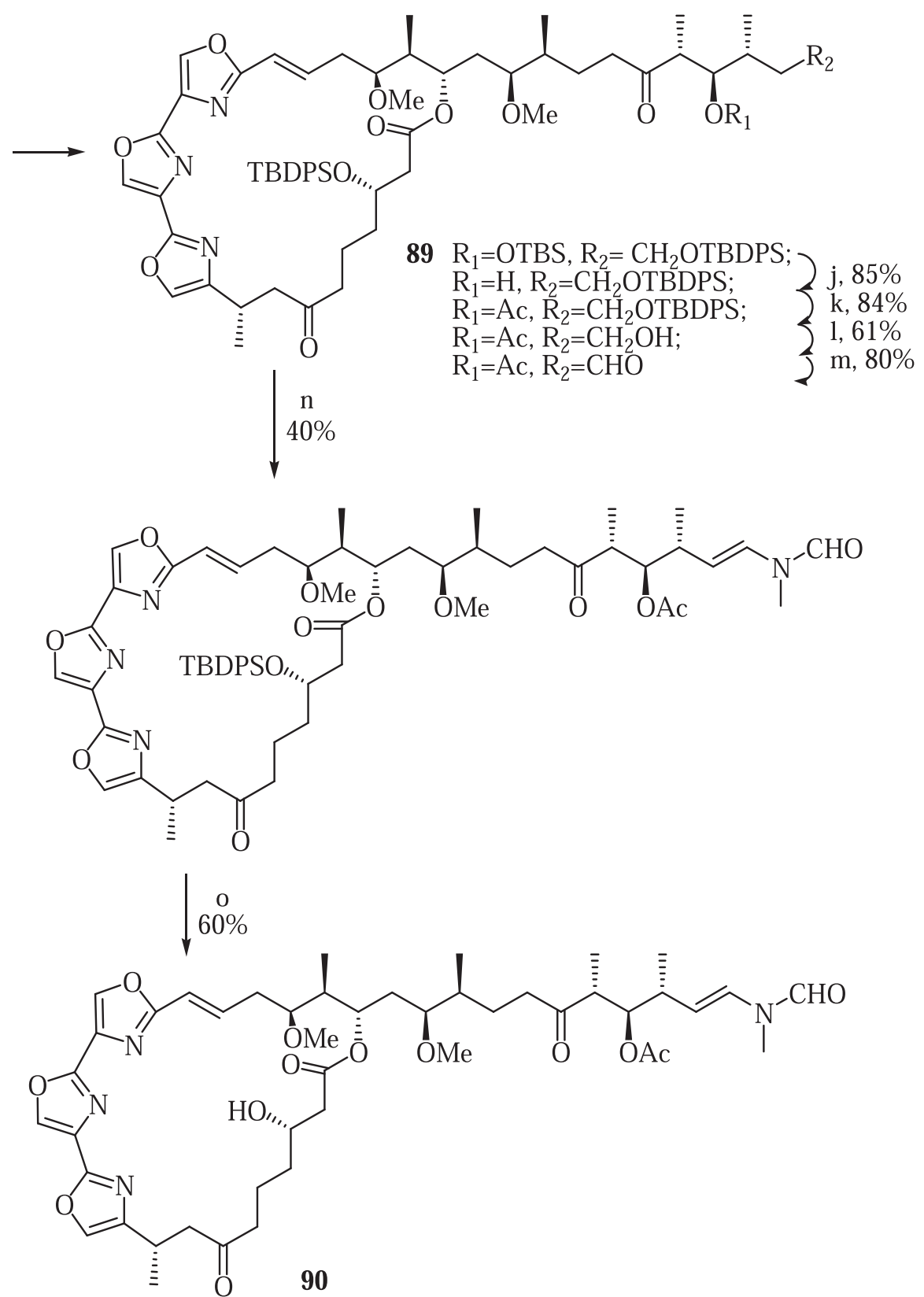

a) 46, $\mathrm{Et}_{3} \mathrm{~N}$, toluene, DMAP, $0^{\circ} \mathrm{C}$; b) TMSOTf, $\mathrm{Et}_{3} \mathrm{~N}, \mathrm{CH}_{2} \mathrm{Cl}_{2}, 0^{\circ} \mathrm{C}$; c)<smiles>CN=C(N=C(C)C)On1nnc2cccnc21</smiles>
$0^{\circ} \mathrm{C}$;

(81), $\mathrm{Et}_{3} \mathrm{~N}, \mathrm{CH}_{2} \mathrm{Cl}_{2}$,

d) DAST, $\mathrm{CH}_{2} \mathrm{Cl}_{2},-78^{\circ} \mathrm{C}$; e) MsCl, DIPEA, $\mathrm{CH}_{2} \mathrm{Cl}_{2}$, $\mathrm{DBU}, 0^{\circ} \mathrm{C}$; f) NBS, $\mathrm{MeOH}, \mathrm{CH}_{2} \mathrm{Cl}_{2}$; g) $\mathrm{Cs}_{2} \mathrm{CO}_{3}$, dioxane, $60^{\circ} \mathrm{C}$;

h) $\mathrm{NiO}_{2}$, benzene; i) CSA, benzene; j) TMSOTf, $\mathrm{CH}_{2} \mathrm{Cl}_{2},-78^{\circ} \mathrm{C}$; k) $\mathrm{Ac} 2 \mathrm{O}$, DMAP, $\mathrm{CH}_{2} \mathrm{Cl}_{2}$, Py; l) HF-Py, $\mathrm{CH}_{2} \mathrm{Cl}_{2}, \mathrm{Py}$; m) Dess-Martin periodinane, $\left.\mathrm{CH}_{2} \mathrm{Cl}_{2} ; \mathrm{n}\right) \mathrm{DMF}$, PPTS, benzene; $\mathrm{k}$ ) HF-Py, THF. 
<smiles>CC(C)(C)OC(=O)CNCc1nc(C2=N[C@H](C(=O)O)CS2)cs1</smiles>

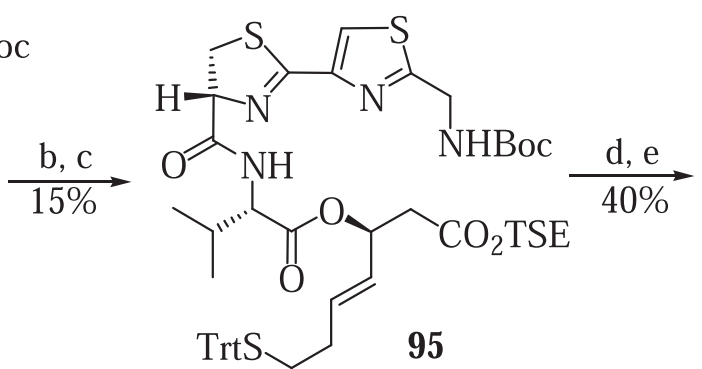

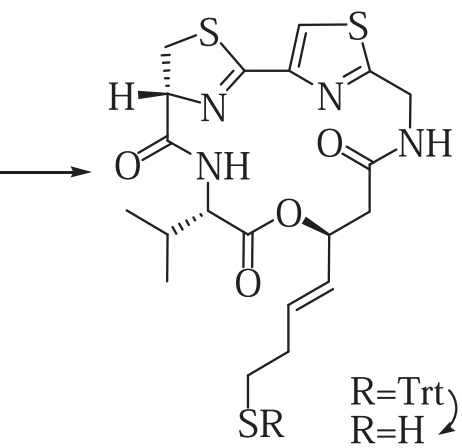

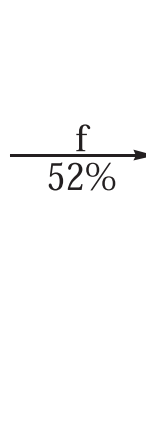<smiles>[R16]CC/C=C\[C@H](CC(=O)NCc1nc(-c2nccs2)cs1)OC(=O)[C@@H](NC(=O)[R19]([H])([H])[H])C(C)C</smiles>

a)<smiles>N[C@@H](CS)C(=O)Cl</smiles>

c) PyBOP, DIPEA, $\mathrm{CH}_{2} \mathrm{Cl}_{2}$; d) $\mathrm{CF}_{3} \mathrm{CO}_{2} \mathrm{H}, \mathrm{CH}_{2} \mathrm{Cl}_{2}$; e) $\mathrm{HATU}(\mathbf{8 1})$, HOBT, DIPEA, $\mathrm{CH}_{2} \mathrm{Cl}_{2}$; f) DBU, $\mathrm{BrCCl}_{3}$, $\mathrm{CH}_{2} \mathrm{Cl}_{2}$.

\section{Схема 22.}<smiles>[R]NCc1nc(C2=NC(C)(C(C)=O)CS2)cs1</smiles>

97: $\mathrm{R}=\mathrm{Boc}$ 98: R=HTFA<smiles>C=CC(CC(=O)NCc1nc(C2=NC(C)(C(=O)N[C@@H](C(=O)OC)C(C)C)CS2)cs1)C(C)C</smiles>

103<smiles>C=CC(O)CC(=O)NCc1nc(C2=NC(C)(C(C)=O)CS2)cs1</smiles>

100<smiles>CCCCC=CC(CC(=O)O)OC(=O)[C@H](NC)C(C)C</smiles>

96: $\mathrm{R}=\mathrm{H} 2$ 


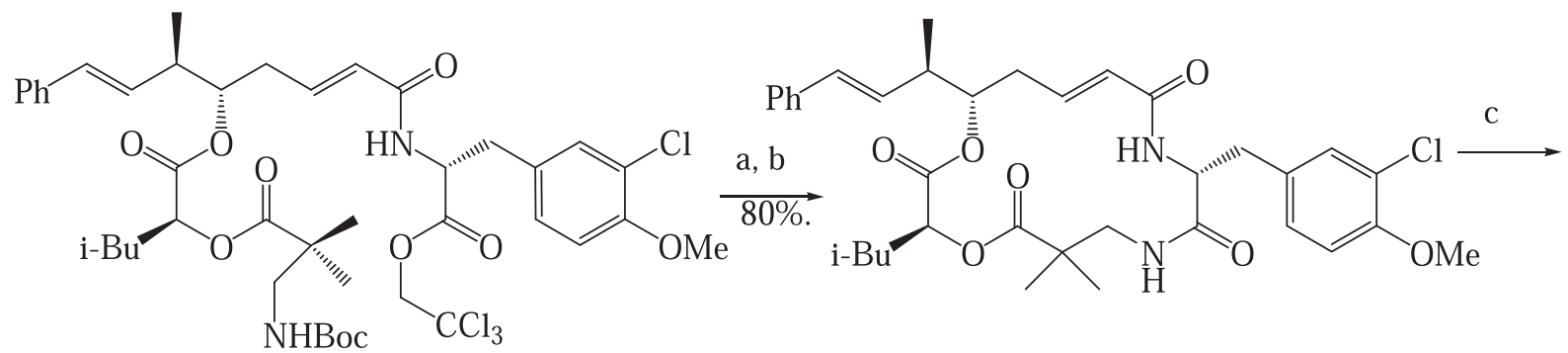<smiles>COc1ccc(C[C@H](NC(=O)/C=C/C[C@H](OC(=O)C(CBr)Cc2ccccc2)C(C)C)C(=O)NCC(C)(C)C(=O)O)cc1Cl</smiles>

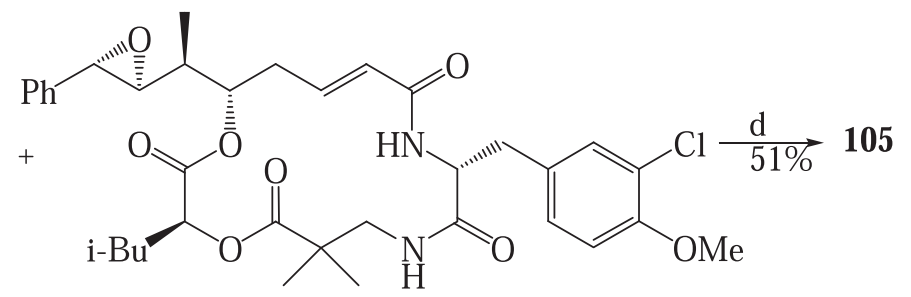

105

a) $\mathrm{CF}_{3} \mathrm{COOH}$; b)

Схема 24.

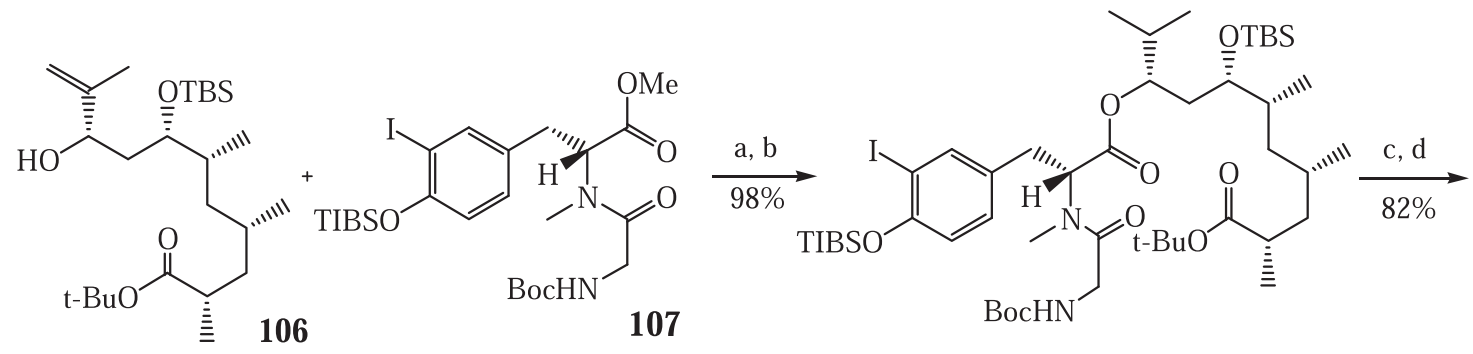

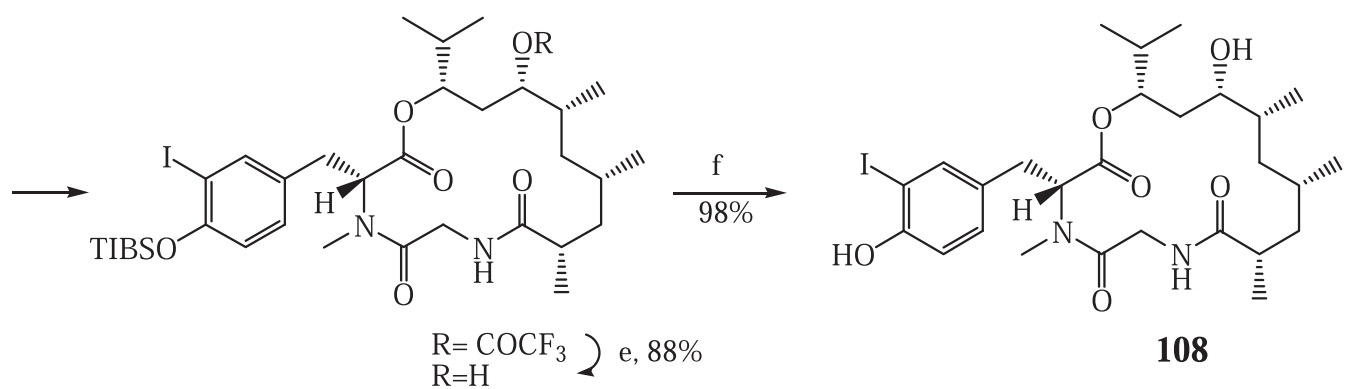

a) $\mathrm{LiOH}, \mathrm{H}_{2} \mathrm{O}, \mathrm{THF}, 0^{\circ} \mathrm{C}$; b) DCC (22), DMAP, $\mathrm{CH}_{2} \mathrm{Cl}_{2},-20^{\circ} \mathrm{C}$; c) $\mathrm{CF}_{3} \mathrm{CO}_{2} \mathrm{H}, \mathrm{CH}_{2} \mathrm{Cl}_{2}, 0^{\circ} \mathrm{C}$;<smiles></smiles>

d) $\mathrm{NMe}_{2}$ (BOP), DMAP, $\mathrm{CH}_{2} \mathrm{Cl}_{2}, 0^{\circ} \mathrm{C}$; e) $\mathrm{NH}_{3}, \mathrm{MeOH}, \mathrm{H}_{2} \mathrm{O}$; f) TBAF, THF, $0^{\circ} \mathrm{C}$.

\section{Схема 25.}



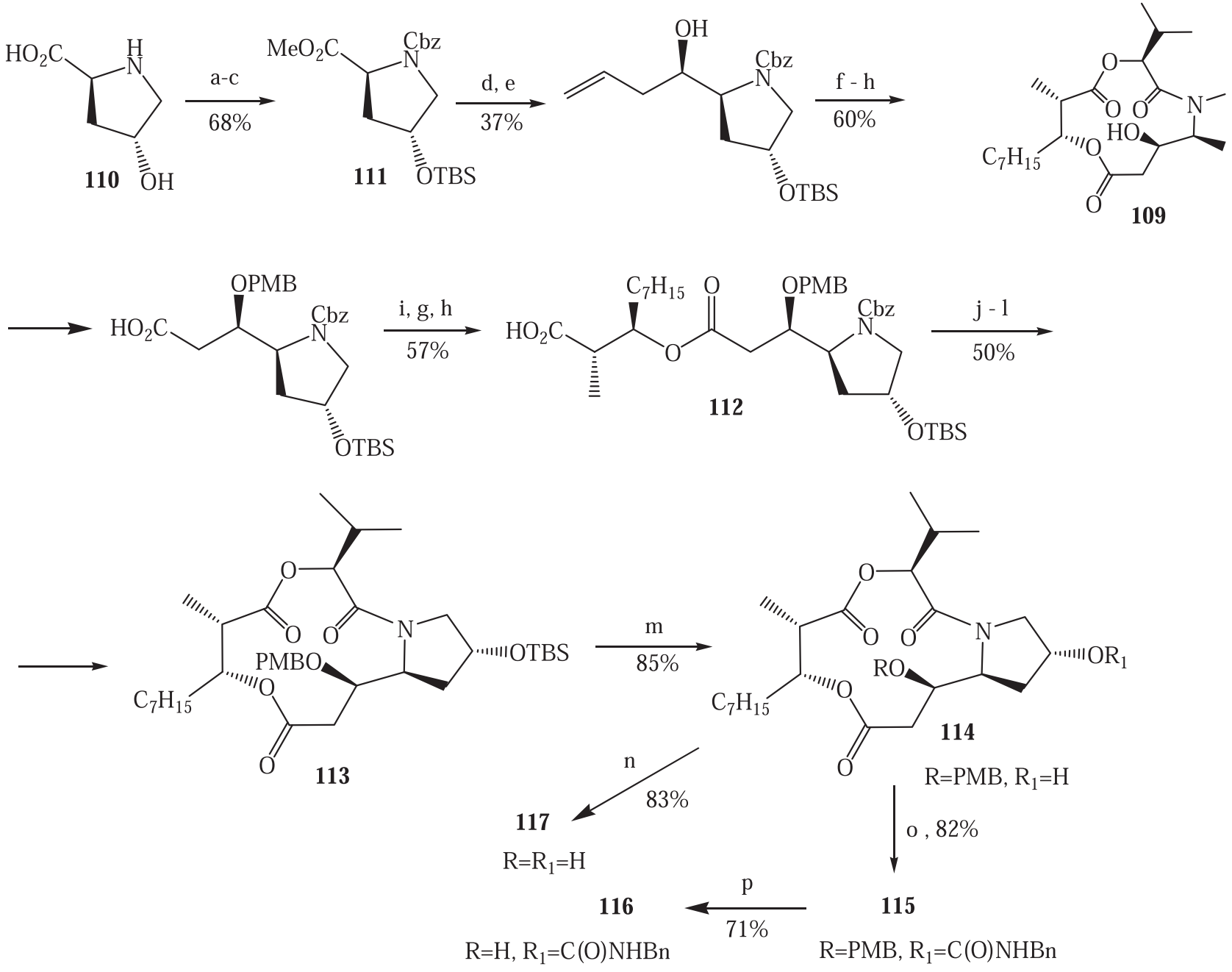

a) $\mathrm{Cbz}-\mathrm{Cl}, \mathrm{Na}_{2} \mathrm{CO}_{3}$, THF; b) DBU, MeI, MeCN; c) TBS-Cl, imidazole, DMF; d) DIBAH, PhMe, $-78^{\circ} \mathrm{C}$; e) $\mathrm{B}\left[(+)-\mathrm{Ipc}_{2},-78^{\circ} \mathrm{C}\right.$, THF then $\mathrm{NaOH}, \mathrm{H}_{2} \mathrm{O}_{2}$; f) PMBTCAl, TfOH, THF; g) $\mathrm{O}_{3}$ then $\mathrm{PPh}_{3}$;

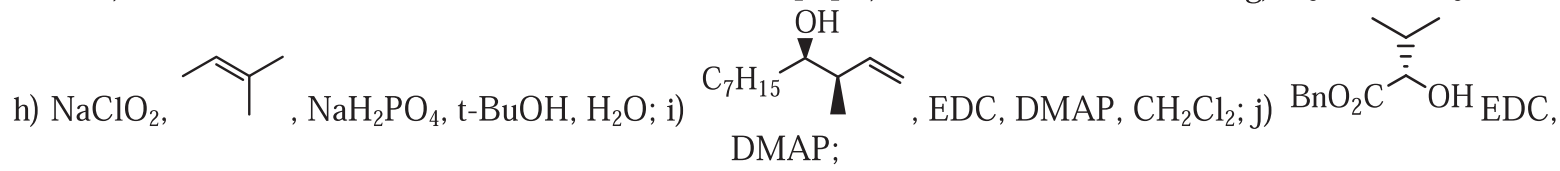
k) W-2 Raney Ni, $\mathrm{H}_{2}$, EtOH; l) BOP-Cl, DIPEA, PhMe, $85^{\circ} \mathrm{C}$; m) HF, Py, THF; n) DDQ, $\mathrm{CH}_{2} \mathrm{Cl}_{2}, \mathrm{H}_{2} \mathrm{O}$; o) $\mathrm{BnN}=\mathrm{C}=\mathrm{O}$, DMAP, $\left.\mathrm{CH}_{2} \mathrm{Cl}_{2} ; \mathrm{p}\right) \mathrm{DDQ}$.

Схема 26.

две последовательные катализируемые DMAP реакции формирования сложноэфирных групп. Макроамидация соединения (112) с использованием активирующего агента $\mathrm{BOP}-\mathrm{Cl}$ в присутствии $i$ - $\mathrm{Pr}_{2} \mathrm{NEt}$ позволяет получить макроцикл (114), содержащий сложноэфирные и пирролидиновые фрагменты, который и был переведен в производные гапалозина (115-117) (Схема 26). ${ }^{[55]}$

Применение ещё одного активирующего агента макролактамизации - DPPA (дифенилфосфорилазида) в присутствии DIPEA - оказалось успешным в синтезе макроциклического депсипептида гаполозина (118), ${ }^{[56]}$ формирование обеих сложноэфирных групп в котором проведено в условиях реакции Ямагучи (Схема 27).
Производные пирролидина - (бензотриазол-1илокси)трипирролидинфосфония гексафторфосфат (РуВОР) и его 7-аза-аналог (РуАОР) в присутствии DMAP - также используются в качестве активирующих агентов в реакции макролактонизации.

В синтезе депсипептида вертициллида (119), ${ }^{[57]}$ проявляющего инсектицидные свойства, РуВОР использован как при построении цепи депсипептида, так и на ключевой стадии циклизации (Схема 28).

Реагент РуАОР успешно применен в синтезе ранее представленного макроциклического 16-членного депсипептида ларгазола (104), для получения ациклического предшественника (121) которого проведена конденсация 


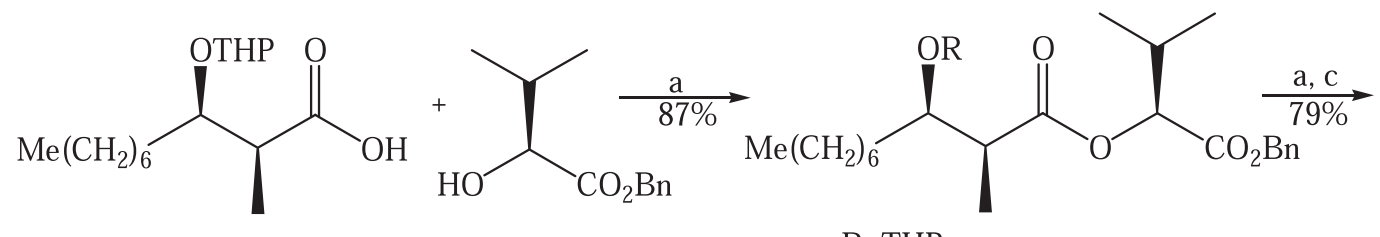

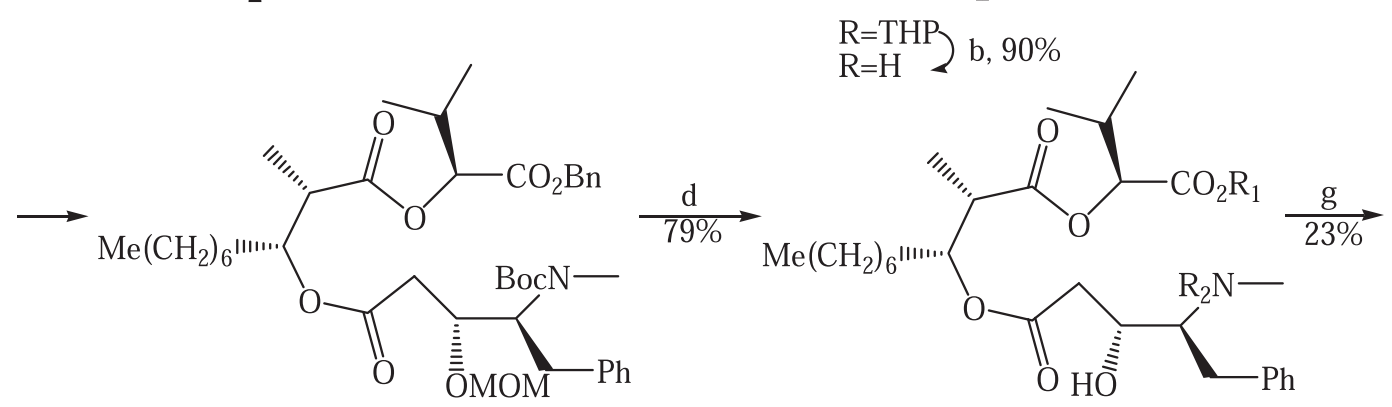

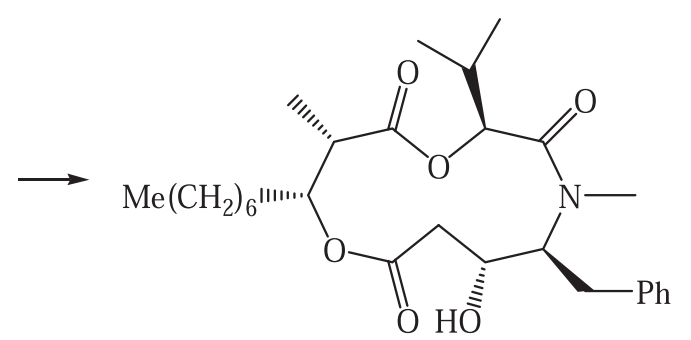

$\mathrm{R}_{1}=\mathrm{Bn} ; \mathrm{R}_{2}=\mathrm{Boc}$ e, $94 \%$ $\mathrm{R}_{1}=\mathrm{H} ; \mathrm{R}_{2}=\mathrm{Boc}$
$\mathrm{R}_{1}=\mathrm{H} ; \mathrm{R}_{2}=\mathrm{H}$$\left\{\begin{array}{l}\mathrm{f}, 93 \% \\ \mathrm{f}, 9\end{array}\right.$

118

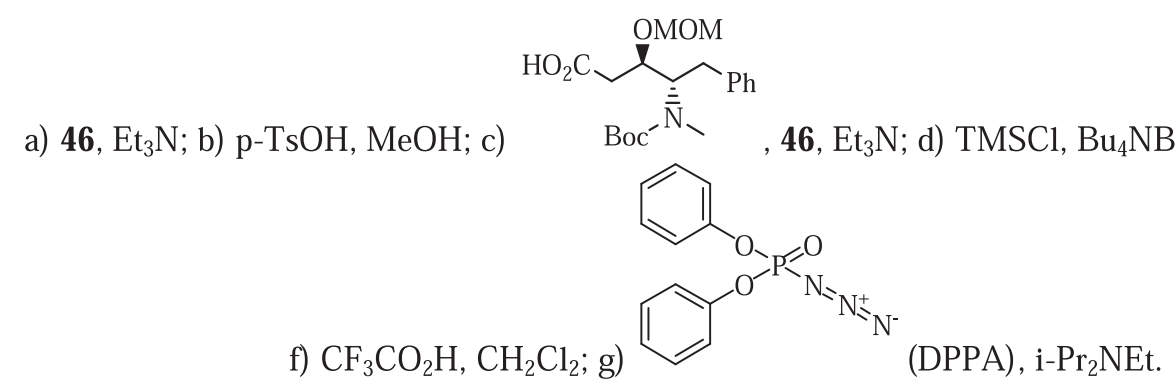

Схема 27.

амина (120) с замещенной кислотой (93) (Схема 29). ${ }^{[58]}$

Еще одним активирующим агентом является пентафторфенилдифенилфосфинат (FDPP).

В синтезе циклогексадепсипептида хирсутеллида А (123), обладающего сильным сродством к щелочным и щелочноземельным металлам, циклизация линейного предшественника (122) под действием FDDP проходила с невысоким выходом. Добавка к катализатору соли серебра $\left(\mathrm{AgBF}_{4}\right)$, образующей хелатный комплекс, увеличила выход продукта циклизации почти в 3 раза (Схема $31)^{[59]}$

\section{2. Реакции межмолекулярной циклизации}

Одним из методов синтеза циклодепсипептидов, включающих углеводную часть и являющихся основными строительными блоками биополимеров, является трехкомпонентная реакция аминоспирта (124), альдегида (125) и дипептидного изонитрила (126), приводящая к образованию 5-аминооксазола (127), который после омыления претерпевает промотируемую $\mathrm{CF}_{3} \mathrm{COOH}$ макроциклизацию (Схема 33). ${ }^{[60,61]}$
Макроциклический карбамоилоксамостиковый циклофан (130) был синтезирован конденсацией ароматических диизоцианометильного (128) и дигидроксиметильного (129) производных в присутствии имидазола (Схема 34). ${ }^{[62]}$

Формирование сложноэфирной функции ациклического предшественника (133 A-B) для хиральных макроциклов (134 A-B, 135 A-B) проведено реакцией ацилирования гидроксиметильного производного пиридина (131) хиральными аминокислотами (132 А-В) в присутствии DCC (22) и DMAP. Взаимодействие полученных диаминов (133 A-B) с дихлорангидом пиридин-2,6дикарбоновой кислоты (72) приводит к образованию сопоставимого количества продуктов как [1+1]- (134 A-B), так и [2+2]-циклизации (135 A-B) (Схема 35). ${ }^{[63]}$

При использовании для конденсации с дихлорангидом (73) производного пироллидина (136) образуется лишь продукт [1+1]-циклизации (137) (Схема 36). ${ }^{[63]}$

Последовательными реакциями взаимодействия 2,6-диаминозамещенного пиридина (138) с дихлорангидридом (139) и [1+1]-конденсацией полученного диамина (140) с ангидридом (141) сформирована структура 34- 


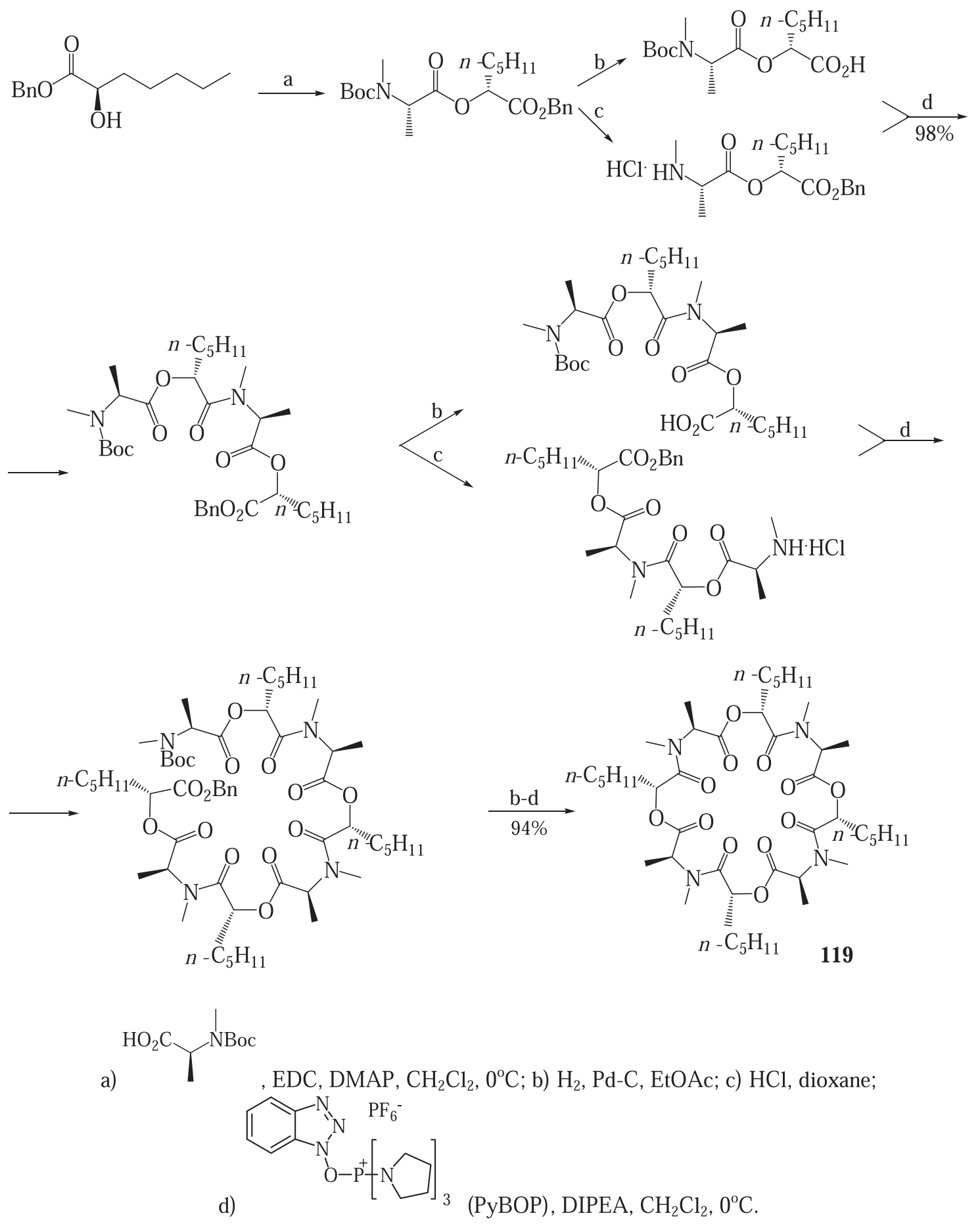

Схема 28.

членного макроцикла (142), содержащего ароматические кольца, в том числе и азотсодержащие (Схема 37). ${ }^{[64]}$

\section{3. Метатезис}

Реакцию метатезиса (от греч. metáthesis перестановка) называют также обменной реакцией, ее общая схема проста и наглядна: при взаимодействии двух молекул олефинов между ними происходит обмен концевыми группами (иногда этот процесс называют диспропорционированием):

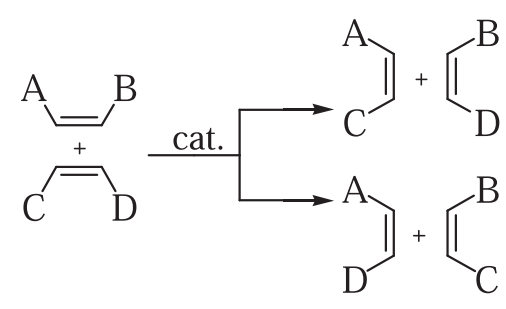

Данные типы реакций в последнее время имеют большое практическое применение в синтезе природных биологически активных макроциклов. Для проведения 


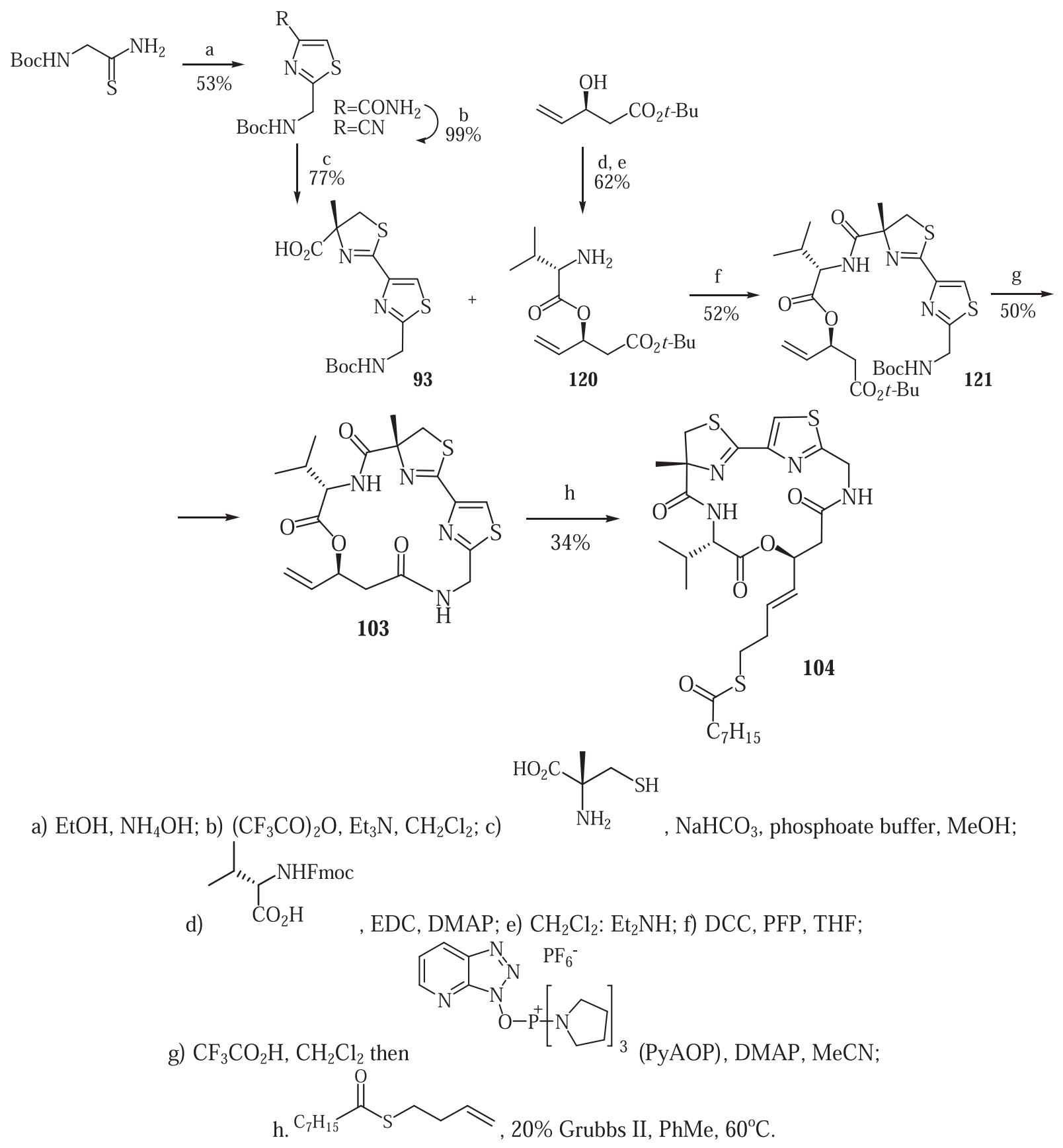

\section{Схема 29.}

такого типа превращений чаще всего используют катализаторы Граббса и Шрока, ${ }^{[65-67]}$ с помощью которых удалось провести трудноосуществимую какимлибо иным способом реакцию - превратить диены в циклические олефины (Схема 30).
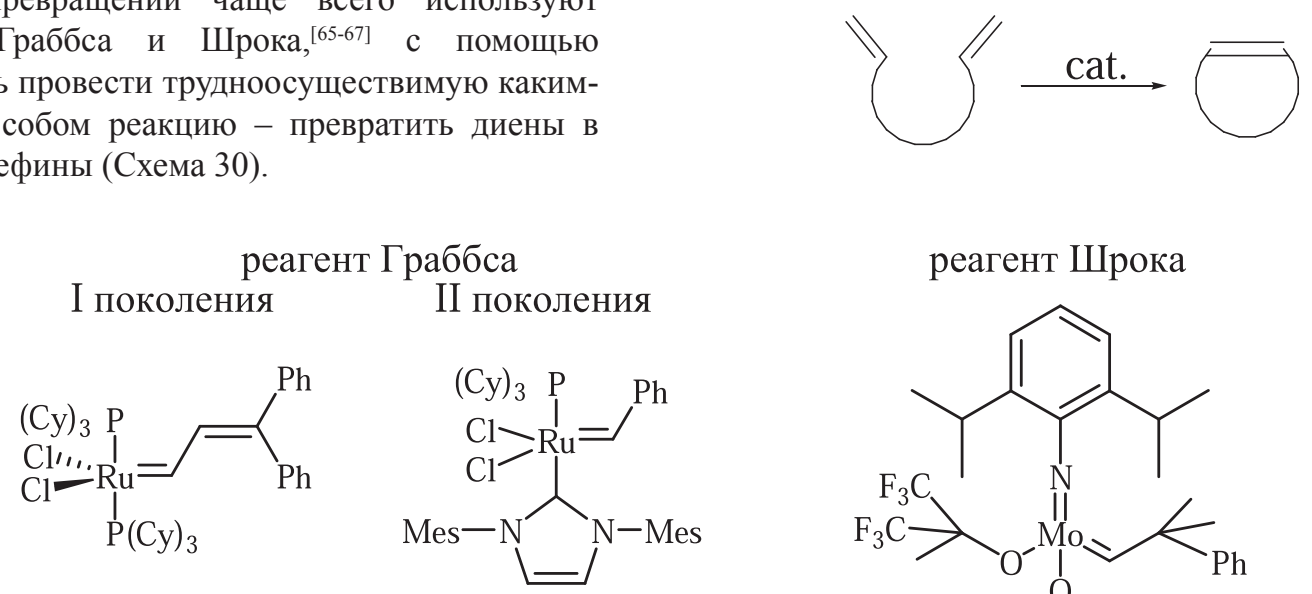

Схема 30.

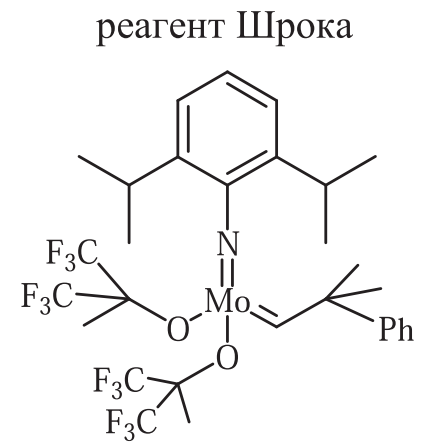




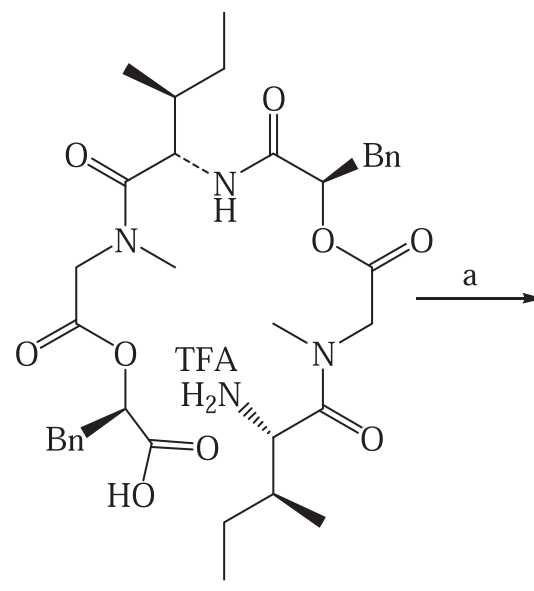

122<smiles>CC[C@H](C)[C@H](NC(=O)[C@H](Cc1ccccc1)OC(=O)CN(C)C(=O)[C@H](N)[C@@H](C)CC)C(=O)N(C)CC(=O)O[C@@H](Br)C(=O)OP(=O)(c1ccccc1)c1ccccc1</smiles>

$\mathrm{Ph} \overbrace{\mathrm{Ph}}$

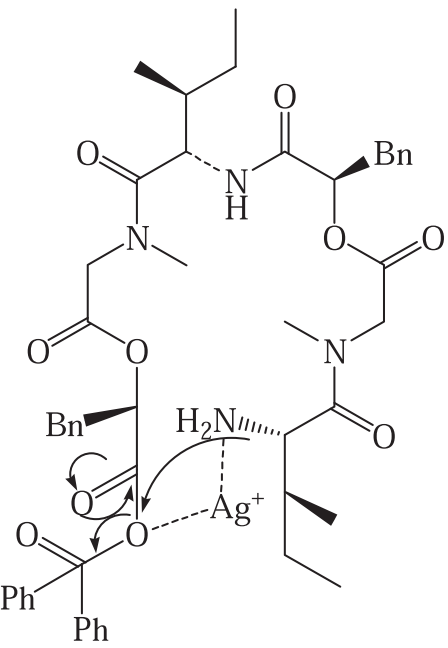

a) $\mathrm{AgBF}_{4}$

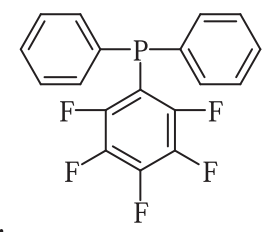

(FDPP), DIPEA, MeCN.

\section{Схема 31.}
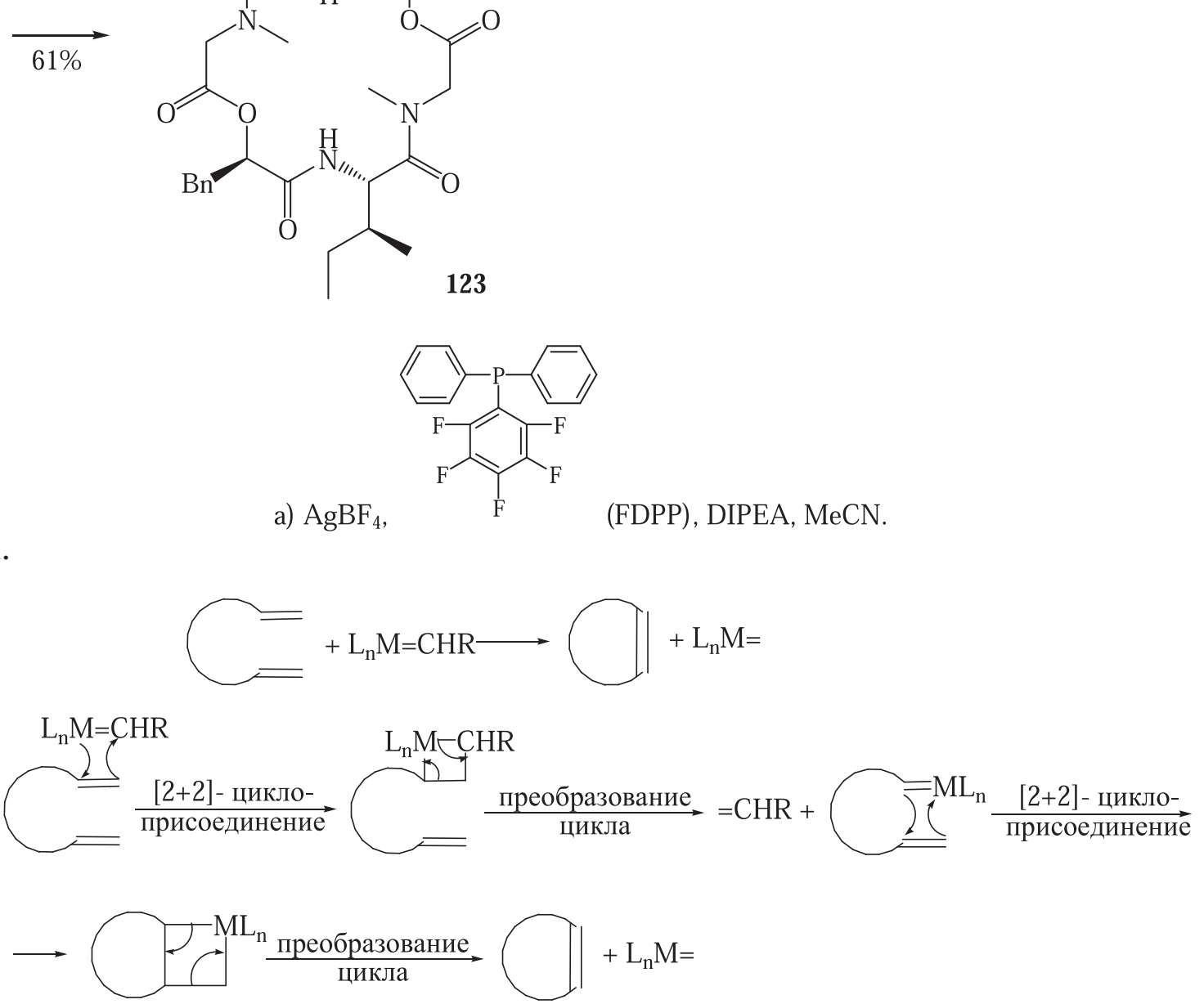

\section{Схема 32.}

Реакция протекает по механизму, в котором все три катализатора представлены общей формулой $\mathrm{L}_{\mathrm{n}} \mathrm{M}=\mathrm{CHR}$ (генерациякатализаторапроисходитизпредшественника) (Схема 32).

Каталитический цикл:

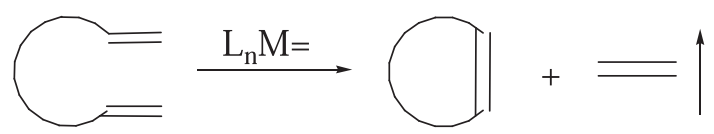

\section{1. Метатезис алкенов}

Представлен ${ }^{[68]}$ синтез ингибирующих развитие СПИД структурно новых HIV протеаз, представляющих собой (Z)-ненасыщенные макроциклические уретаны (147 A-D). Построение цепи их ациклических предшественников (146 A-D) проведено последовательными реакциями непредельных спиртов (143 A-D) с $N, N^{\prime}$-дисукцинилимидкарбонатом (DSC) 


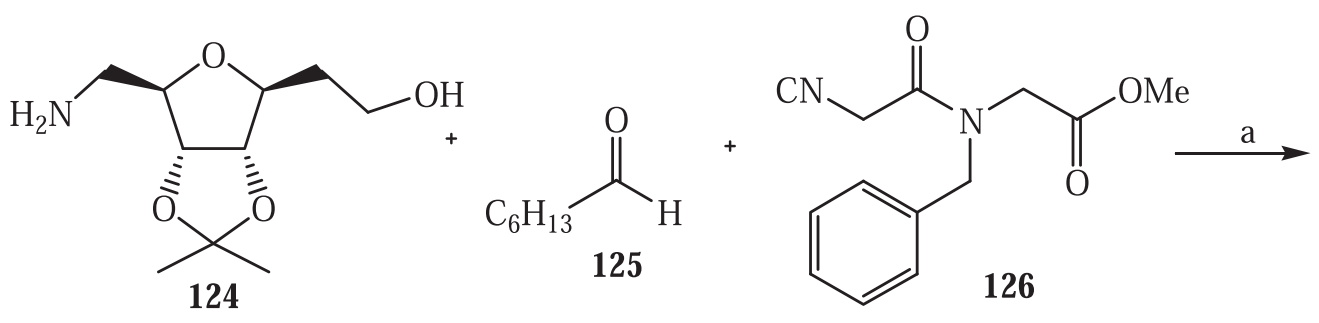

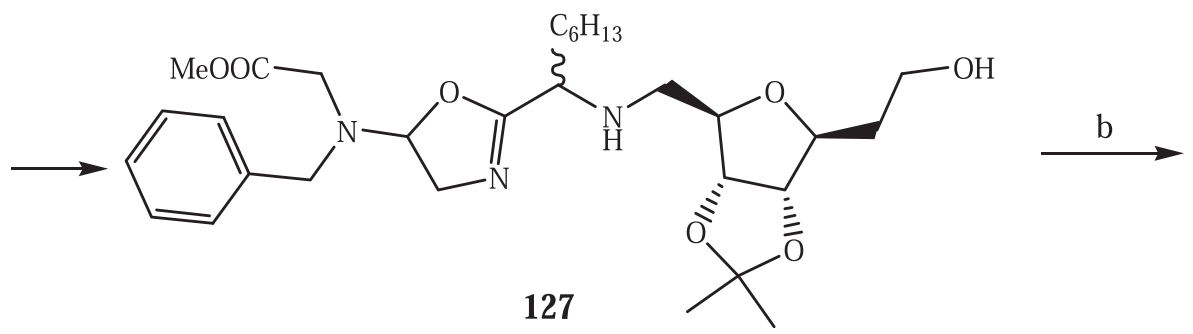

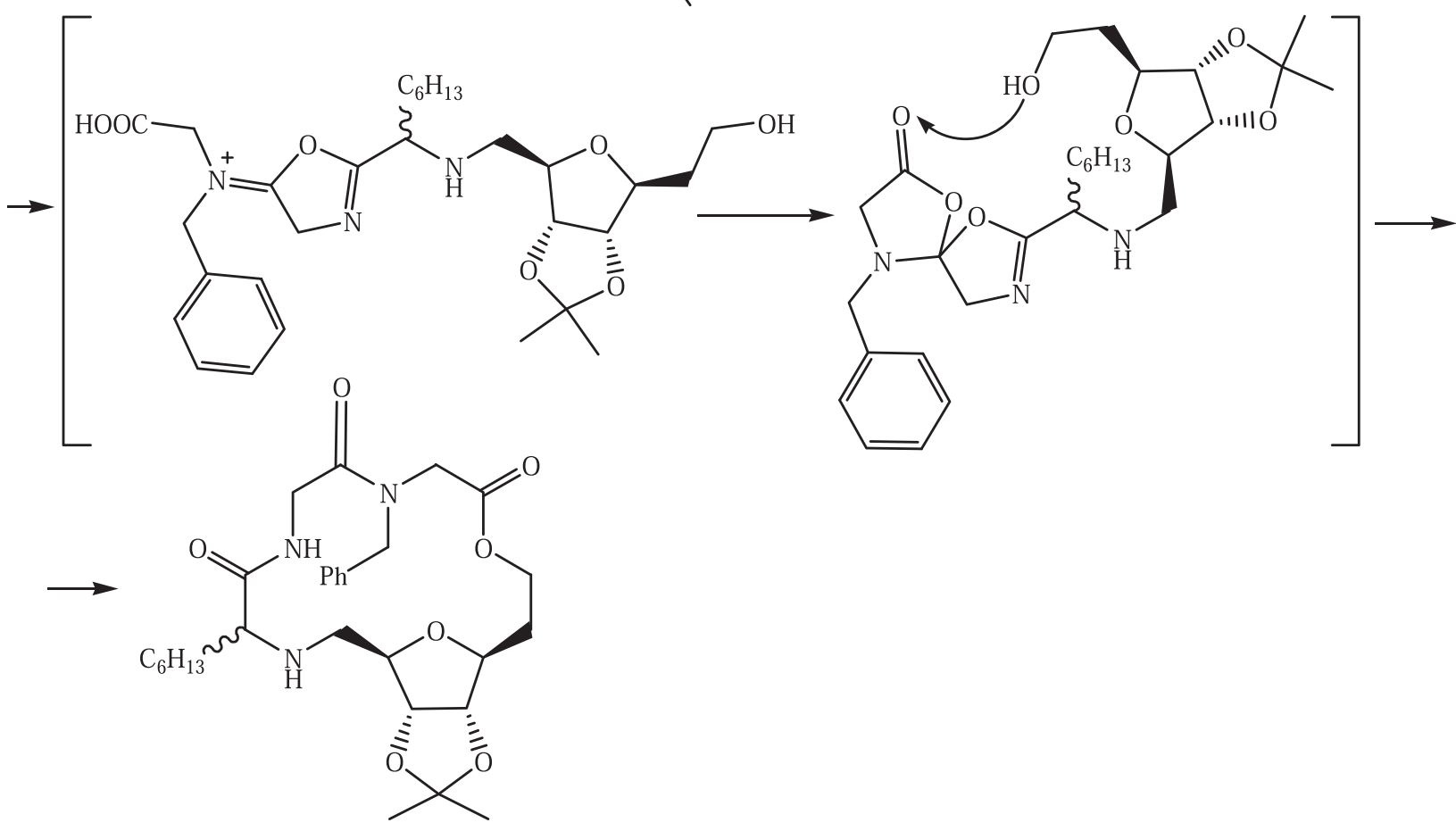

a) $\mathrm{MeOH}, \Delta$; b) LiOH, THF-H $\mathrm{H}_{2} \mathrm{O}$ then $\mathrm{MeCN}, \mathrm{CF}_{3} \mathrm{COOH}$.

Схема 33.<smiles>O=NCc1cccc(C[N+]=O)c1</smiles><smiles>OCc1cccc(CO)c1</smiles>

a) imidazole, toluene.<smiles>O=C1NCc2cccc(c2)CNC(=O)OCc2cccc(c2)CO1</smiles>

Схема 34. 
<smiles>OCc1cccc(CO)n1</smiles>

131<smiles>[R]C(NC(=O)OCc1ccccc1)C(=O)O</smiles>

132<smiles>[R][C@H](N)C(=O)OCc1cccc(COC(=O)[C@@H]([R])N)n1</smiles>

$133 \mathrm{~A}, \mathrm{~B}$<smiles>[R]C(NC(=O)c1cccc(C(=O)N[C@@]([R])([NH+])C(=O)OCc2ccccn2)n1)C(=O)OCc1ccccc1</smiles>

134 A,B

$15 \%(\mathrm{~A}) ; 2.5 \%(\mathrm{~B})$

$\mathrm{R}=\mathrm{Me}(\mathrm{A}), i-\operatorname{Pr}(\mathrm{B})$<smiles>[R]C(NC(=O)c1cccc(C(N)=O)n1)[C@@H](NC(=O)[C@@H]([R2])C(=O)OCc1cccc(C([R])([Y5])[3H])n1)C(N)=O</smiles>

$12 \%(\mathrm{~A}) ; 5 \%(\mathrm{~B})$<smiles>O=C(Cl)c1cccc(C(Cl)Cl)n1</smiles>

(73), $\mathrm{Et}_{3} \mathrm{~N}, \mathrm{CH}_{2} \mathrm{Cl}_{2}$.
a) DCC, DMAP, $\mathrm{CH}_{2} \mathrm{Cl}_{2}$; b) $\mathrm{HBr}-\mathrm{HOAc}$; )
$\mathrm{Cl}$
$\mathrm{Cl}$

\section{Схема 35.}<smiles>CC(C)(C)OC(=O)[C@@H]1CCCN1C(=O)[C@@H]1CCCN1[C@H]1CCCN1C(=O)OCc1cccc(COC(=O)[C@@H]2CCCN2)n1</smiles>

a) DCC, DMAP, $\mathrm{CH}_{2} \mathrm{Cl}_{2}$; b) $\mathrm{HBr}-\mathrm{HOAc}$; ) $73, \mathrm{Et}_{3} \mathrm{~N}, \mathrm{CH}_{2} \mathrm{Cl}_{2}$.

\section{Схема 36.}

(144) и аллильными аминами (145 А-В). Циклизация полученных диенов (146 A-F) на катализаторе Граббса I поколения с высокими выходами приводит к целевым уретанам (145 A-D) (Схема 38).

C применением того же катализатора на стадии циклизации осуществлен конвергентный синтез новых неприродных макролидов, содержащих углеводные заместители. Присутствие в аллильном положении к двойной связи атома кислорода снижает селективность реакции. В результате образуется хроматографически разделяемая смесь $(E)$ - и $(Z)$-изомеров макролидов (150 А-C) и (151 А,В), показавших активность в отношении грамотрицательных (E. coli, P. aeruginosa) и грамположительных бактерий (S. aureus, E. faecalis, C. perfringens), дрожжей (C. albicans, C. neoformans) и плесневых грибов (A. fumigatus, T. mentagrophytes) (Схема 39). ${ }^{[69]}$

Поскольку пиридинсодержащие субстраты в свободном виде не могут участвовать в реакции метатезиса, так как избыток пиридина дезактивирует 
<smiles>CCCCC(=O)Nc1cccc(NC(=O)c2cccc(C(=O)Nc3cccc(NC(=O)c4cccc(NC(=O)c5cc(C(C)(C)c6ccc(OC(=O)CCC(=O)Cl)cc6)ccc5OC(=O)CCC(=O)Nc5cccc(NC(=O)CCC(=O)Oc6ccc(C(C)(C)c7ccc(C(=O)Cl)cc7)cc6)n5)n4)n3)c2)n1</smiles>

a) $\mathrm{Et}_{3} \mathrm{~N}, \mathrm{THF}$.

Схема 37.

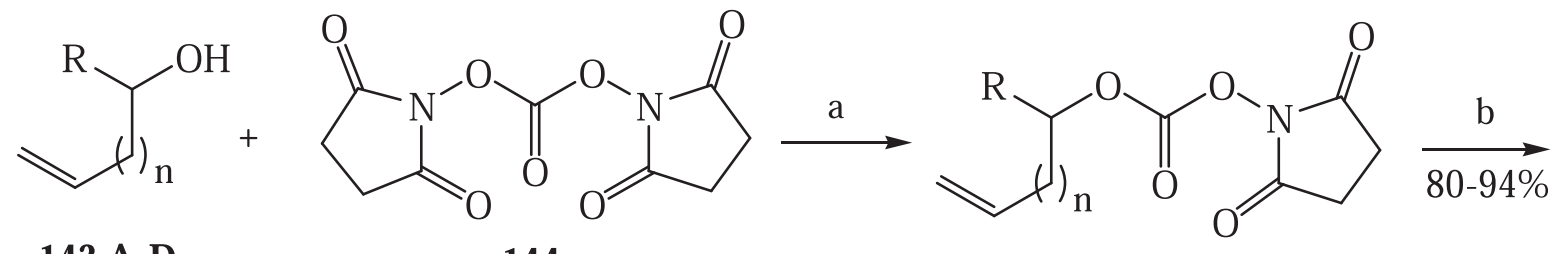

143 A-D

144<smiles>[R]C(C=CC)OC(=O)NNC/C=C\CNC(=O)OC([R])CCCCCCCCCC</smiles>

146 A-F

147 A-F

a) $(\mathrm{COCl})_{2}, \mathrm{DMSO}, \mathrm{Et}_{3} \mathrm{~N}, \mathrm{CH}_{2} \mathrm{Cl}_{2},-50^{\circ} \mathrm{C}$; b) $\mathrm{MeMgBr}, \mathrm{Et}_{2} \mathrm{O}, 0^{\circ} \mathrm{C}$; c) $\mathrm{Et}_{3} \mathrm{~N}, \mathrm{MeCN}$; d) $\mathrm{H}_{2} \mathrm{~N}_{\mathrm{m}} \mathrm{P}_{(145 \mathrm{~A}, \mathrm{~B})}$ e) Grubbs catalyst I, $\mathrm{CH}_{2} \mathrm{Cl}_{2}$.

$\begin{array}{lcccc} & \mathrm{R} & \mathrm{n} & \mathrm{m} & \text { Выход (147), \% } \\ \mathbf{A} & \mathrm{H} & 7 & 1 & 78 \\ \mathbf{B} & \mathrm{Me} & 7 & 1 & 74 \\ \mathbf{C} & \mathrm{H} & 8 & 1 & 58 \\ \mathbf{D} & \mathrm{Me} & 8 & 1 & 69 \\ \mathbf{E} & \mathrm{H} & 8 & 2 & 64 \\ \mathbf{F} & \mathrm{Me} & 8 & 2 & 69\end{array}$

Схема 38. 
<smiles>C=CCOCC1OC(c2ccccc2)C(OC)C(OC)C1O</smiles>

148<smiles>C=CCOCC1OCC(OC)C(OC)C1O</smiles>

149

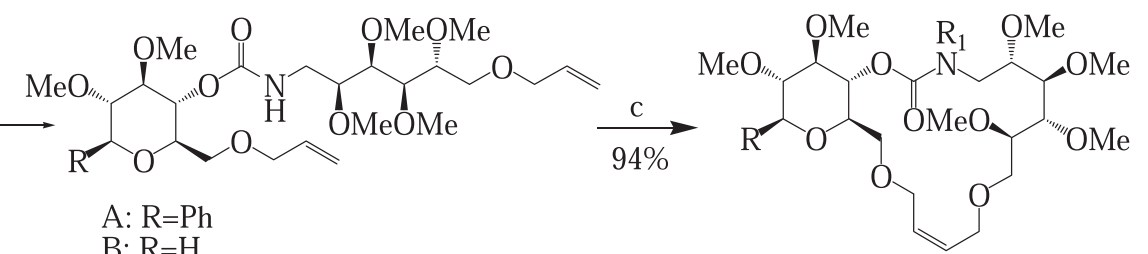

$150 \mathrm{~A}-\mathrm{C}$

A: $R=H, R_{1}=H$ ) f, $99 \% \quad$ a: $R=P h, R_{1}=H$

B: $\mathrm{R}=\mathrm{Ph}, \mathrm{R}_{1}=\mathrm{H}^{2}$

$\mathrm{C}: \mathrm{R}=\mathrm{Ph}, \mathrm{R}_{1}=\mathrm{Me}$

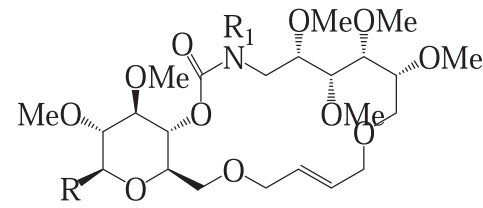

$151 \mathrm{~A}, \mathrm{~B}$

b: $\mathrm{R}=\mathrm{H}, \mathrm{R}_{1}=\mathrm{H}$
a) DSC, DMAP, DMF; b)
, DMAP, Et ${ }_{3} \mathrm{~N}$, THF; c) Grubbs catalyst I, $\mathrm{CH}_{2} \mathrm{Cl}_{2}$.<smiles>C=CCOC[C@H](OC)[C@@H](OC)[C@H](OC)[C@H](CN)OC</smiles>

\section{Схема 39.}
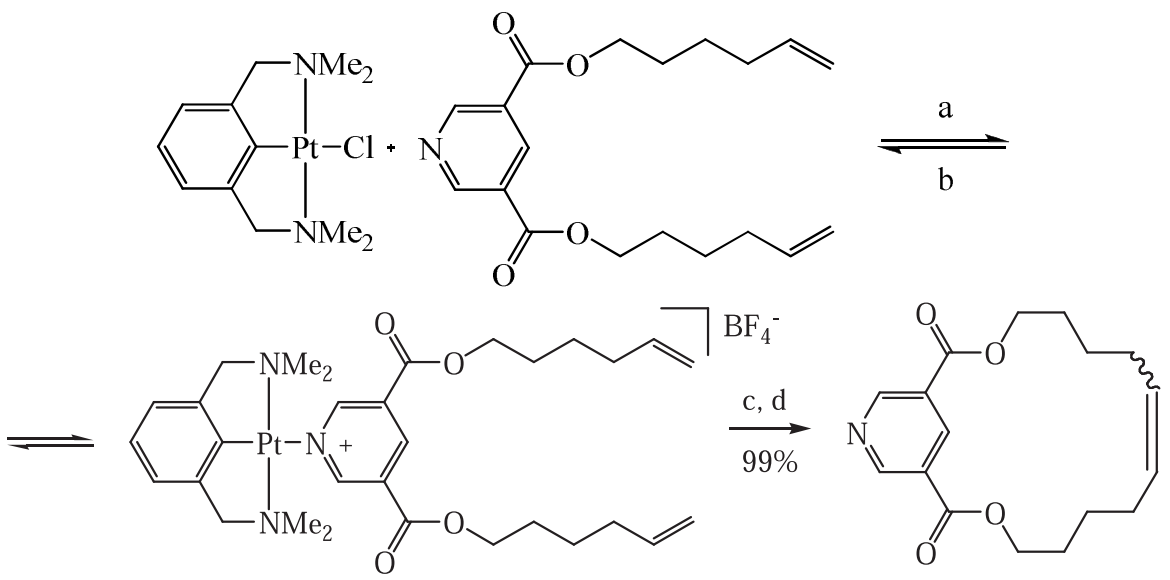

152

a) $\mathrm{AgBF}_{4}, \mathrm{CH}_{2} \mathrm{Cl}_{2}$; b) $\mathrm{NaCl}, \mathrm{H}_{2} \mathrm{O}, \mathrm{CH}_{2} \mathrm{Cl}_{2}$; c) Grubbs catalyst I, $\left.\mathrm{CH}_{2} \mathrm{Cl}_{2}, \mathrm{~d}\right) \mathrm{NaCl}, \mathrm{H}_{2} \mathrm{O}$.

\section{Схема 40.}

металлоорганический катализатор, в этом процессе тестировался пинцерный комплекс платины. Полученный в присутствии $\mathrm{AgBF}_{4}$ катионный комплекс (152) легко вступает в реакцию на катализаторе Граббса I поколения (Схема 40). ${ }^{[70]}$

Реакция метатезиса на катализаторе Граббса II поколения, протекающая с образованием строго (Z)-олефина, успешно применена в синтезе депсипептида криптофицина с противораковой, ${ }^{[71]}$ a также в конвергентном стереоселективном синтезе циклодепсипептида (-)-спонгидепсина (154), облада- ющего цитотоксическим и антираковым действием (Схема 41). ${ }^{[72]}$

Метатезис диенов может проходить не только в присутствии катализаторов Граббса и Шрока. Так, азотсодержащие макроциклические бис-лактоны (157 А-C) были получены с хорошими выходами восстановительной внутримолекулярной конденсацией бис-иминоэфиров (156) с помощью цинкового порошка, доступных, в свою очередь, по реакции этерификации защищенного $(S)$-валина (155) различными диолами в присутствии DCC (22) (Схема 42). ${ }^{[73]}$ 


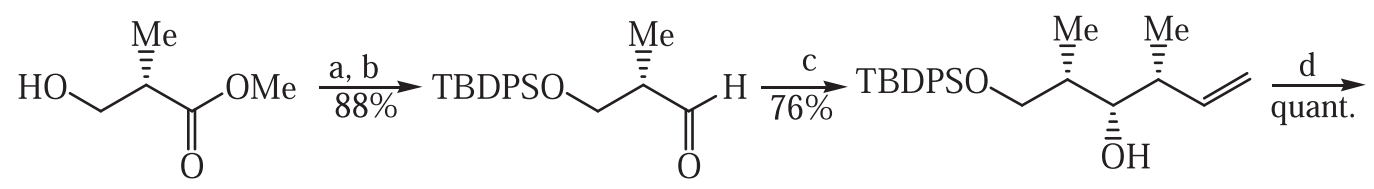

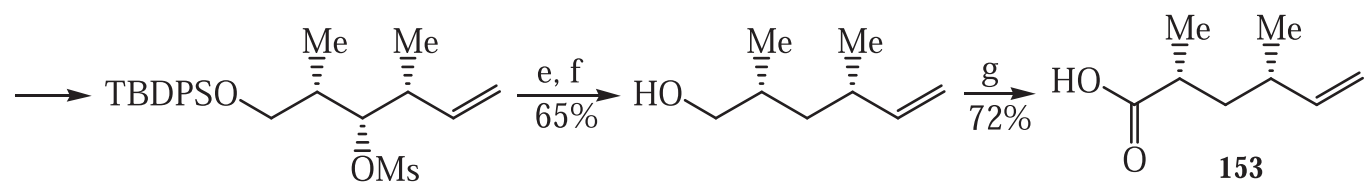

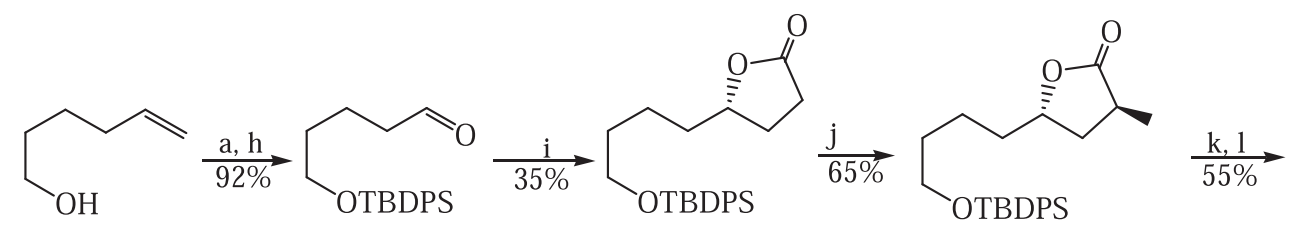

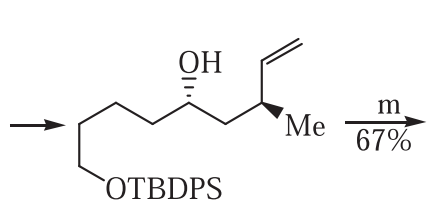<smiles>C=C[C@H](C)C[C@H](CCCCO[18O])OC(=O)[C@H](Cc1ccccc1)N(C)C(=O)c1ccccc1</smiles>

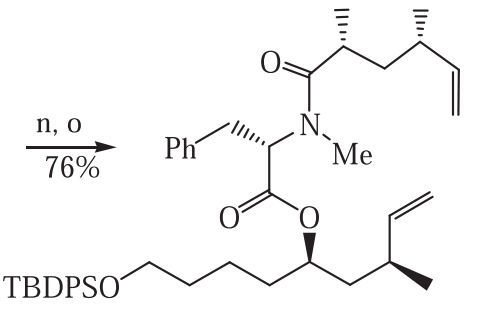

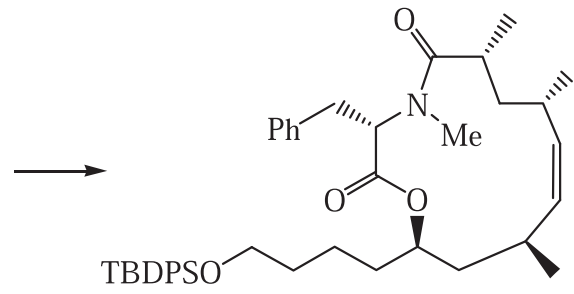<smiles>C#CCCC[C@H](C[C@@H](C)CC[C@@H](C)C[C@@H](C)C(=O)N(C)[C@H](Cc1ccccc1)C(C)(C)C)OC(=O)C(C)C</smiles>

a) TBDPSCl, imidazole, DMF; b) DIBAH, hexane, $-78^{\circ} \mathrm{C}$; c) $\mathrm{Bu}_{3} \mathrm{Sn}$

$, \mathrm{BF}_{3} \cdot \mathrm{OEt}_{2}, \mathrm{CH}_{2} \mathrm{Cl}_{2},-78^{\circ} \mathrm{C}$

d) $\mathrm{MsCl}$, Py; e) $\mathrm{LiAlH}_{4}, \mathrm{Et}_{2} \mathrm{O}$; f) TBAF, THF; g) $\mathrm{H}_{2} \mathrm{CrO}_{4}$, acetone; h) $\mathrm{O}_{3}, \mathrm{Et}_{3} \mathrm{~N}, \mathrm{CH}_{2} \mathrm{Cl}_{2},-78^{\circ} \mathrm{C}$;

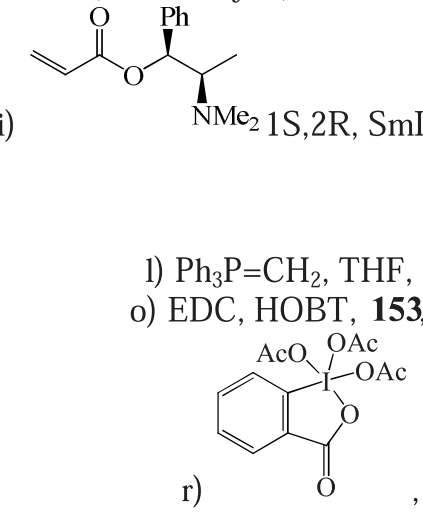

, $\left.\mathrm{CH}_{2} \mathrm{Cl}_{2}, 0^{\circ} \mathrm{C} ; \mathrm{s}\right) \mathrm{MeOH}, \mathrm{K}_{2} \mathrm{CO}_{3}, 35^{\circ} \mathrm{C},(\mathrm{MeO}){ }_{2} \mathrm{POC}\left(\mathrm{N}_{2}\right) \mathrm{COMe}$.

Схема 41.

Высокая стереоселективность реакции, обусловленная присутствием объемной изопропильной группы, объясняется дипротонированием промежуточного соединения (158) по механизму (Схема 43).

\section{2. Метатезис енинов}

Катализаторы Граббса показывают превосходную эффективность при метатезисе енинов. ${ }^{[74]}$ Однако макроциклизация соединений, содержащих терминальные 
Macrolides with Nitrogen-Containing Fragments
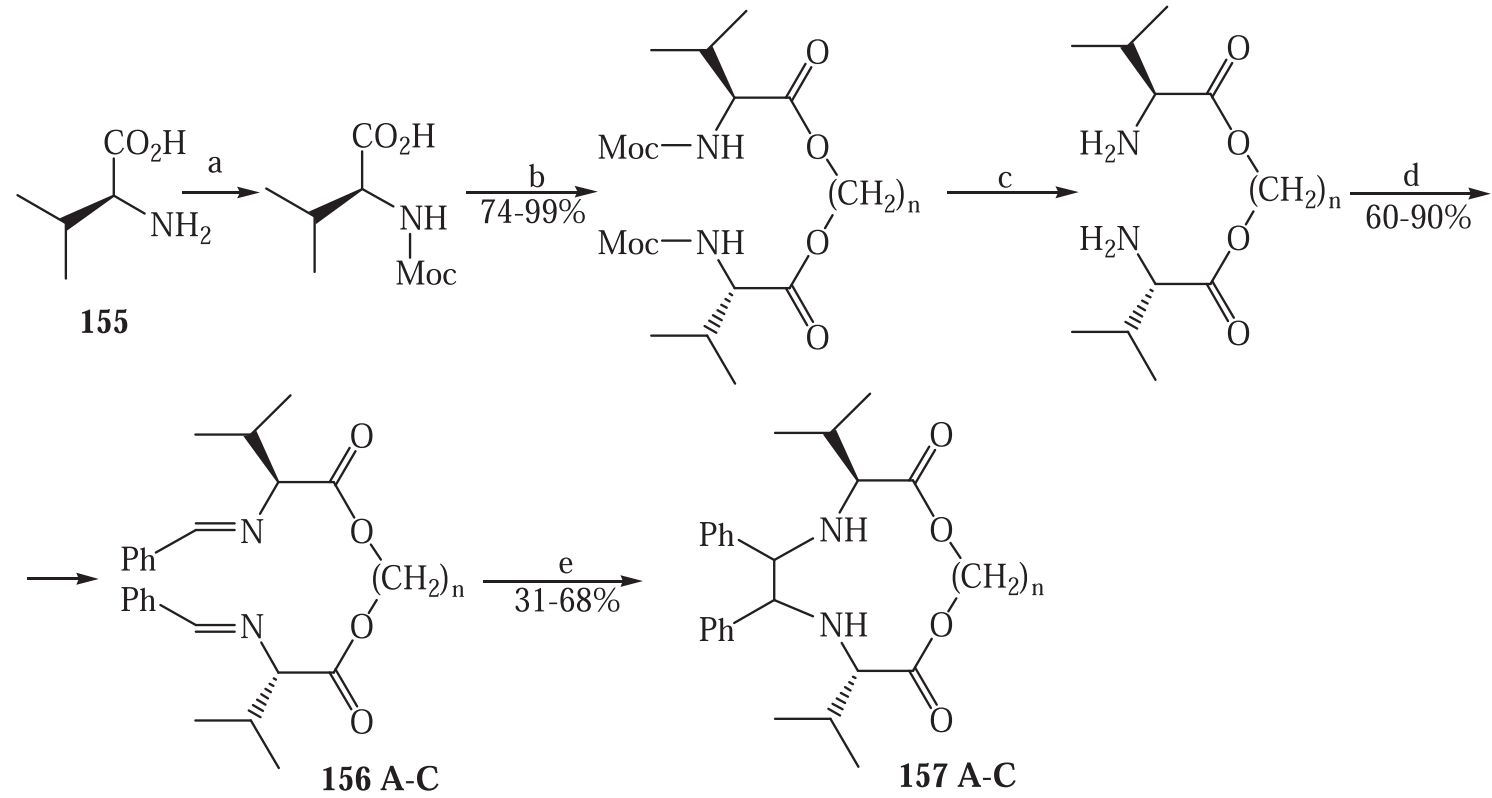

a) $\mathrm{ClCO}_{2} \mathrm{Me}$; b) diol, $\mathrm{DCC}$; c) $\mathrm{HBr}, \mathrm{AcOH}$; d) $2 \mathrm{PhCHO}$; e) $\mathrm{Zn}$; $\mathrm{MsOH}, 0^{\circ} \mathrm{C}$.

\begin{tabular}{|c|c|c|c|c|c|}
\hline 156 & $\mathrm{n}$ & Растворитель & 157 & Выход(\%) & $(R, R):(R, S):(S, S)$ \\
\hline \multirow[t]{2}{*}{ 156a } & 2 & THF & $157 a$ & 53 & $72: 22: 0$ \\
\hline & & DMF & & 52 & $43: 57: 0$ \\
\hline \multirow[t]{2}{*}{$156 b$} & 3 & THF & $157 b$ & 68 & 91:9:0 \\
\hline & & DMF & & 44 & $43: 57: 0$ \\
\hline \multirow[t]{2}{*}{$156 \mathrm{c}$} & 4 & THF & $157 \mathrm{c}$ & 47 & 70:30:0 \\
\hline & & DMF & & 47 & $25: 75: 0$ \\
\hline
\end{tabular}

\section{Схема 42.}

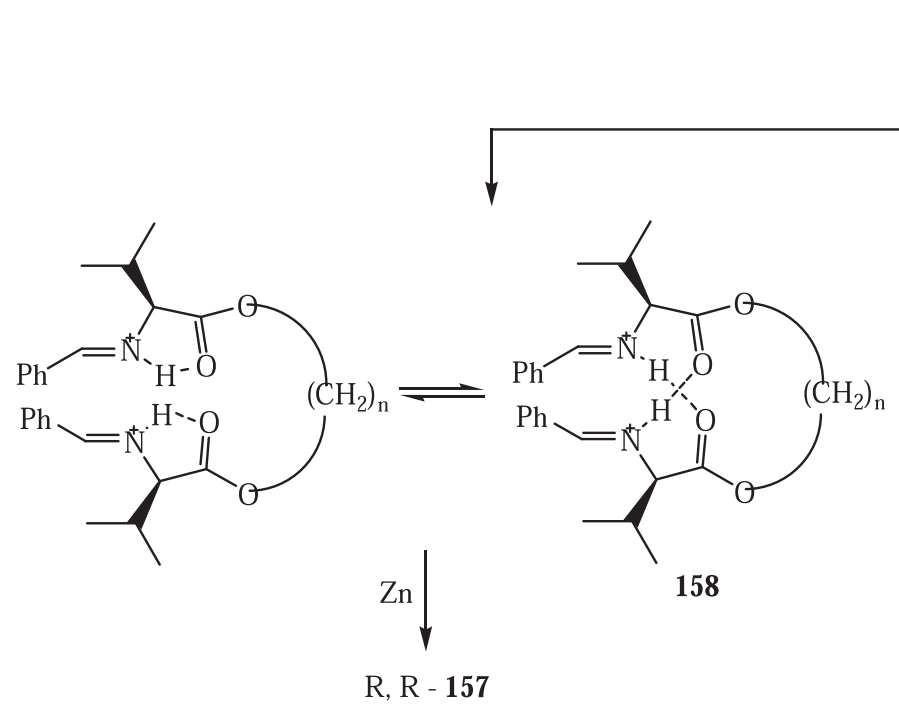

Схема 43.

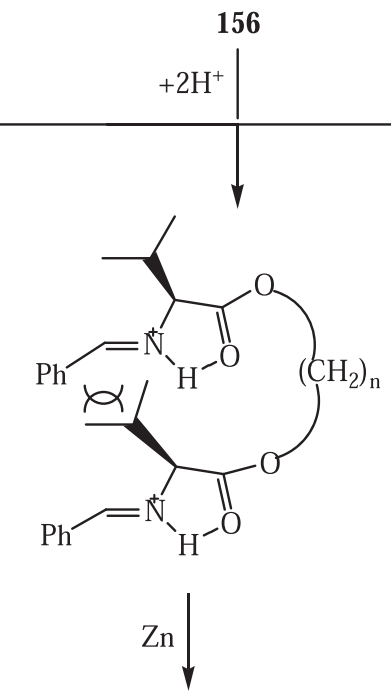

R, S - 157

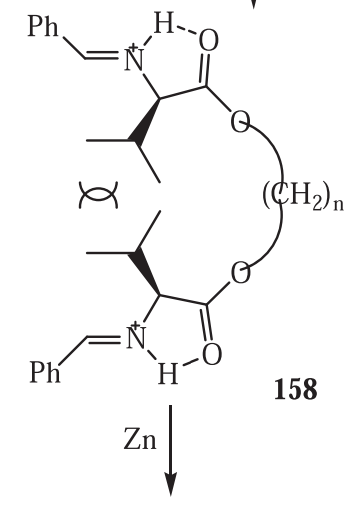

S,S - 157<smiles>[Y]CC(=C)CC([R])C[Y]#CC</smiles><smiles>[R]C(=C)C[X]([14CH3])CC(=C)C=[R]</smiles><smiles>[X]CC(=C)C=C([R])CC</smiles>

Схема 44.<smiles>[X]CC(=C)CC([R])C=C</smiles> 


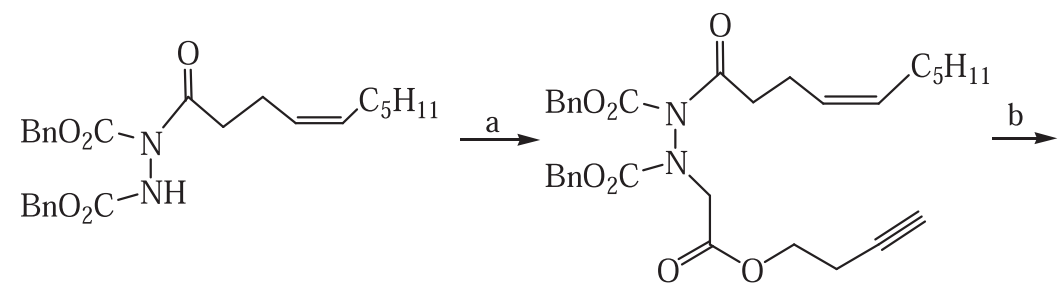

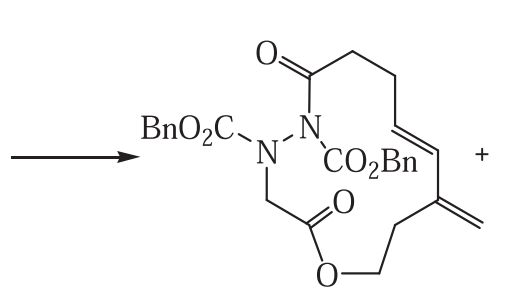

$159(60 \%)$<smiles>[R]C=CCCC(=O)N(CC(=O)OCCC(=C)C=C)N(C(=O)O)C(=O)Br</smiles>

$160 \mathrm{~A}, \mathrm{~B}$

$159: 160 \mathrm{~A}: 160 \mathrm{~B}=2: 1: 1$

A: $\mathrm{R}=\mathrm{C}_{5} \mathrm{H}_{11}$;

$\mathrm{B}: \mathrm{R}=\mathrm{H}$.

a)

$\mathrm{Br}$

)<smiles>C#CCCOC(=O)CBr</smiles>

, $\mathrm{Cs}_{2} \mathrm{CO}_{3}, \mathrm{DMF}$; b) Grubbs catalyst II, $\mathrm{CH}_{2} \mathrm{Cl}_{2}$.

\section{Схема 45.}
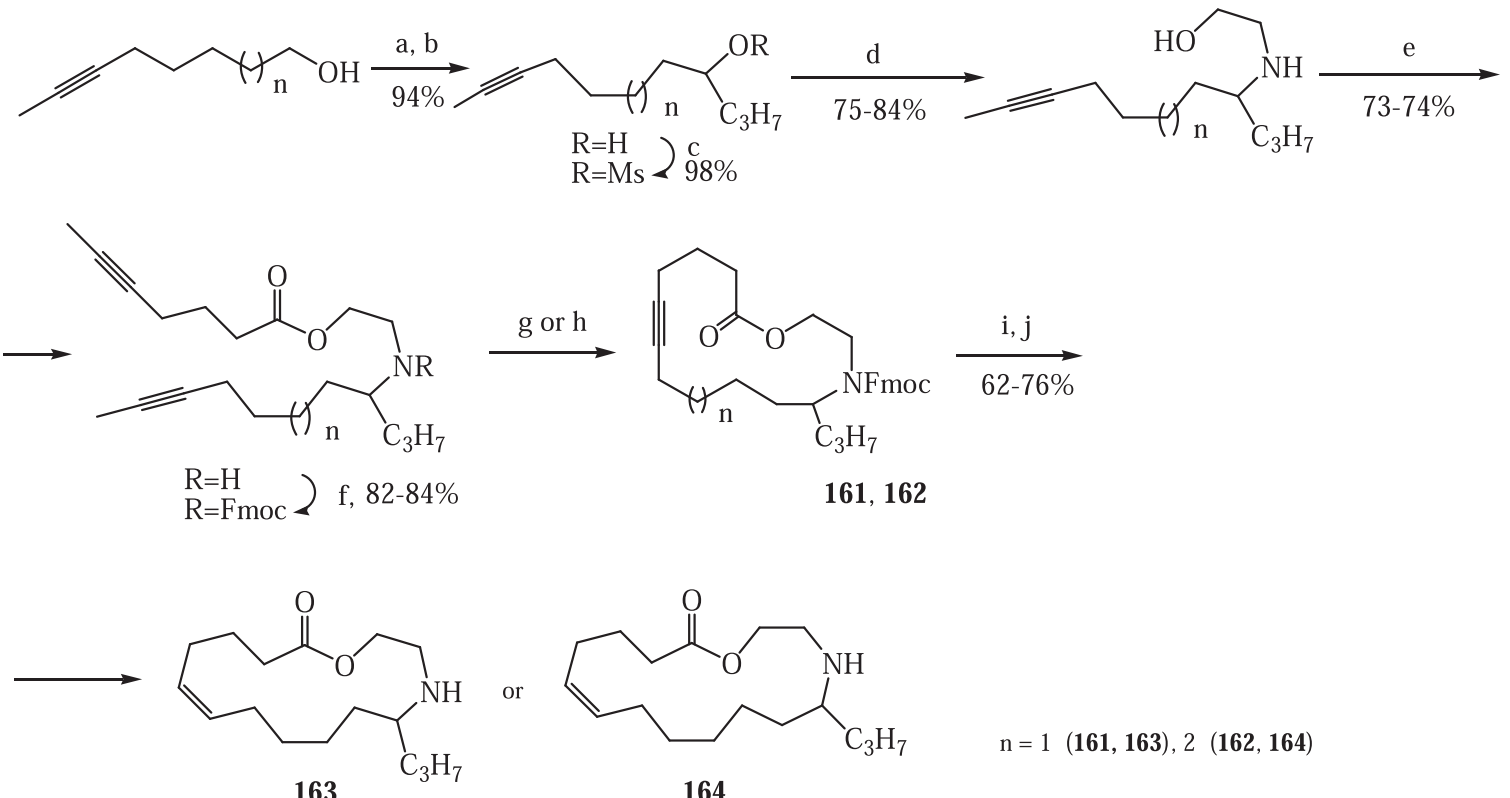

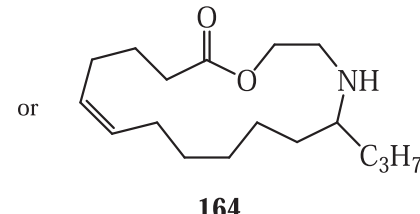
$\mathrm{n}=1 \quad(161,163), 2 \quad(162,164)$

a) $\mathrm{PDC}$; b) n-PrMgBr; c) $\mathrm{MsCl}, \mathrm{Et}_{3} \mathrm{~N}$; d) $\mathrm{H}_{2} \mathrm{NCH}_{2} \mathrm{CH}_{2} \mathrm{OH}$; e) 5-heptynoic acid, $\mathrm{TsOH}$; f) FmocCl, $\mathrm{NaHCO}_{3}$; g) W-cat (5\%); h) Mo-cat (5\%), p- $\mathrm{ClC}_{6} \mathrm{H}_{4} \mathrm{OH}$; i) $\mathrm{H}_{2}$, Lindlar; j) TBAF.

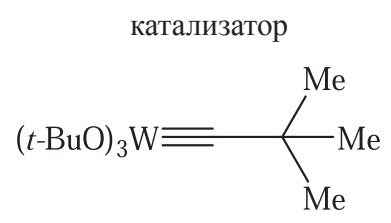

$\left[\mathrm{Mo}(\mathrm{CO})_{6}\right]$

$$
\text { Выход (163) }
$$

$71 \%$

$67 \%$
Выход (164)

$69 \%$

$64 \%$

\section{Схема 46.}


двойную и тройную связи, обычно сопровождается образованием побочного продукта (Схема 44).

Предложенный механизм данной реакции объясняет присутствие в реакционной смеси ациклических продуктов (160 A,B) при образовании макрогетероцикла (159) с эндо-двойной связью исключительно $(E)$ конфигурации (Схема 45). ${ }^{[75,76]}$

\section{3. Метатезис алкинов}

Также возможно вовлечение в реакцию метатезиса алкинов на вольфравомовом и молибденовом катализаторах: ${ }^{[77]}$<smiles>CC(=O)OCC(C)(C)C#N</smiles>

Это использовано в синтезе азамакролидов (163, 164), выделенных из мексиканского жука Epilachnar varivestis и являющихся первыми примерами макролактонов, содержащих азот в кольце (Схема 46).

\section{4. Другие методы получения макролициклов}

Известны и некоторые другие способы получения макроциклов.

Один из них, например, это введение азотсодержащего фрагмента в уже готовую молекулу макроциклического антибиотика лейкомицина (159) с помощью различных иминонитрозо-производных по реакции Дильса-Альдера (Схема 47). ${ }^{[78]}$

Другим методом циклизации является катализируемая сульфоксидным комплексом палладия (166) циклизация терминальных алкеновых кислот. Реакция заключается в активации двойной связи комплексным палладиевым катализатором, приводящей к разрыву С-Н и формированию С-О связей (Схема 48). ${ }^{[79]}$

Этим методом был получен макроциклический депсипептид (167) $(61 \%),{ }^{[36]}$ обладающий мощным цитотоксическим, антибактериальным и противовоспалительным действием (Схема 49). ${ }^{[80]}$

Еще одним примером эффективного получения макроциклов является замыкание кольца 14-членного макролида (169) с помощью протекающей по механизму внутримолекулярной $\mathrm{S}_{\mathrm{N}} 2$ реакции между нуклеофильным малонат-анионом и хлораллильным фрагментом ациклического предшественника (168) (Схема 50). ${ }^{[81]}$

Также используется катализируемая солями титана реакция альдольной конденсации, вероятно, протекающая по Схеме 51:

С использованием этой реакции синтезирован иммунодепрессант рапамицин (172) через ключевую стадию альдольной макроциклизации предшественника (170) под действием $\mathrm{TiCl}_{3}\left(\mathrm{O}^{i} \mathrm{Pr}\right)$ и последующим десилилированием промежуточного соединения (171) (Схема 52). ${ }^{[82]}$

Метод получения макроциклов, основанный на внутримолекулярном олефинировании альдегида

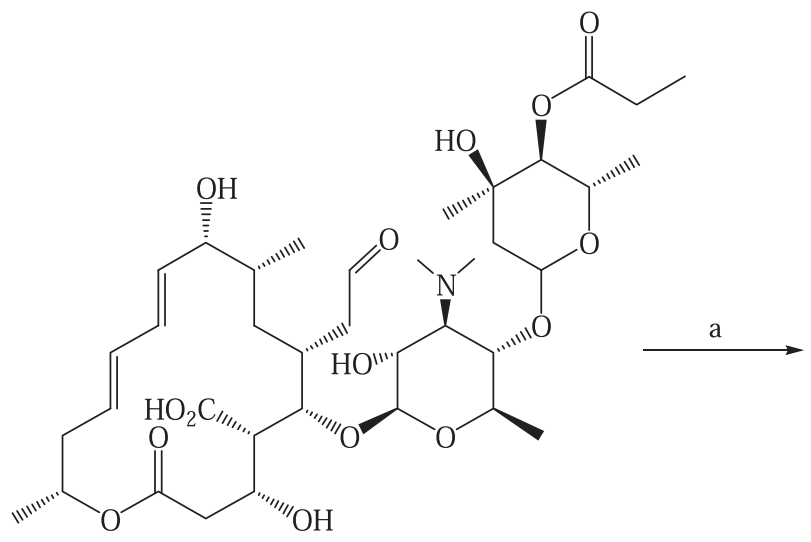

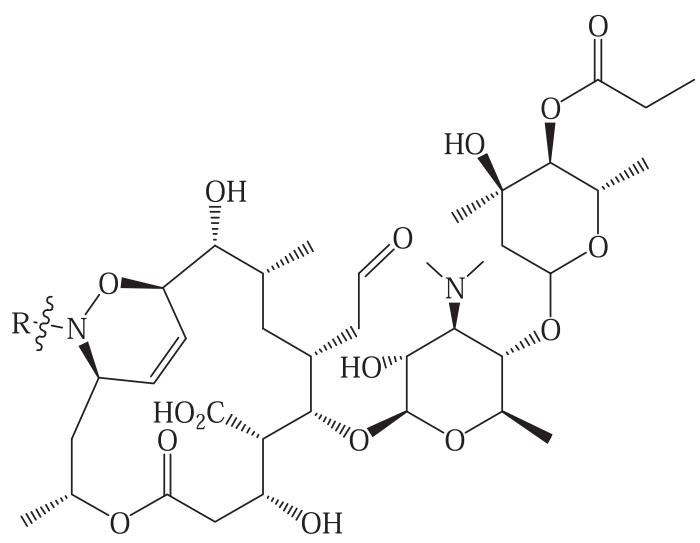

165<smiles></smiles><smiles>Cc1cc(C)on1</smiles><smiles>[R]N=O</smiles>

Схема 47. 


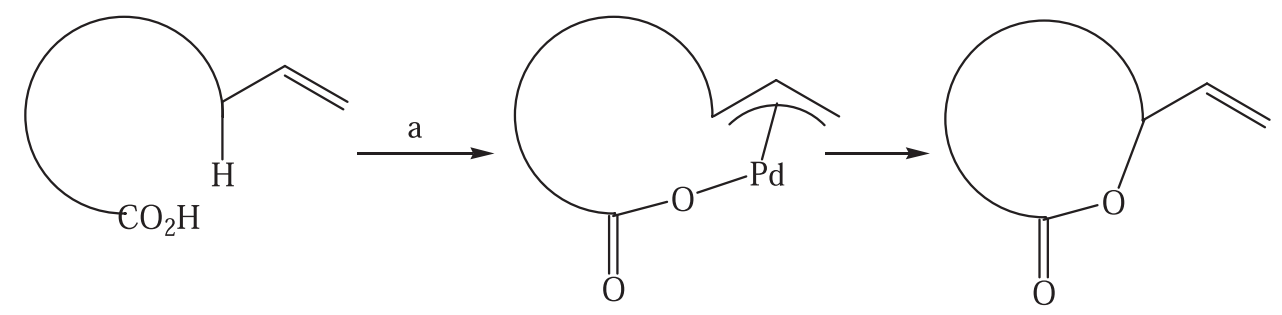

a)<smiles>O=[R10](O)c1ccccc1S(=O)(=O)c1ccccc1</smiles>

166

\section{Схема 48.}

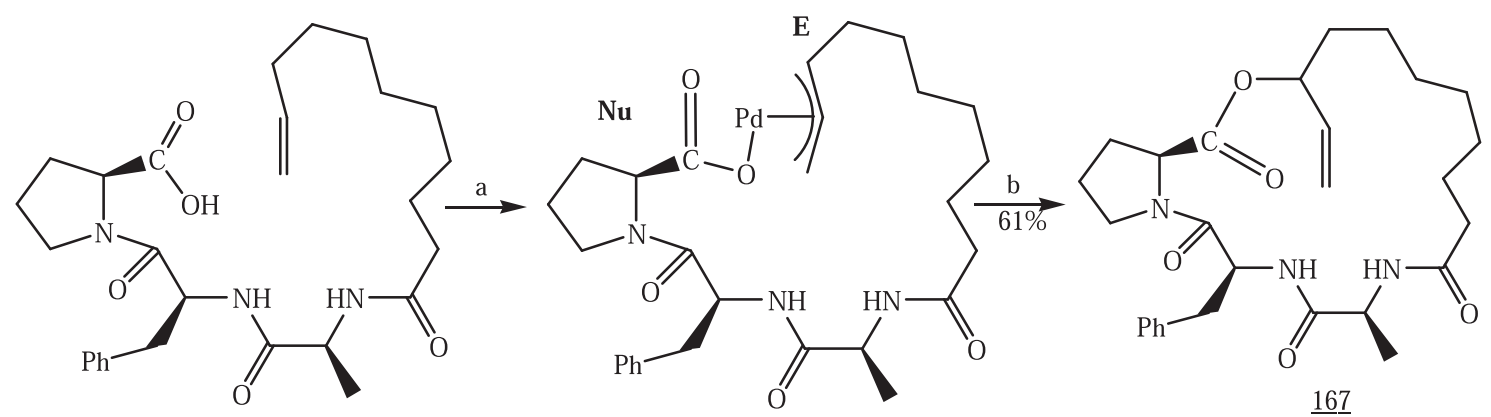

a) $166, \mathrm{CDCl}_{3}, 45^{\circ} \mathrm{C}$; b) $\mathrm{BQ}, 45^{\circ} \mathrm{C}$.

Схема 49.

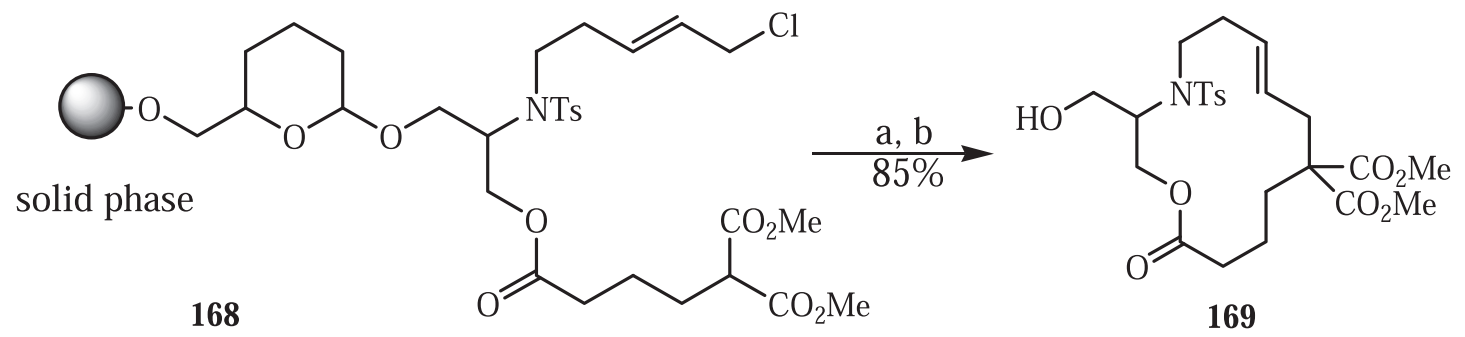

a) $\mathrm{CsCO}_{3}, \mathrm{MeCN}, 70^{\circ} \mathrm{C}$; b) $\mathrm{CF}_{3} \mathrm{CO}_{2} \mathrm{H}, \mathrm{CH}_{2} \mathrm{Cl}_{2}$.

Схема 50.

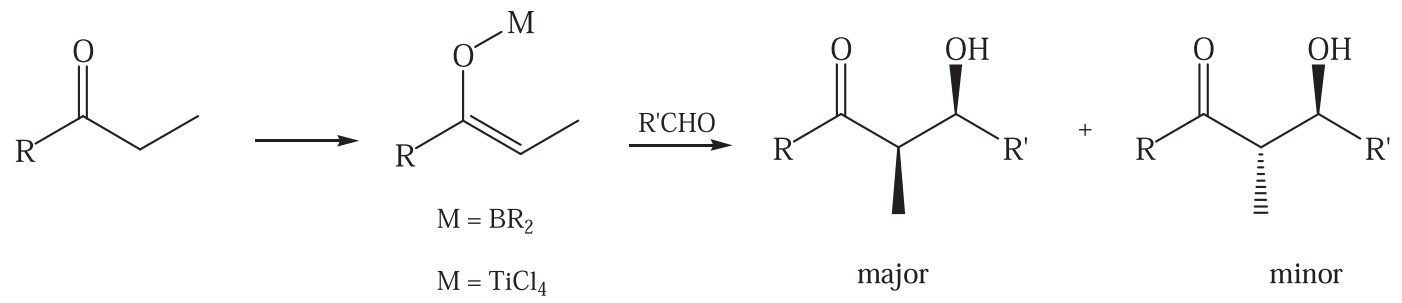

Схема 51. 
<smiles>CC(C)OC(=O)[C@H]1CCCCN1C(=O)CS(=O)c1ccccc1</smiles>

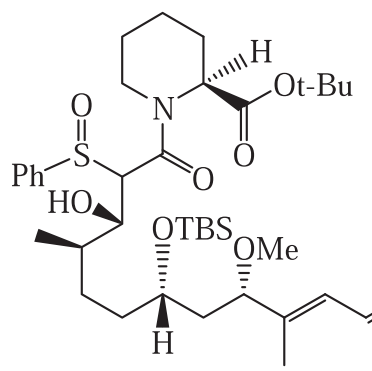

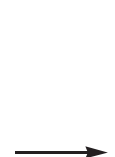<smiles>[R]OC(=O)[C@@H]1CCCCN1CCOC</smiles><smiles>C=C/C=C/[C@H](C)C[C@H](C)C(=O)COC</smiles>

$$
\begin{aligned}
& \mathrm{R}=\mathrm{t}-\mathrm{Bu} \\
& \mathrm{R}=\mathrm{Allyl}
\end{aligned} \prec \begin{array}{r}
\mathrm{d}, \mathrm{e} \\
66 \%
\end{array}
$$

$\mathrm{R}=\mathrm{Si}(\operatorname{Pr}-\mathrm{i})_{3}$

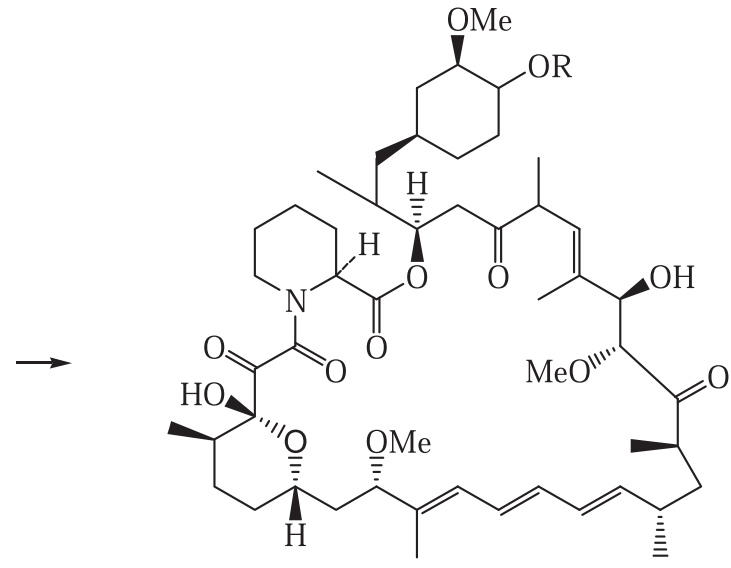

$\mathrm{R}=\mathrm{Si}(\mathrm{Pr}-\mathrm{i})_{3} 171 \mathrm{~A}$ $\mathrm{R}=\mathrm{H}$ 172A 2

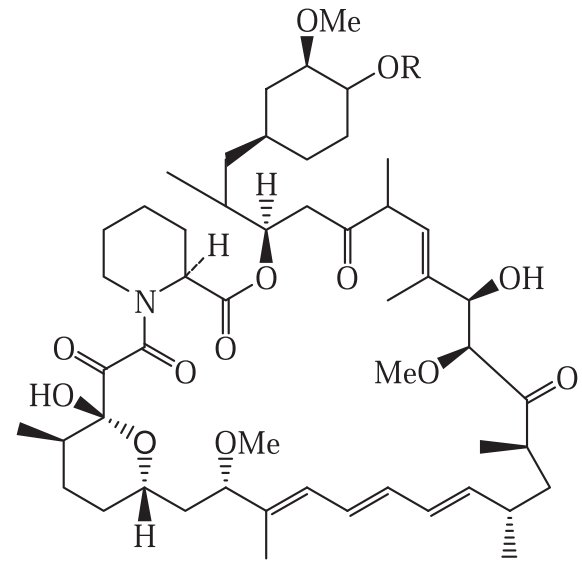

$\mathrm{R}=\mathrm{Si}(\mathrm{Pr}-\mathrm{i})_{3} 171 \mathrm{~B}$ $\mathrm{R}=\mathrm{H}$ 172B

a)

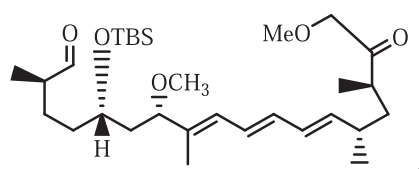<smiles>CC(=O)O[Te]1(OC(C)=O)(OC(C)=O)OC(=O)c2ccccc21</smiles>

d) $\mathrm{HCO}_{2} \mathrm{H}, \mathrm{CH}_{2} \mathrm{Cl}_{2}$; e) $\mathrm{CH}_{2}=\mathrm{CHCH}_{2} \mathrm{Br}, \mathrm{K}_{2} \mathrm{CO}_{3}$, TBAI, DMF; f) TMS-imidazole, DMAP, DMF;

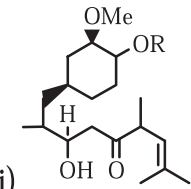

g) $\mathrm{Pd}\left(\mathrm{PPh}_{3}\right)_{4}, \mathrm{PPh}_{3}, \mathrm{CH}_{2} \mathrm{Cl}_{2}$; h) DCC, DMAP, $\mathrm{CH}_{2} \mathrm{Cl}_{2},-20^{\circ} \mathrm{C}$; i) OH O N, TBAF, HOAc, THF, $50^{\circ} \mathrm{C}$; j) $\mathrm{TiCl}_{3}(\mathrm{OPr}-\mathrm{i}), \mathrm{CH}_{2} \mathrm{Cl}_{2},-78^{\circ} \mathrm{C}$; k) $\mathrm{Et}_{3} \mathrm{~N}$; 1) $\mathrm{HF} \bullet \mathrm{Py}, \mathrm{THF}$. 


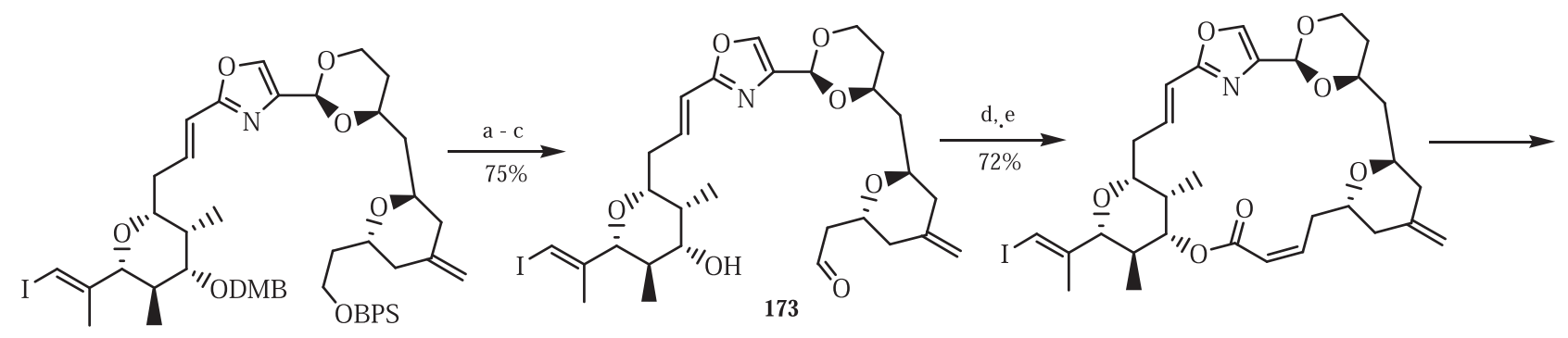

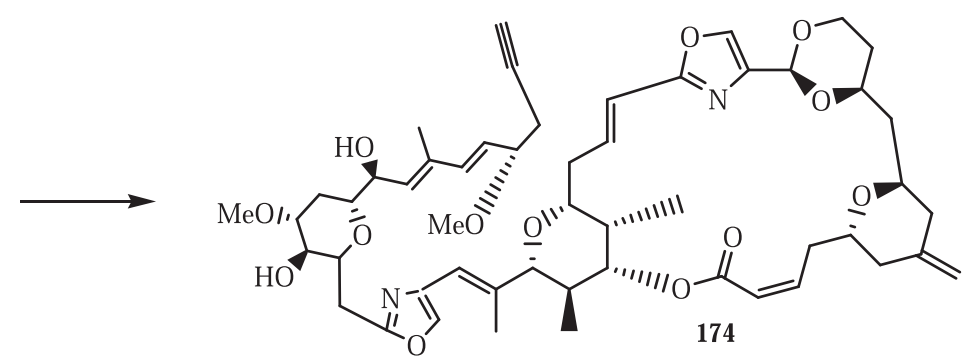

a) TBAF; b) Dess-Martin periodinate; c) DDQ; d) $\mathrm{HO}^{\mathrm{P}}\left(\mathrm{OCH}_{2} \mathrm{CF}_{3}\right)_{2}$ (175), EDC . MeI, HOBT; e) $\mathrm{K}_{2} \mathrm{CO}_{3}, 18$-Crown-6.

Схема 53.<smiles>CC(C)N[C+]1CCCCC(=O)C1</smiles>

177 A-C

176 A-C

A: $n=1$

B: $n=2$;

C: $n=3$.
A: $m=1$;

B: $m=2$;

$\mathrm{C}: \mathrm{m}=3$.<smiles>O=C1CCCCCCC1NCCO</smiles>

178 A-I

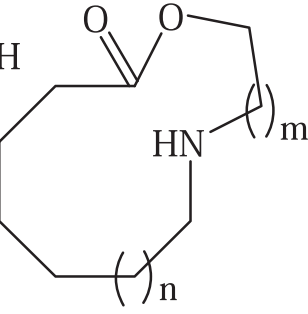

179 A-I

A: $n=1, m=1 ; B: n=1, m=2 ; C: n=1, m=3$;

$D: n=2 ; m=1 ; E: n=2, m=2 ; F: n=2, m=3$;

G: $n=3, m=1 ; H: n=3, m=2 ; I: n=3 . m=3$.

Схема 54.

(173) енолятом кислоты (175) по Хорнеру-Эммонсу в модификации Стилле и приводящий к смеси $(2: 1)$ $Z / E$-изомеров, применен в синтезе цитотоксического макролида форбоксазола (174) и его структурных аналогов (Схема 53). ${ }^{[83,84]}$

Еще один метод синтеза азотсодержащих лактонов - взаимодействие кетонов (176 А-C) и азидов (177 A-C), приводящее к образованию лактамов (178 A-I) и лактонов (179 A-I), соотношение которых зависит от кислотности среды на стадии гидролиза промежуточных иминиевых эфиров. При проведении реакции в сильнощелочной среде (в присутствии КОН) образуются преимущественно лактамы (178 A-I), выход которых достигает 99\%. В слабощелочной среде (в присутствии $\mathrm{NaHCO}_{3}$ ) увеличивается (до 79\%) выход лактонов, а лактамов, соответственно, уменьшается (Схема 54).
Авторами ${ }^{[85]}$ приводятся механизмы для объяснения формирования лактамов и лактонов в зависимости от кислотности среды.

Гидролиз иминоэфира А с помощью КОН протекает по двум направлениям. Первое заключается в том, что гидрокси-группа атакует углерод (*), непосредственно образуя лактам. Второе - гидроксид-ион атакует углерод иминогруппы, образуя промежуточный продукт $\mathbf{B}$, который депротонируется и впоследствии разрушается с образованием лактама (Схема 55).

При гидролизе в присутствии $\mathrm{NaHCO}_{3} \quad(\mathrm{pH}=9)$ реализуется другой механизм: образование из аминоэфира A продукта $\mathbf{B H}^{+}$, протонирование азота и разрыв связи C-N с образованием аминолактона (179) (Схема 56).

Ключевой стадией синтеза макроциклических диазоновых природных холанового ряда (180 A-B, 181 
Macrolides with Nitrogen-Containing Fragments

$\mathrm{pH} \sim 14$

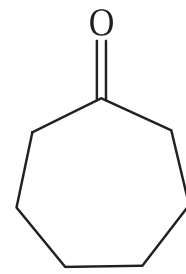

176

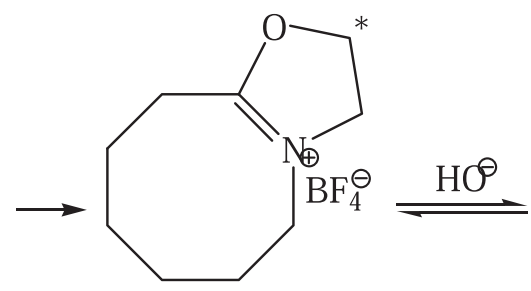

A

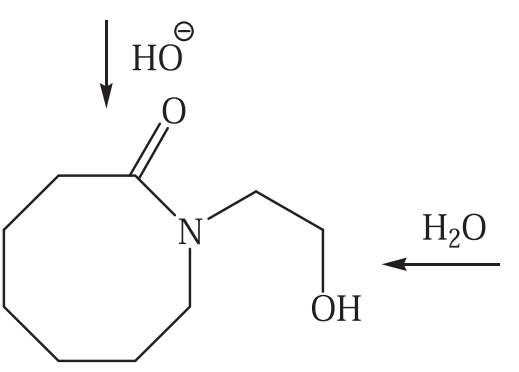

178

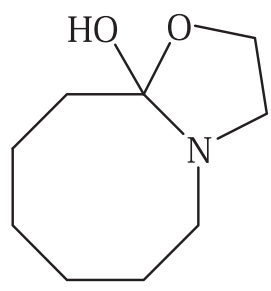
$\mathrm{HO}^{\odot}$

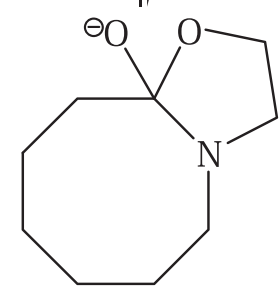

Схема 55.

$\mathrm{pH} \sim 9$

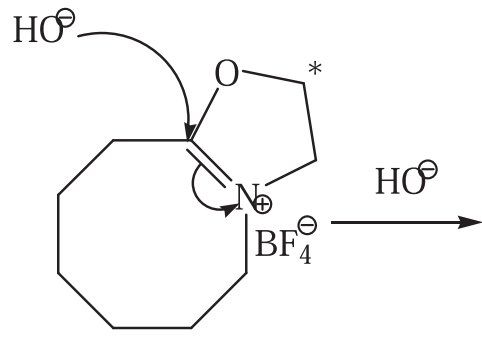

A

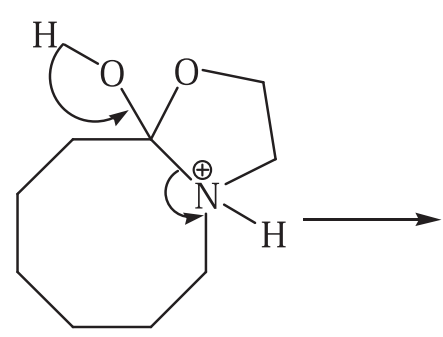

$\mathrm{BH}^{+}$

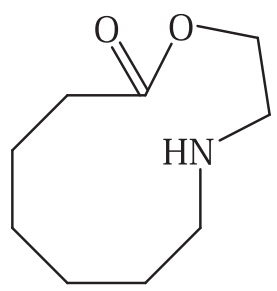

179

\section{Схема 56.}
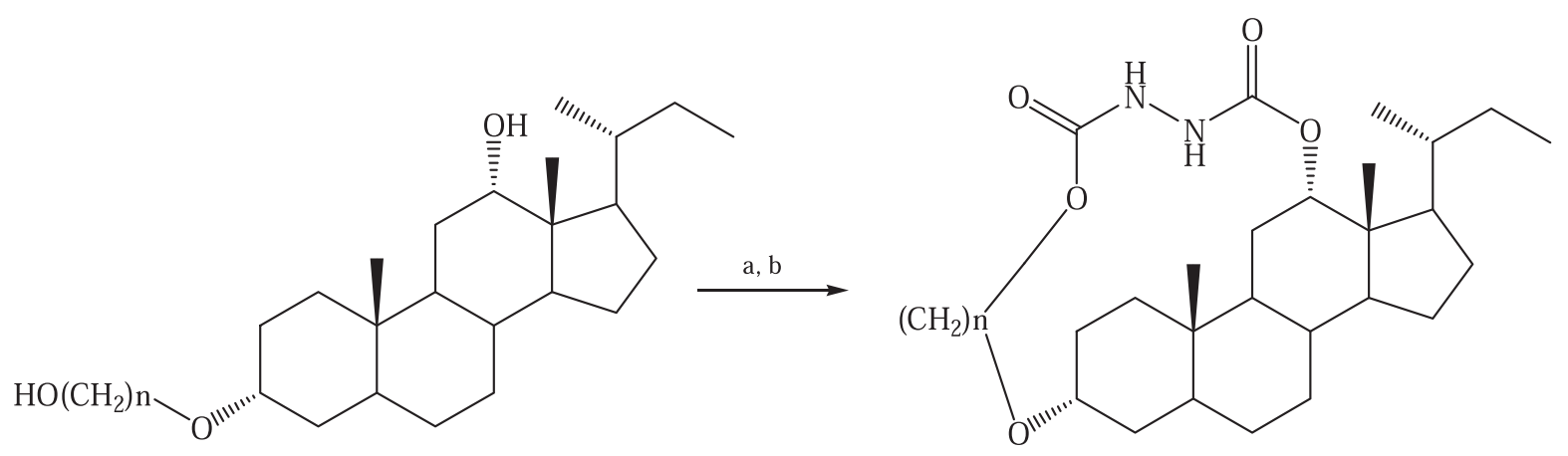

$180 \mathrm{~A}, \mathrm{~B}$
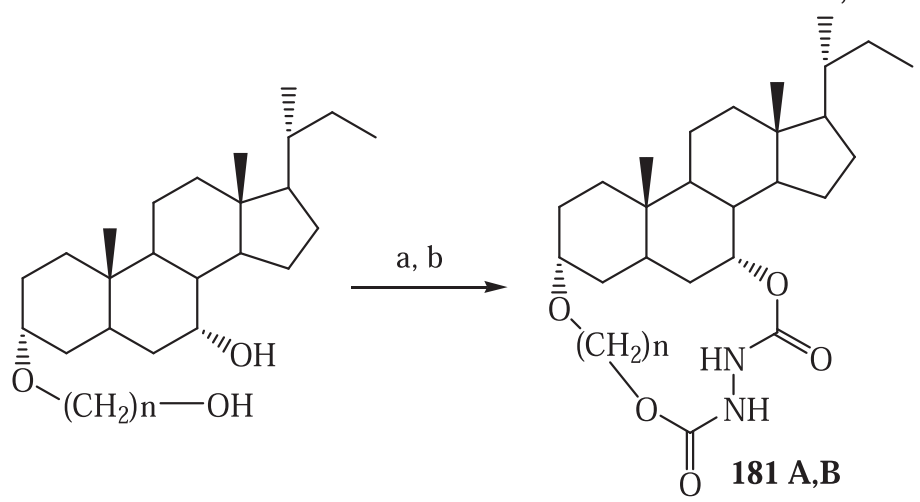

$\mathbf{A}: \mathrm{n}=2 ; \mathbf{B}: \mathrm{n}=3$.

a) $\mathrm{COCl}_{2}, \mathrm{Et}_{3} \mathrm{~N}$; b) $\mathrm{N}_{2} \mathrm{H}_{4} \cdot \mathrm{H}_{2} \mathrm{O},-98^{\circ} \mathrm{C}$.

Схема 57. 


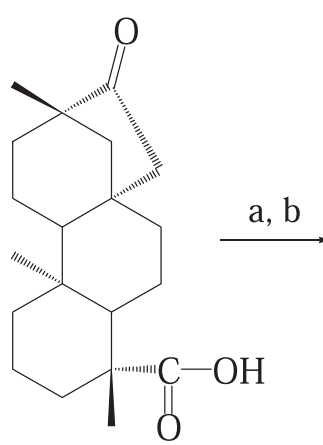

182

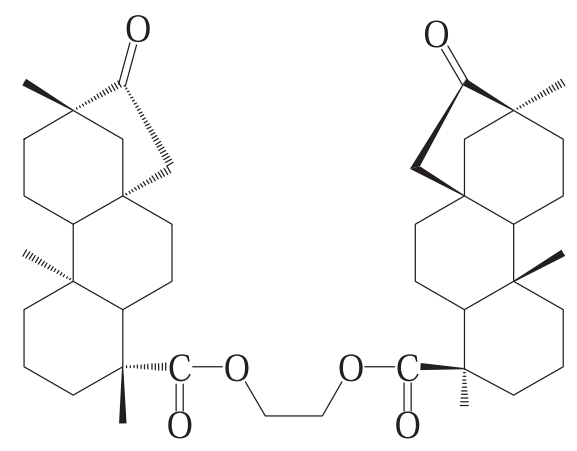

183
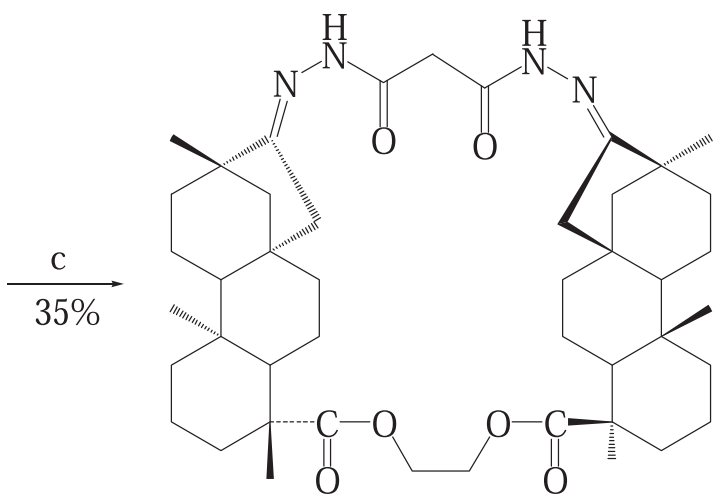

185<smiles>CCOCCNNC(=O)CC(=O)NN</smiles>

Схема 58.

C-D) является взаимодействие бисхлорформиатов с гидразингидратом (Схема 57). ${ }^{[86]}$

Эффективный подход к синтезу макроцикла (185) заключался в объединении двух молекул изостевиола (182) (через его хлорангидрид) сложноэфирным спейсером в дикетодиэфир (183) и вовлечении кетонных групп последнего в реакцию с дигидразидом двухосновной кислоты (184) (Схема 58). ${ }^{[6,7]}$

Нами $^{[87]}$ предложены эффективные синтезы 15-, $17-, 20-, 22 \div 25$-членных макролидов с азинными или гидразидными фрагментами исходя из доступного синтетического [тетрагидропиран (186) и его 4-метилпроизводное (187)] и природного [l-ментол (198)] сырья. Все они базируются на первоначальном их превращении, ${ }^{[88,89]}$ в соответствующие кетоальдегиды: 7-оксооктаналь (188), 3-метил-7-оксооктаналь (189) и 3R,7-диметил-6-оксооктаналь (199), которые затем в условиях реакции диспропорционирования по Тищенко переведены соответственно в дикетоэфиры (190), (191) и (200). [1+1]-Конденсация последних в диоксане в условиях высокого разбавления при комнатной температуре с гидразингидратом или дигидразидами малоновой, янтарной, глутаровой и адипиновой кислот приводит с хорошими (40-54\%) выходами к макролидам с азинным $(192,201)$ или гидразидными $(193-197,202)$ фрагментами соответственно (Схема 59).

Кроме того, нами предложены ${ }^{[90]}$ эффективные пути превращения соединений $(\mathbf{1 8 6}, \mathbf{1 8 7}, \mathbf{1 9 8})$, а также доступных монотерпенов [ $\Delta^{3}$-карена $(\mathbf{2 2 3})$ и (+)- $\alpha$-пинена (231)] в макроциклические азинодиэфиры (209 - 211, $219,220,227,228,235,236)$ и диэфиродигидразиды (212 - 215, 221, 222, 229, 230, 237, 238).

Все они основаны на первоначальном их превращении в соответствующие гидроксикетоны: 8-гидроксиоктан-2-он (203) ${ }^{[91]}$ и его 6-метилпроизводное (204), ${ }^{[92]}(6 R)-8$-гидрокси-2,6-диметилоктан-3-он (216), ${ }^{[93]}$ 1 -((1R,3S)-3-(2-гидроксиэтил)-2,2-диметилциклопропил)пропан-2-он (224) ${ }^{[94]}$ и 1-[(1R,3R)-3-(2-гидроксиэтил)2,2-диметилциклобутил]этанон (232). ${ }^{[94]}$ Дальнейшая их [2+1]-конденсация с полными хлорангидридами глутаровой или адипиновой кислот приводит к биспроизводным (205-208, 217, 218, 225, 226, 233, 234), в которых два углеродных остова кетоспиртов (203, 204, 216, 224, 232) соединены диэфирными спейсерами. Циклизация ключевых дикетодиэфиров (205 - 208, 217, $\mathbf{2 1 8}, 225,226,233,234)$ в целевые азинодиэфиры (209-211, 219, 220, 227, 228, 235, 236) либо диэфиродигидразиды (212 - 215, 221, 222, 229, 230, 237, 238) выполнена [1+1]-конденсацией соответственно с гидразингидратом или дигидразидом глутаровой кислоты в диоксане при комнатной температуре в условиях высокого разбавления (Схема 60).

Таким образом, представленный обзор литературы свидетельствует о том, что синтезы азотсодержащих макролидов с использованием реакций макролактонизации, макроамидации и метатезиса являются хорошо разработанными. В последнее время развивается подход к синтезу макрогетероциклов с азотсодержащими (азинными и дигидразидными) фрагментами, основанный на [1+1]-конденсации $\alpha, \omega$-дикетонов с гидразингидратом и гидразидами двухосновных кислот.

\section{Список литературы}

\section{References}

1. Gromov S.P., Dmitrieva S.N., Churakova M.V. Uspekhi Khimii 2005, 74, 503-532 (in Russ.).

2. Davidova S.L. Udivitel'nye Makrotsikly [Surprising Macrocycles]. Leningrad: Khimiya, 1989. 72 p. (in Russ.).

3. Bogatskei A.V. Mezo- $i$ Makrogeterotsikly [Meso- and Macroheterocycles]. Kiev: Nayk. dymka, 1986. 204 p. (in Russ.).

4. Radyshev A.V., Chekanova L.G., Gusev V.U. Gidrazid $i$ 1,2-Diatsylgidrazin: Poluchenie, Svoistva i Primenenie $v$ Protsessakh Kontsentrirovania Metallov [Hydrazide and 1,2-Diacylhydrazine:Obtaining, Properties and Using in the Processes of Metal Concentrating]. Ekaterinburg: UrO RAN, 2010. 140 p. (in Russ.). 
<smiles>[R]C1CCOCC1</smiles>

186, 187<smiles>[R]C(CC=O)CCCCCCCC(C)=O</smiles>

188,189<smiles>[R]C(CC)CCOC(=O)CC([R])CCCC(C)=O</smiles>

190,191<smiles>CC1=N/N=C(/C)CCCCCCOC(=O)CCCCC1</smiles>

192
$\mathrm{R}=\mathrm{H}(186,188,190,193-196), \operatorname{Me}(187,189,191,197)$ $\mathrm{n}=1$ (193), 2 (194), 3 (195, 197), 4 (196). d \42-54\%<smiles>[R]C(CCCC(C)=NNC(C)=O)CCCC(C)=NNC(C)=O</smiles>

$193-197$<smiles>CC(C)[C@H]1CC[C@@H](C)C[C@H]1O</smiles>

198<smiles>CC(C)C(=O)CC[C@@H](C)CC=O</smiles>

199<smiles>[R]C(C)CCC(=O)C(C)C</smiles><smiles>[R]C(C)CCC(=O)C(C)C</smiles><smiles>CCC/C(=N/N=C(/CC[C@H](C)CC(=O)OCC[C@H](C)CC)C(C)C)C(C)C</smiles>

201

a) some stages; b) $\mathrm{Al}(\mathrm{O} \text { i-Pr })_{3}$, hexane; c) $\mathrm{N}_{2} \mathrm{O}_{4} \cdot \mathrm{H}_{2} \mathrm{O}, 1$,4-dioxane; d)<smiles>C/C(=N/NC(=O)CC(=O)N/N=C(/CC[C@H](C)CC(=O)OCC[C@H](C)CC/C(=C(\C)C(C)C)C(C)C)C(C)C)C(C)C</smiles>

202 $\mathrm{H}_{2} \mathrm{NHN}$

e) some stages; f) 
<smiles>[R]C(CCCO)CCCC(C)=O</smiles>

186, 187<smiles>[R]C(CCCCCC)CCOC(=O)NC(=O)OCCC([R])CCC(C)=O</smiles><smiles>[R]C(CCCc1nnc(CCCC([R])CC(=O)O)s1)CCOC(=O)OCCCC</smiles>

$\mathrm{R}=\mathrm{H}(\mathbf{1 8 6}, 203,205,206,209,210,212,213), \mathrm{Me}(187,204,207,208,211,214,215)$. $\mathrm{n}=3(\mathbf{2 0 5}, 207,209,212,214), 4(206,208,210,211,213,215)$.<smiles>[R]C(CCCO)CCCC(C)=O</smiles>
186, 187

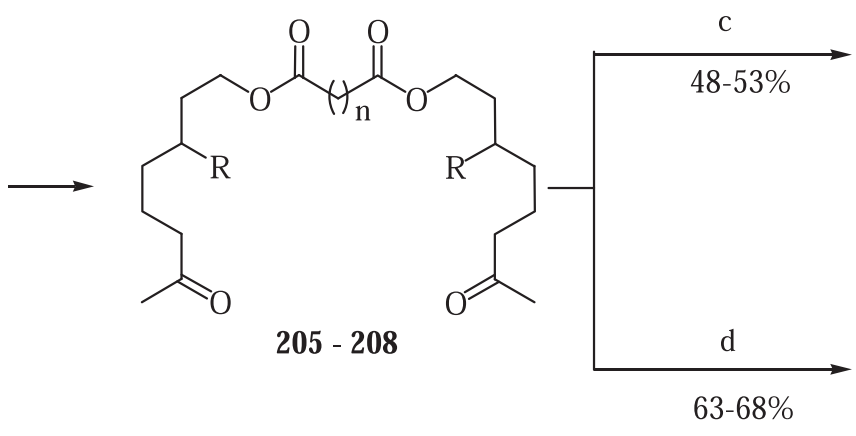<smiles>[R]C(CCCc1nnc(CCCC([R])CC(=O)O)s1)CCOC(=O)OCCCC</smiles>

$\mathrm{R}=\mathrm{H}(186,203,205,206,209,210,212,213), \mathrm{Me}(187,204,207,208,211,214,215)$ $\mathrm{n}=3(205,207,209,212,214), 4(206,208,210,211,213,215)$. 


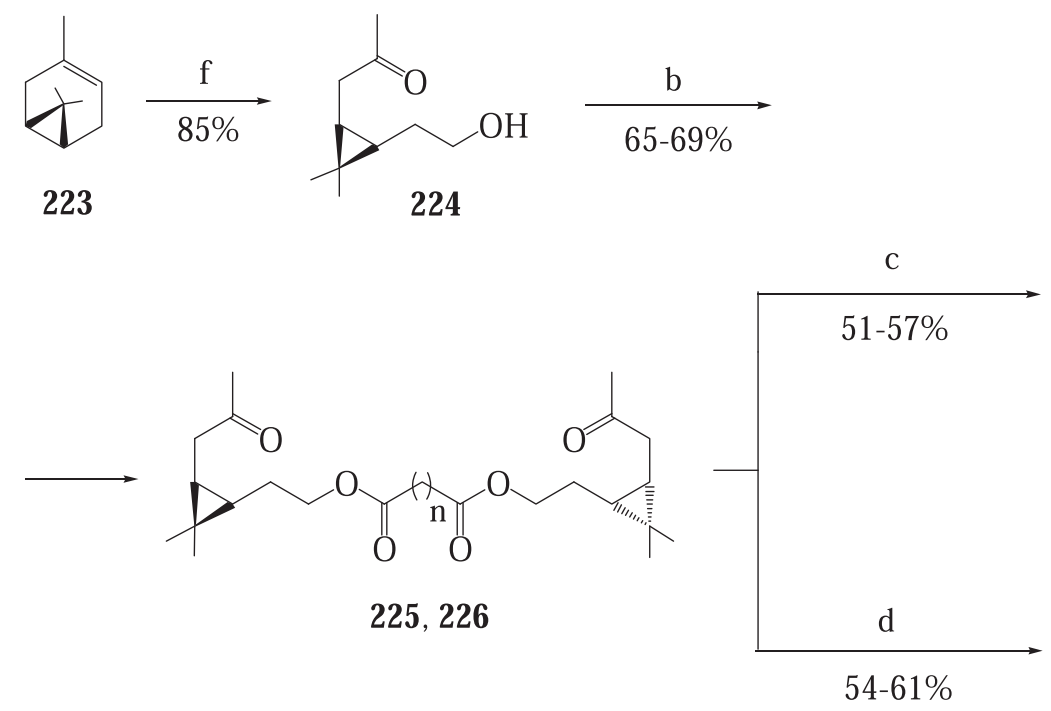

$\mathrm{n}=3(225,227,229), 4(226,228,230)$.
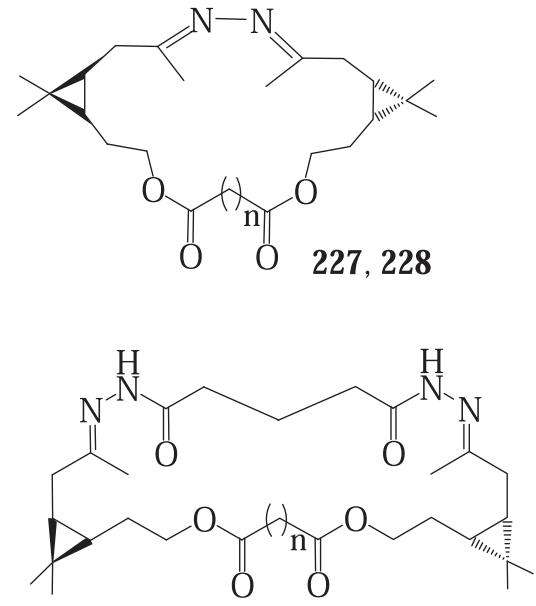

229,230

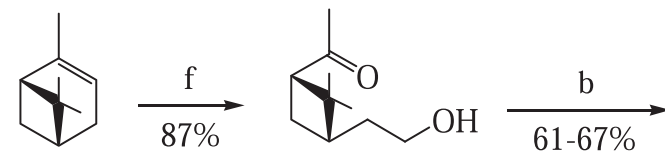

231

232

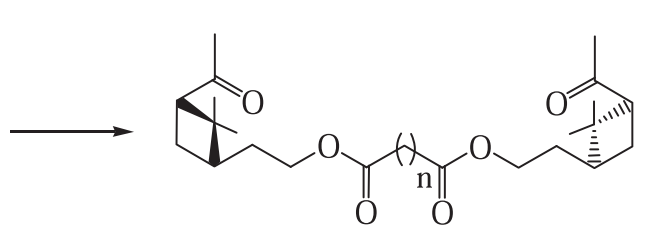

233,234

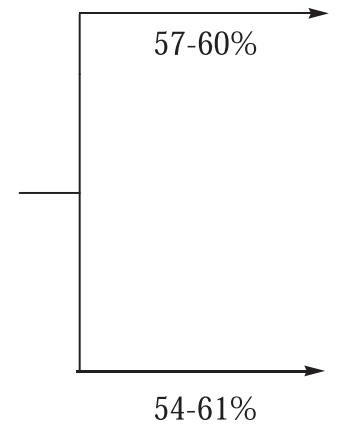

$\mathrm{n}=3(233,235,237), 4(234,236,238)$.

a) some stages; b)
, Py; c) $\mathrm{N}_{2} \mathrm{O}_{4} \cdot \mathrm{H}_{2} \mathrm{O}, 1,4$-dioxane; d)

e) some stages; f) $\mathrm{O}_{3}, \mathrm{CH}_{2} \mathrm{Cl}_{2}, \mathrm{AcOH}$ then $\mathrm{NaBH}(\mathrm{OAc})_{3}$. 
5. Zvereva O.V., Milyutin A.V., Bobrovskaya O.V., Odegova T.F. Pharm. Chem. J. 2004, 38(2), 90-92.

6. Strobykina I.Yu., Garifullin B.F., Kovylyaeva G.I., Kataev V.E., Musin R.Z. Russ. J. Gen. Chem. 2007, 77, 1277-1279.

7. Kataev V.E., Khaybullin R.N., Strobykina I.Yu. Review Journal of Chemistry 2011, 1, 93-160.

8. Shyhaev A.V. New Type of Nitrogen and Oxygen Containing Mono-, Bis- and Trismacrocycles. Autoref. Cand. Chem. Sci. Moscow, 2009, 26 p. (in Russ.).

9. Ollis D.W. Comprehensive Organic Chemistry. Oxford-New York-Toronto-Sydney-Paris-Frankfurt: Pergamon press, 1979.

10. Reutov O.A., Kurtz A.L., Butin K.P. Organicheskaya Khimiya [Organic Chemistry]. Moskva: BINOM. Laboratoriya Znanii, 2004, 726 p. (in Russ.).

11. Sykes P. A Guidebook to Mechanism in Organic Chemistry. New York: Longman Scientific and Techniccal, 1985.

12. March J. Advanced Organic Chemistry. Reaction, Mechanisms and Structure. A Wiley-Interscience publication. New YorkChichester-Brisbane-Toronto-Singapore, 1985.

13. Farmer J.J., Schroedr F.C., Meinwald J. Helv. Chim. Acta. 2000, 83, 2594-2606.

14. Palomo C., Oiarbide M., Garcia J.M., Gonzólez A., Pazos R., Odriozola J.M., Bañuelos P., Tello M., Linden A. J. Org. Chem. 2004, 69, 4126-4134.

15. Henkel B., Lis M., Illgen K., Eckl R. Synlett 2006, 9, 1315-1318.

16. Maddess M.L., Tackett M.N., Watanabe H., Brennan P.E., Spilling C.D., Scott J.S., Osborn D.P., Ley S.V. Angew. Chem., Int. Ed. 2007, 46, 591-597.

17. Romo D., Rzasa R.M., Shea H.A., Park K., Langenhan J.M., Sun L., Akhiezer A., Liu J.O. J. Am. Chem. Soc. 1998, 120, 12237-12254.

18. Nicolaou K.C., Schlawe D., Kim D.W., Longbottom D.A., De Noronha R.G., Lizos D.E., Manam R.R., Faulkner D.J. Chem. Eur. J. 2005, 11, 6197-6211.

19. Nicolaou K.C., Kim D.W., Schlawe D., Lizos D.E., De Noronha R.G., Longbottom D.A. Angew. Chem., Int. Ed. 2005, 44, 4925-4929.

20. Yu S., Xianhua P., Ma D. Chem. Eur. J. 2006, 12, 6572-6584.

21. Nicolaou K.C., Lizos D.E., Kim D.W., Schlawe D., de Noronha R.G., Longbottom D.A., Rodriquez M., Bucci M., Cirino G. J. Am. Chem. Soc. 2006, 128, 4460-4470.

22. Eggen M.J., Nair S.K., Georg G.I. Org. Lett. 2001, 3, 1813-1815.

23. Vidya R., Eggen M.J., Nair S.K., Georg G.I., Himes R.H. J. Org. Chem. 2003, 68, 9687-9693.

24. Lygo B. Williams L. Synthetic Studies on Novel Cyclic Depsipeptide Systems Related to the Geodiamolides, http:// www.ch.ic.ac.uk/ectoc/papers/58/

25. Inanaga J., Hirata K., Seaki H., Katsaki Y., Jamaguchi M. Bull. Chem. Soc. Jap. 1979, 52, 1989-1993.

26. Wipf P., Graham T.H. J. Am. Chem. Soc. 2004, 126, 15346-15347.

27. Hillier M.C., Price A.T., Meyers A.I. J. Org. Chem. 2001, 66, 6037-6045.

28. Sarabia F., Chammaa S., Lopez-Herrera F.J. Tetrahedron Lett. 2002, 43, 2961-2965.

29. Chakraborty T.K., Ghosh S., Laxman P., Dutta S., Samanta R. Tetrahedron Lett. 2005, 46, 5447-5450.

30. Yurek-George A., Cecil A.R.L., Mo A.H.K., Wen S., Roger H., Habens F., Maeda S., Yoshida M., Packham G., Genesan A. J. Med. Chem. 2007, 50, 5720-5726.

31. Falck J.R, He A., Fukui H., Tsutsui H., Radha A. Angew. Chem., Int. Ed. 2007, 46, 4527-4529.

32. Narasaka K., Sakakura T., Uchimaru T., Guedin-Vuong D. J. Am. Chem. Soc. 1984, 106, 2954-2961.

33. Zhao G., Sun X., Bienayme H., Zhu J. J. Am. Chem. Soc. 2001, 123, 6700-6701.

34. Yavolovskii A.A., Ivanov E.I., Ivanov Yu.E. Chem. Heterocycl. Compd. 1996, 32, 975-978.
35. Kurihara T., Nakajima Y., Mitsunobu O. Tetrahedron Lett. 1976, 17, 2455-2458.

36. Chen Y., Gambs C., Abe Y., Wentworth Jr. P., Janda K.D. J. Org. Chem. 2003, 68, 8902-8905.

37. Kumar S., Hundal M.S., Kaur N., Singh R., Singh H. J. Org. Chem. 1996, 61, 7819-7825.

38. Kumar S., Kaur N., Singh H. Tetrahedron Lett. 1996, 37, 2071-2072.

39. Gao M.Zh., Chen Y.-W., Xu Z.L. Acta sci. natur. univ. Sutyatseni. Natur. Sci. 2000, 39(5), 54-57.

40. Gao M.Zh., Reibenspies J.H., Wang B., Xu Z.L., Zingaro R.A. J. Heterocycl. Chem. 2004, 41, 899-908.

41. Campayo L., Pardo M., Cotillas A., Jauregui O., Yunta M.J.R., Cano C., Gomez-Contreras F., Navarro P., Sanz A.M. Tetrahedron 2004, 60, 979-986.

42. Adrio J., Cuevas C., Manzanares I., Joullie M.M. Org. Lett. 2006, 8, 511-514.

43. Zou B., Long K., Ma D. Org. Lett. 2005, 7, 4237-4240.

44. Zou B., Wei J., Cai G., Ma D. Org. Lett. 2003, 5, 3503-3506.

45. Chen J., Forsyth C.J. J. Am. Chem. Soc. 2003, 125, 87348735 .

46. Pattenden G., Ashweek N.J., Baker-Glenn Ch.A.G., Kempson J., Walker G.M., Yee J.G.K. Org. Biomol. Chem. 2008, 6, 1478-1497.

47. Bowers A.A., West N., Newkirk T.L., Troutman-Youngman A.E., Schreiber S.L., Wiest O., Brander J.E., Williams R.M. Org. Lett. 2009, 11, 1301-1304.

48. Ghosh A.K., Kulkarni S. Org. Lett. 2008, 10, 3907-3909.

49. Bowers A., West N., Taunton J., Schreiber S.L., Brander J.E., Williams R.M. J. Am. Chem. Soc. 2008, 130, 11219-11222.

50. Ying Y., Taori K., Kim H., Hong J., Luesch H. J. Am. Chem. Soc. 2008, 130, 8455-8459.

51. Ying Y., Liu Y., Byeon S.R., Kim H., Luesch H., Hong J. Org. Lett. 2008, 10, 4021-4024.

52. Liang J., Moher E.D., Moore R.E., Hoard D.W. J. Org. Chem. 2000, 65, 3143-3147.

53. Seufert W., Beck Z.Q., Sherman D.H. Angew. Chem. Int. Ed. 2007, 46, 9298-9300.

54. Ghosh A.K., Liu Ch. Org. Lett. 2001, 3, 635-638.

55. Dinh T.Q., Smith C.D., Armstrong R.W. J. Org. Chem. 1997, 62, 790-791.

56. Hermann Ch., Pais G.C.G., Geyer A., Kühnert S.M., Maier M.E. Tetrahedron 2000, 56, 8461-8471.

57. Monma S., Sunazuka T., Nagai K., Arai T., Shiomi K., Matsui R., Omura S. Org. Lett. 2006, 8, 5601-5604.

58. Nasveschuk Ch.G., Ungermannova D., Liu X., Phillips A.J. Org. Lett. 2008, 10, 3595-3598.

59. Xu Y., Chen L., Ma Y., Li J., Cao X. Synlett 2007, 12, 19011904.

60. Bughin C., Masson G., Zhu J. J. Org. Chem. 2007, 72, 18261829.

61. Pirali T., Tron G.S., Masson G., Zhu J. Org. Lett. 2007, 9, 5275-5278.

62. Irie Sh., Yamamoto M., Iida I., Nishio T., Kishikawa K., Kohmoto Sh., Yanada K. J. Org. Chem. 1994, 59, 935-937.

63. Zhao H., Hua W. J. Org. Chem. 2000, 65, 2933-2938.

64. Kluger R., Tsao B. J. Am. Chem. Soc. 1993, 115, 2089-2090.

65. Trnka T.M., Grubbs R.H. Acc. Chem. Res. 2001, 34, 18-29.

66. Love J.A., Morgan J.P., Trnka T.M. Grubbs R.H. Angew. Chem., Int. Ed. 2002, 41, 4035-4037.

67. Nguyen S.T., Johnson L.K., Grubbs R.H., Ziller J.W. J. Am. Chem. Soc. 1992, 114, 3974-3975.

68. Gosh A.K., Hussain K.A. Tetrahedron Lett. 1998, 39, 1881-1884.

69. Rurrens B., Blom P., Van Hoff S., Hubrecht I., Van der Eycken J., Sas B., Van hemel J., Vandenkerckhove J. J. Org. Chem. 2007, 72, 5514-5522.

70. Chuchuryukin A.V., Dijkstra H.P., Suijkerbuijk B.M.J.M., 
Gebbink R.J.M.K., van Klink G.P.M., Mills A.M., Spek A.L., van Koten G. Russ. J. Org. Chem. 2003, 39, 422-429 [Zh. Org. Khim. 2003, 39, 449-456 (in Russ.)].

71. McCubbin J.A., Maddess M.L., Lautens M. Org. Lett. 2006, 8, 2993-2996.

72. Ferrie L., Reymond S., Capdevielle P., Cossy J. Org. Lett. 2006, 8, 3441-3443.

73. Kise N., Oike H., Okazaki E., Yoshimoto M., Shono T. J. Org. Chem. 1995, 60, 3980-3992.

74. Nicolaou K.C., Bulger P.G., Sarlah D. Angew. Chem., Int. Ed. 2005, 44, 4490-4527.

75. Kim Y.J., Lee D. Org. Lett. 2004, 6, 4351-4353.

76. Li J.J. Name Reaction. A Collection of Detailed Mechanisms. Springer-Verlag Berlin Heidelberg, 2003, 456 p.

77. Fürstner A., Guth O., Rumbo A., Seidel G. J. Am. Chem. Soc. 1999, 121, 11108-11113.

78. Yang B., Zollner T., Gebhardt P., Mollmann U., Miller M.J. Org. Biomol. Chem. 2010, 8, 691-697.

79. Fraunhoffer K.J., Prabagaran N., Sirois L.E., White M.C. J. Am. Chem. Soc. 2006, 128, 9032-9033.

80. Subodh K., Maninder S.H., Navneet K., Rajinder S., Harjit S. J. Org. Chem. 1996, 61, 7819-7825.

81. Ramaseshan M., Ellingboe J.W., Dory Y.L., Deslongchamps P. Tetrahedron Lett. 2000, 41, 4743-4749.

82. Hayward C.M., Yohannes D., Danishefsky S.J. J. Am. Chem. Soc. 1993, 115, 9345-9346.

83. Smith A.B., Razler T.M., Meis R.M., Pettit G.R. Org. Lett. 2006, 8, 797-799.

84. Smith A.B., Razler T.M., Ciavarri J.P., Hirose T., Ishikawa T. Org. Lett. 2005, 7, 4399-4402.
85. Forsee J.E., Aubé J. J. Org. Chem. 1999, 64, 4381-4385.

86. Harris J.M., Bolessa E.A., Vederas J.C. J. Chem. Soc. Perkin Trans 1 1995, 15, 1951-1959.

87. Ishmuratov G.Yu., Mingaleeva G.R., Yakovleva M.P., Muslukhov R.R., Shakhanova O.O., Vyrypaev E.M., Tolstikov G.A. Russ. J. Org. Chem. (in press, № 221/10).

88. Ishmuratov G.Yu., Yakovleva M.P., Mingaleeva G.R., Muslukhov R.R., Vyrypaev E.M., Galkin E.G., Ivanov S.P., Tolstikov A.G. Chem. Nat. Compd. 2009, 45, 465-469 [Khimiya Prirodnykh Soedinenii 2009, 4, 395-399 (in Russ.)].

89. Ishmuratov G.Yu., Mingaleeva G.R., Yakovleva M.P., Muslukhov R.R., Vyrypaev E.M., Galkin E.G., Tolstikov A.G. Chem. Nat. Compd. 2009, 4, 470-473[Khimiya Prirodnykh Soedinenii 2009, 4, 400-403 (in Russ.)].

90. Ishmuratov G.Yu., Mingaleeva G.R., Yakovleva M.P., Shakhanova O.O., Muslukhov R.R., Tolstikov G.A. Russ. J. Org. Chem. (in press, № 285/10).

91. Ishmuratov G.Yu., Yakovleva M.P., Gareeva G.R., Kravchenko L.V., Ishmuratova N.M., Talipov R.F. Bulletin Bashkir University 2008, 3, 466-469 (in Russ.).

92. Ishmuratov G.Yu., Yakovleva M.P., Mingaleeva G.R., Muslukhov R.R., Vyrypaev E.M., Tolstikov G.A. Butlerov Communications 2008, 14(4), 59-62 (in Russ.).

93. Ishmuratov G.Yu., Yakovleva M.P., Vydrina V.A., Khasanova E.F., Muslukhov R.R., Ishmuratova N.M., Tolstikov G.A. Khimiya Rastitel'nogo Syr'ya 2007, 3, 23-32 (in Russ.).

94. Ishmuratov G.Yu., Kharisov R.Ya., Yakovleva M.P., Botsman O.V., Muslukhov R.R., Tolstikov G.A. Russ. J. Org. Chem. 2001, 37, 37-39 [Zh. Org. Khimii 2001, 37, 49-50 (in Russ.)]. 